Andrews University

Digital Commons @ Andrews University

\title{
Educator's Implementation of the Connecticut Guidelines for the Identification and Education of Children and Youth with Autism
}

\author{
Linda K. Grimm
}

Andrews University, grimm@andrews.edu

Follow this and additional works at: https://digitalcommons.andrews.edu/dissertations

Part of the Congenital, Hereditary, and Neonatal Diseases and Abnormalities Commons, and the Education Commons

\section{Recommended Citation}

Grimm, Linda K., "Educator's Implementation of the Connecticut Guidelines for the Identification and Education of Children and Youth with Autism" (2015). Dissertations. 1599.

https://digitalcommons.andrews.edu/dissertations/1599

https://dx.doi.org/10.32597/dissertations/1599

This Dissertation is brought to you for free and open access by the Graduate Research at Digital Commons @ Andrews University. It has been accepted for inclusion in Dissertations by an authorized administrator of Digital Commons@ Andrews University. For more information, please contact repository@andrews.edu. 


\begin{abstract}
EDUCATOR'S IMPLEMENTATION OF THE CONNECTICUT GUIDELINES FOR THE IDENTIFICATION AND EDUCATION OF CHILDREN AND YOUTH WITH AUTISM
\end{abstract}

by

Linda K. Grimm

Chair: Shirley Freed 


\title{
ABSTRACT OF GRADUATE STUDENT RESEARCH
}

Dissertation

\author{
Andrews University \\ School of Education
}

\section{Title: EDUCATOR'S IMPLEMENTATION OF THE CONNECTICUT GUIDELINES FOR THE IDENTIFICATION AND EDUCATION OF CHILDREN AND YOUTH WITH AUTISM}

Name of researcher: Linda K. Grimm

Name and degree of faculty chair: Shirley Freed, Ph.D.

Date completed: December 2015

The Problem

As the number of children with autism needing educational support continues to increase, combined with the limited availability of resources, this study aims to examine how educators responsible for teaching children with autism have experienced implementation of the Connecticut Guidelines for the Identification and Education of Children and Youth with Autism (2005), (Guidelines). At this time there have been no studies done in the State of Connecticut to assess the implementation of the components for effective education of children with autism, as set forth in the Connecticut Guidelines. 


\section{Method}

The Connecticut Autism Needs Survey, an on-line self-report survey designed for this study, was used to collect cross sectional data reflecting special education teachers practices and attitudes towards the Connecticut Guidelines for Identification and Education of Children and Youth with Autism. The first three research questions assess participants experience with implementation, level of difficulty implementing and level of importance of the Connecticut Guidelines for Identification and Education of Children and Youth with Autism. To further explore implementation, level of difficulty implementing and importance the data was examined specifically for teachers practice with 17 recommended evidence based practices for students with autism. The responses to the questions were analyzed using descriptive statistics. Three additional research questions address the association between the dependent variables reported on in the first three questions and the predictor variables of (a) years of experience, (b) assignment, (c) place, (d) region of the state, (e) number of students on caseload, (f) percentage of students with ASD on caseload, or (g) personal relationship. The dependent variable for each question and the 7 predictor variables were analyzed using logistic regression.

\section{Results}

The findings reveal $89.5 \%$ of respondents were either not familiar with the Connecticut Guidelines or found them difficult to implement. Additionally, the findings suggest an association between a special educator's use of the Connecticut Guidelines and the specificity of their role and tenure. Teachers who are primarily responsible for students with autism were more likely to use the Guidelines than were teachers who were responsible for providing specialized instruction to students with a range of disabilities. 
The research found that special education teachers in private schools were nine times less likely to rate the Connecticut Guidelines as difficult to implement than teachers in public schools. The findings suggest teachers with more experience were slightly more likely to implement the Connecticut Guidelines. Interestingly, the findings identified teachers who have a personal relationship were twice as likely to use the Guidelines as those who did not. Three of the most critical evidence-based strategies for educating students with autism: pivotal response training, video modeling, and voice output communication aide had the lowest percentage of implementation and were perceived as "not important" by teachers.

\section{Conclusions}

The results show the Connecticut Guidelines are not used or viewed as important by the majority of special education teachers in Connecticut. The Guidelines were written 10 years ago and much has changed in the field of autism over that time period. It appears it is time to reexamine and make changes to the Connecticut Guidelines. 
Andrews University

School of Education

\title{
EDUCATOR'S IMPLEMENTATION OF THE CONNECTICUT GUIDELINES FOR THE IDENTIFICATION AND EDUCATION OF CHILDREN AND YOUTH WITH AUTISM
}

\author{
A Dissertation \\ Presented in Partial Fulfillment \\ of the Requirements for the Degree \\ Doctor of Philosophy
}

by

Linda K. Grimm

December 2015 
(C) Copyright by Linda K. Grimm 2015

All Rights Reserved 


\title{
EDUCATOR'S IMPLEMENTATION OF THE CONNECTICUT GUIDELINES FOR THE IDENTIFICATION AND EDUCATION OF CHILDREN AND YOUTH WITH AUTISM
}

\author{
A dissertation \\ presented in partial fulfillment \\ of the requirements for the degree \\ Doctor of Philosophy
}

by

Linda K. Grimm

APPROVAL BY THE COMMITTEE:

Chair: Shirley Freed, Ph.D.

Member: James Tucker, Ph.D.

Member: Jimmy Kijai, Ph.D.

External: John N. Frame, Ph.D.
Dean, School of Education

Robson Marinho, Ph.D. 


\section{DEDICATION}

"They say it takes a village to raise a child. I think it takes a child with autism or other special needs to raise the consciousness of a village."

\section{Elaine Hall}

This dissertation is dedicated to all the individuals with autism and the many amazing people from the Benhaven community that have touched and enriched my journey. 


\section{TABLE OF CONTENTS}

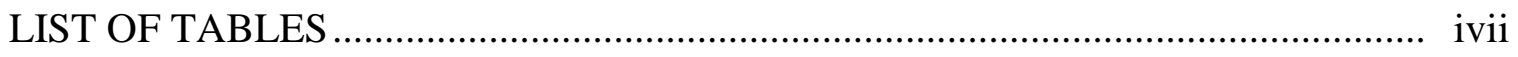

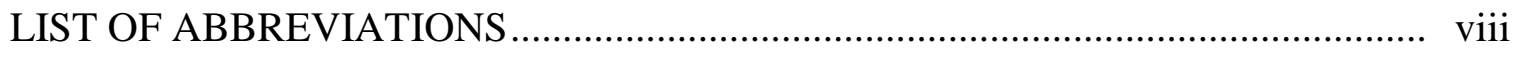

ACKNOWLEGMENTS .........................................................................

\section{Chapter}

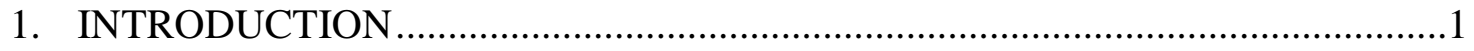

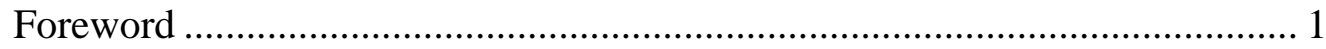

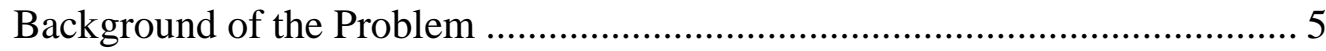

Statement of the Problem .......................................................................... 8

Purpose of the Study ............................................................................ 9

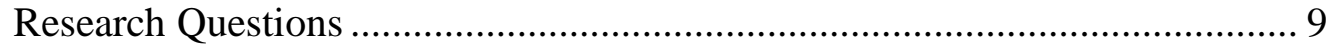

Research Design ................................................................................... 11

Conceptual/Theoretical Framework ........................................................ 12

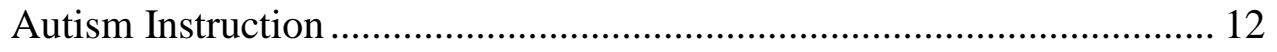

Professional Development............................................................ 14

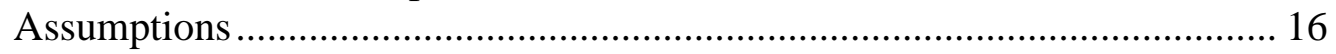

Delimitations ..................................................................................... 16

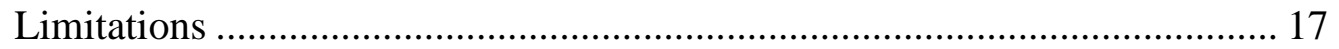

Significance of the Study .................................................................. 17

Definition of Terms ........................................................................... 18

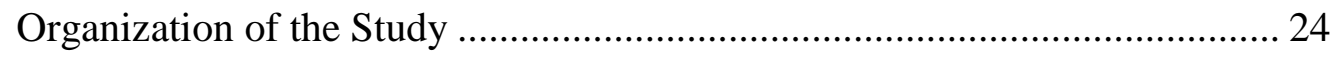

2. REVIEW OF RELATED LITERATURE .......................................................26

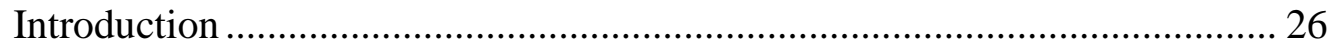

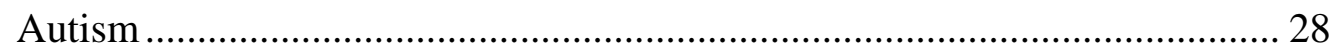

History of Autism Identification ........................................................ 28

Diagnostic Criteria for Autism Spectrum Disorders ............................. 33

Core Deficits of Autism Spectrum Disorders ............................................... 35

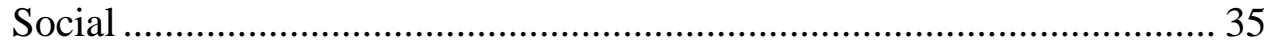

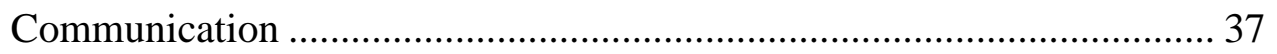

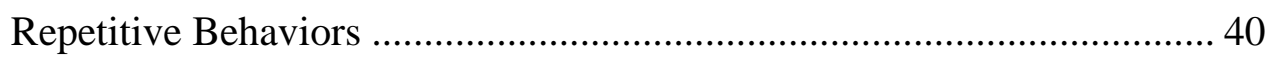

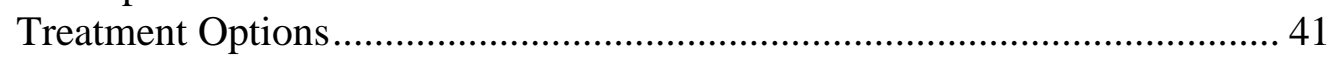

Comprehensive Treatment Models......................................................... 43

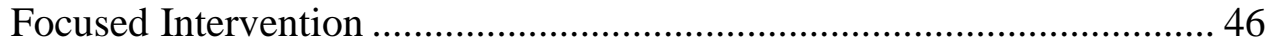

Reviews of Effective Practices.................................................................... 48

Key Components of Effective Programs....................................................... 53 


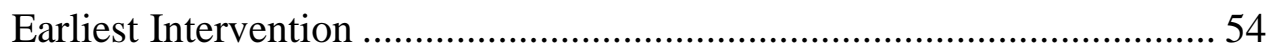

Family Involvement and Cooperative Planning ........................................ 55

Individualized and Intensive Programming ............................................. 55

Comprehensive Curriculum..................................................................... 57

Systematic Instruction and Ongoing Objective Assessment ..................... 59

Structured/Predictable Learning Environment ........................................... 60

Specifically Trained Personnel................................................................. 61

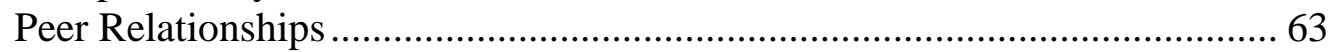

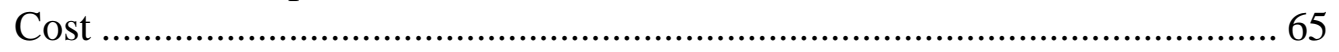

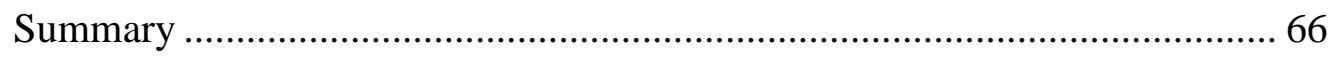

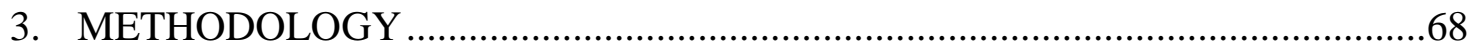

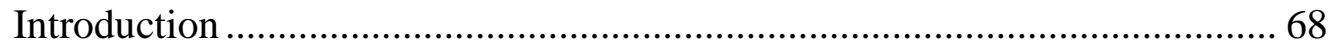

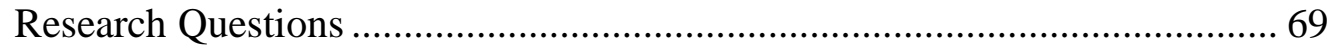

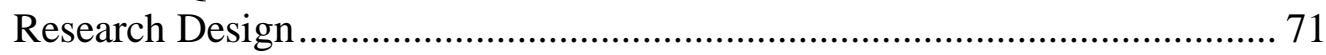

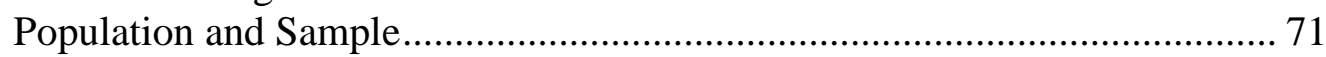

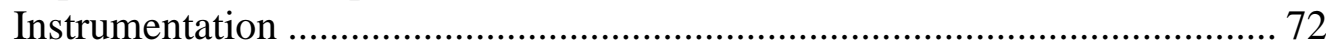

Description and Development ............................................................. 72

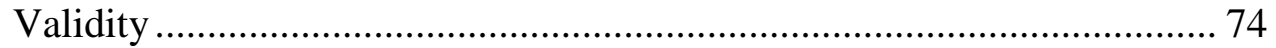

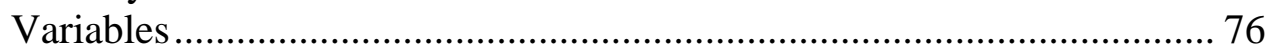

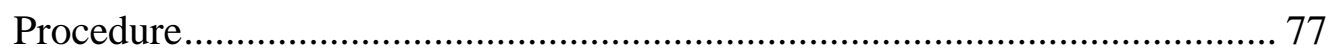

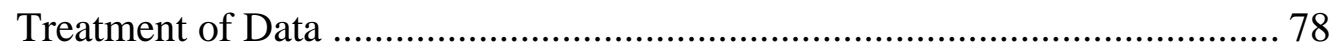

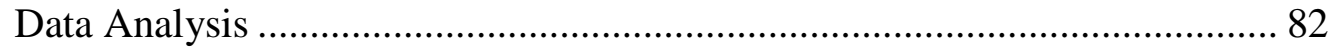

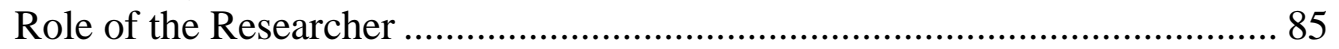

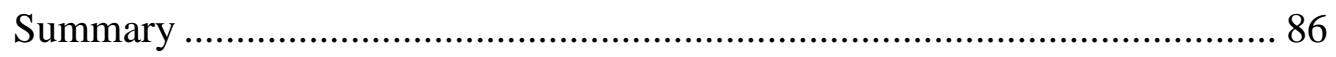

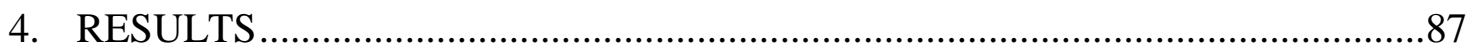

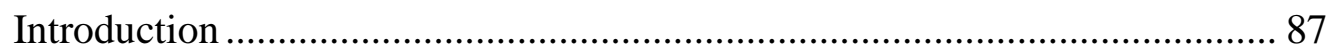

Description of the Sample ......................................................................... 88

Results by Questions …………………………………….......................... 93

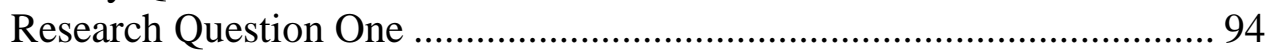

Research Question Two..................................................................... 96

Research Question Three..................................................................... 101

Research Question Four ................................................................. 104

Research Question Five .................................................................. 106

Research Question Six........................................................................ 109

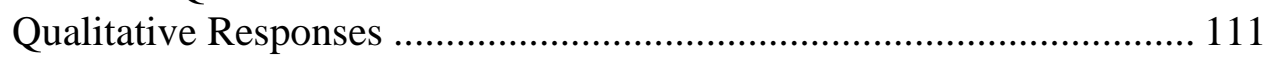

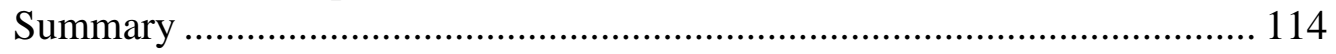

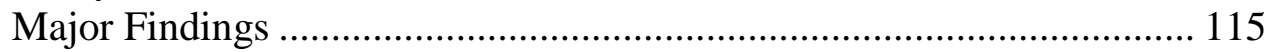

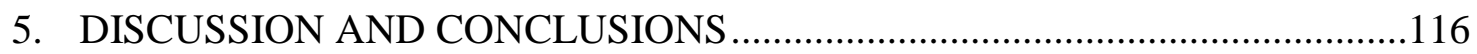

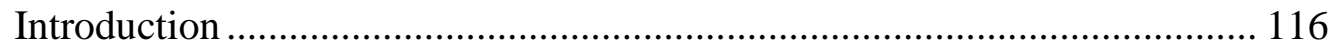

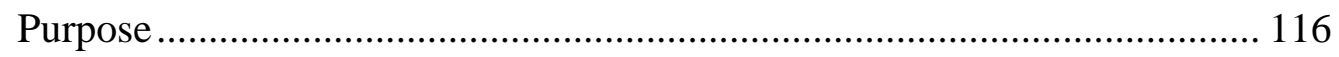

Overview of the Literature ...................................................................... 117 
Methodology of the Study ................................................................. 119

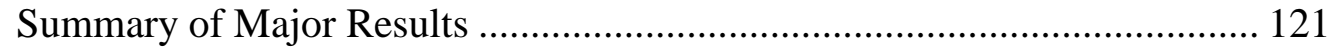

Discussion of Major Findings ............................................................ 122

Limitations of the Study ................................................................. 128

Implications for Practice .............................................................. 129

Recommendations for Further Study .................................................. 130

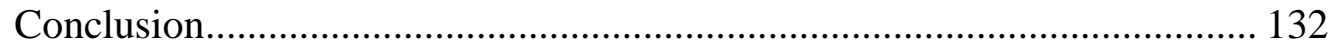

Appendix

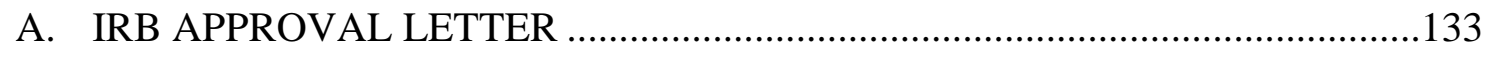

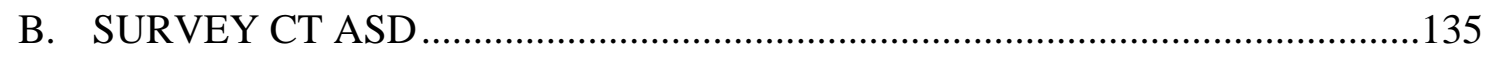

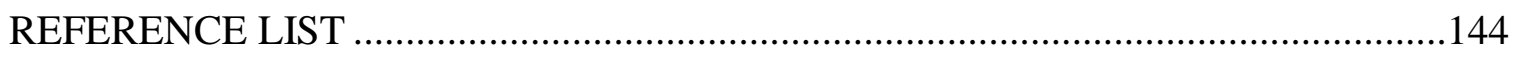

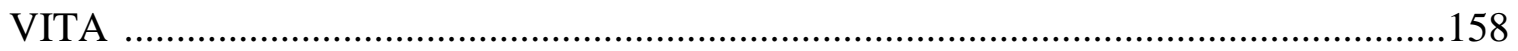




\section{LIST OF TABLES}

1. Effective Evidence-Based Practices ...............................................................47

2. Overlap in Evidence-Based Practices Comparing NPDC on ASD and NSP.....

3. Differences in Evidence-Based Practices Between NPDC on ASD and NSP

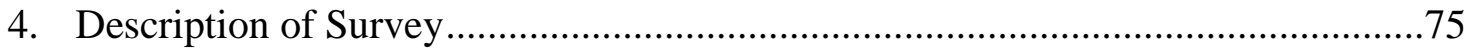

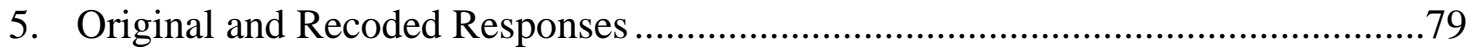

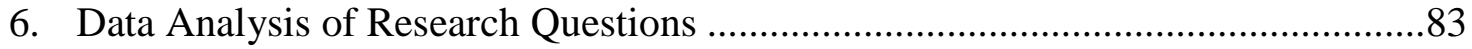

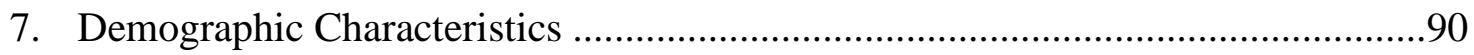

8. ASD Related Experiences .................................................................. 91

9. Teacher Responses for Implementing Connecticut Guidelines ...........................95

10. Implementation of Evidence-Based Practices .................................................97

11. Level of Difficulty Implementing Recommendations....................................98

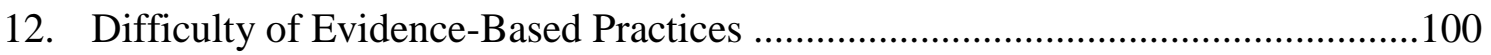

13. Importance in Designing Programs for Students With ASD ..............................102

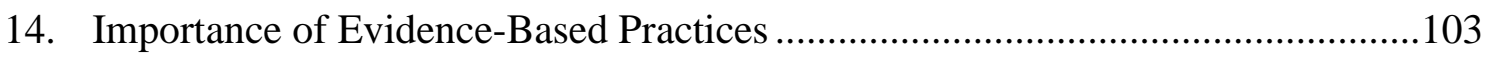

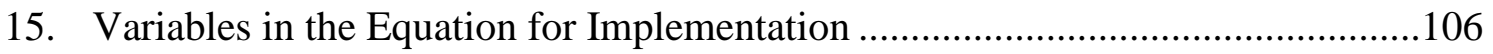

16. Variables in the Equation for Level of Difficulty ........................................108

17. Variables in the Equation for Importance ..................................................111

18. Key to Success for Students With ASD ............................................................112

19. Significant Barrier to Educating a Student with ASD .......................................113

20. Description of the Connecticut Guidelines ....................................................113

21. What is Desired From the Connecticut Guidelines .........................................114

22. Effective Evidence-Based Instruction - National Professional Development Center... 


\section{LIST OF ABBREVIATIONS}

APA American Psychological Association

ABI Antecedent-Based Intervention

ABA Applied Behavioral Analysis

APQI Autism Program Quality Indicators

ASD Autism Spectrum Disorder

BACB Behavior Analysis Certification Board

CBI Cognitive Behavioral Intervention

CTMs Comprehensive Treatment Models

CREC Capitol Region Education Council

DDS Department of Developmental Services

DSM Diagnostic and Statistical Manual of Mental Disorders

DRA Differential Reinforcement of Alternative Behavior

DRA/I/O Differential Reinforcement of Alternative, Incompatible, or Other Behavior

DRI Differential Reinforcement of Incompatible Behavior

DRO Differential Reinforcement of Other Behavior

DTT Discrete Trial Teaching

DSM II Diagnostic and Statistical Manual of Mental Disorders 2nd Edition

DSM-I Diagnostic and Statistical Manual of Mental Disorders 1st Edition

DSM-III-R Psychiatry Diagnostic \& Statistical Manual of Mental Disorders 3rd Edition Revised

DSM-IV Psychiatry Diagnostic \& Statistical Manual of Mental Disorders 4th Edition 


$\begin{array}{ll}\text { DSM-IV-TR } & \begin{array}{l}\text { Diagnostic and Statistical Manual of Mental Disorders, Fourth Edition, } \\ \text { Text Revision }\end{array} \\ \text { EBE } & \text { Evidence-Based Education } \\ \text { ECE } & \text { Exercise } \\ \text { EXT } & \text { Extinction } \\ \text { FBA } & \text { Functional Behavior Assessment } \\ \text { FCT } & \text { Functional Communication Training } \\ \text { IEP } & \text { Individualized Education Plan } \\ \text { IDEA } & \text { Individuals with Disabilities Act } \\ \text { ICAN } & \text { Interactive Collaborative Autism Network, } \\ \text { MD } & \text { Modeling } \\ \text { NECTAS } & \text { National Early Childhood Technical Assistance System } \\ \text { NPDC } & \text { National Professional Development Center on Autism Spectrum Disorders } \\ \text { NRC } & \text { National Research Council } \\ \text { NI } & \text { Naturalistic Intervention } \\ \text { NYAN } & \text { New York Autism Network } \\ \text { OSEP } & \text { Office of Special Education Programs } \\ \text { PII } & \text { Parent-Implemented Intervention } \\ \text { PMII } & \text { Peer-Mediated Instruction and Intervention } \\ \text { PECS } & \text { Picture Exchange Communication System } \\ \text { PRT } & \text { Pivotal Response Training } \\ \text { PPT } & \text { Planning and Placement Team } \\ \text { PP } & \text { Prompting } \\ \text { R+ } & \text { Reinforcement } \\ \text { RESC } & \text { Regional Education Service Center } \\ \text { SC } & \end{array}$




$\begin{array}{ll}\text { SM } & \text { Self-Management } \\ \text { SN } & \text { Social Narratives } \\ \text { SST } & \text { Social Skills Training } \\ \text { SEEP } & \text { Special Education Expenditure Project } \\ \text { SERC } & \text { Special Education Resource Center } \\ \text { SPG } & \text { Structured Play Group } \\ \text { TA } & \text { Task Analysis } \\ \text { TAII } & \text { Technology-Aided Instruction and Tntervention } \\ \text { TD } & \text { Time Delay } \\ \text { VM } & \text { Video Modeling } \\ \text { VS } & \text { Visual Support }\end{array}$




\section{ACKNOWLEDGMENTS}

I would like to thank the people that have supported me on this journey.

- Benhaven, especially Larry Wood for providing me the support to pursue my dissertation.

- My colleagues for providing editing, feedback and encouragement whenever I needed it.

- To Chris Brown, I wouldn't have finished without the time and knowledge you provided.

- My committee for seeing this through with me. Jim Tucker, thank you for being there in the beginning to encourage me to start the journey. Shirley Freed, thank you for getting me back on track. I am so grateful that you believed in me and kept checking in on me. You always knew what to say when I was feeling discouraged. Thank you for helping me to become comfortable with the discomfort. Dr. Kijai for all the hours in cyber space helping me to understand the foreign language of statistics.

- To my friends, especially Christine, Patti, Melissa and Simonne, thank you for not letting me give up and believing in me.

- Thank you to my mom for all the Saturday coffee runs and helping out in any way you could.

- To Bob, Rob and AJ thank you for being there for the journey with your love, support and humor. I truly am blessed to have you as my family. I am grateful for your 
patience with me during the times when I was struggling and believing in me. The Dr. Mom sign on my office door always made me smile. 


\section{CHAPTER 1}

\section{INTRODUCTION}

\section{Foreword}

AUTISM IS LIKE ...

SEEING THE WORLD THROUGH A KALEIDOSCOPE AND

TRYING TO LISTEN TO A RADIO STATION

THAT'S JAMMED WITH STATIC AT THE SAME TIME.

ADD TO THAT A BROKEN VOLUME CONTROL WHICH

CAUSES THE VOLUME TO JUMP ERRATICALLY

FROM A LOUD BOOM TO INAUDIBLE.

AND THEN IMAGINE A STATE OF HYPERAROUSAL

WHERE YOU WERE BEING PURSUED BY A DANGEROUS ATTACKER.

Temple Grandin 
Dr. Temple Grandin, was one of the first individuals with autism to describe the disorder from a personal perspective (Grandin, 1996). Dr. Grandin is an Associate Professor at Colorado State University, and is responsible for designing the meat packing plant facilities that handle half the cattle in the United States. Both as a well-read author and public speaker, she reveals what her life has been like, as a child and as an adult, with autism. Autism is a complex lifelong neuro-developmental disorder characterized by early onset of problems with social communication and stereotypic behaviors. People with Autism Spectrum Disorder (ASD) process information differently from other people.

Leo Kanner (1943) was the first to describe autism in his professional work with a small group of boys who demonstrated extreme aloofness and total indifference to other people (Kanner, 1943). Kanner reported that the children made little eye contact and had impaired communication skills. There was a lack of pretend or imagination in their play skills and they often reacted to the environment in unusual ways.

In 1980 the term "Infantile Autism" first appeared as a diagnostic label in the Diagnostic and Statistical Manual of Mental Disorders (DSM), Third Edition. In the late 1980s there was a shift in the language used to describe a broader clinical phenotype for autism. Allen (1988) used the phrase "autistic spectrum disorder" and Lorna Wing (1988) used the phrase "autistic continuum" to describe her view that, rather than thinking rigidly of autism as a discrete syndrome, it should be viewed as a continuum of autistic disorders (Bishop, 1989). In the years between the publication of the Psychiatry Diagnostic \& Statistical Manual of Mental Disorders 3rd Edition Revised (DSM-III-R) and the Psychiatry Diagnostic \& Statistical Manual of Mental Disorders 4th Edition 
$(D S M-I V)$ there was a slow consensus that "pervasive developmental disorders" does reflect an "autistic spectrum" (Wing, 1997). Autism Spectrum Disorders was a layman's umbrella term that referred to the diagnostic categories in the Diagnostic and Statistical Manual of Mental Disorders, Fourth Edition, Text Revision (DSM-IV-TR) including Autistic Disorder, Asperger Disorder, and Pervasive Developmental Disorder—Not Otherwise Specified (PDD-NOS) (DSM-IV-TR, 2000; Johnson, Myers \& the Council on Children with Disabilities, 2007). Although the clinical presentation of autism spectrum disorder may vary depending on severity, all children with ASD will demonstrate some qualitative degree of impairment in a triad of areas: (a) reciprocal social interaction, (b) communication, and (c) restricted, repetitive, and stereotypic patterns of behaviors, interests, and activities (Frith, 1989; Wing, 1988). In the recently published fifth edition of the Diagnostic and Statistical Manual of Mental Disorders (DSM-5), the American Psychiatric Association (APA) has modified the diagnostic criteria for Autism Spectrum Disorder. The diagnosis will be called ASD, and there no longer will be subdiagnoses (Autistic Disorder, Asperger Syndrome, PPD-NOS, Disintegrative Disorder). The new diagnostic criteria have been consolidated into two areas: (a) social communication/interaction, and (b) restricted and repetitive behaviors (American Psychiatric Association, 2013).

Autism is a lifelong disability that currently affects 1 in every 68 children (Center for Disease Control, 2014). There has been much discussion among professionals about the increase in prevalence, and even the media has joined in the debate with special reports referring to autism as an epidemic. "That the number of new autism diagnoses is dramatically increasing is generally accepted and not a point of debate" (Novella, 2008, 
para. 3). There are two general hypotheses regarding why the increase in the incidence of autism: the first is due to environmental factors including the link to thimerosal in vaccinations; the second due to broadening the definition and awareness. Two studies, one done by Rutter (2005) and the second by Taylor (2006), applied modern criteria used to diagnosis autism to historical data and found similar rates of diagnoses. As the research grows that supports that there is not an epidemic, the vaccination hypothesis becomes less viable (Novella, 2008). While it is generally accepted that the prevalence rate of autism has increased, researchers have varying explanations for the cause of the increase including: changes in diagnostic criteria to include a wider spectrum of cases, substitution of an autism diagnosis for mental retardation, an increased availability of services for children with an ASD diagnosis resulting in a willingness of parents to accept such a diagnosis, a greater awareness of autism in the general public, and evidence for multiple genetic factors as the cause for the small genuine increase (Fombonne, 2003; Novella, 2008; Rutter, 2005; Taylor, 2006; Volkmar, Lord, Bailey, Schultz \& Klin, 2004; Wing \& Potter, 2002).

Autism affects more than just the child with the disorder. The family and community feel the responsibility of providing support to someone who experiences the world so differently. Interventions and services for individuals with autism are, however, intensive and significantly impact the educational resources of school districts. The average per pupil expenditure for educating a child with autism was estimated by the Special Education Expenditure Project (SEEP) to be over \$18,800 in the 1999-2000 school year, the most recent year for which data were available. This estimate was nearly three times the cost for a typical regular education student, and the only higher per-pupil 
cost was for students with multiple disabilities (U. S. Government Accountability Office, January, 2005). There are some private residential school placements that exceed $\$ 150,000$ tuition per year for one child with autism. In 2007, Michael L. Ganz, Ph.D. of

the Harvard School of Public Health published research which estimated the lifetime cost of caring for an individual with autism to be more than $\$ 3$ million.

Unfortunately, the high cost of education is not yielding high quality of life outcomes for individuals with autism a profile of 400 adults on the spectrum yielded the following statistics: $.04 \%$ of the adults live independently, $10 \%$ of the adults have some type of occupation, $14 \%$ of the adults socialize outside the home, and $95 \%$ of the adults report no friendships at all (Seltzer et al., 2003). As leaders in the field of education, we must take responsibility to implement effective programs that address the specific social, communication, and behavioral needs of individuals with autism that will improve the outcomes for their adult lives. "Only a true natural servant automatically responds to any problem by listening first" (Greenleaf, 1977, p. 31). This study was an attempt to listen to a need that exists in the field of autism in the State of Connecticut.

\section{Background of the Problem}

In 2001 the National Research Council (NRC) published Educating Children with Autism. This report was the outcome of a charge given by the U.S. Department of Education's Office of Special Education Programs to evaluate the current status of educating children with autism. In this report, the NRC made recommendations for the inclusion of core elements of educational practice in the program design for children with autism spectrum disorder. Their findings were based on empirical research, information from selected autism programs, and findings in the general and developmental literature 
(National Research Council, 2001). In 2005, the Connecticut State Department of Education utilized the findings from the NRC report to revise the 1998 Report of the Connecticut Task Force on Issues for Education of Children with Autism. A task force drafted the Connecticut Guidelines (Connecticut State Department of Education, 2005), which identified benchmarks for appropriate educational supports for children with autism.

The task force that developed the document considered critical issues and current research with the purpose of developing guidelines to improve educational outcomes for children with autism. The intent was to define a consistent statewide standard of service, provide information on research-based interventions, and identify resources to be utilized by those who provide support to individuals with autism. The Connecticut Guidelines is organized into five sections: Autism and Autistic Spectrum Disorders - Definition and Distinctions, Assessment and Eligibility, Characteristics of Effective Programs, Interventions, and Transitions and Transition Planning (Connecticut State Department of Education, 2005).

The Connecticut Guidelines recognized that the Planning and Placement Team (PPT) makes instructional decisions based upon the needs of the individual child while keeping in mind evidence-based practices. Success for a child is based upon matching the child's needs and learning profile with the appropriate strategies while giving consideration to age, cognitive level, behavioral factors, and family priorities. Respect of the individual should be assured within the framework of an effective program that contains components of best practice- those validated by research. The Connecticut Guidelines identified eight components for this framework: Earliest Intervention, Family 
Involvement and Cooperative Planning, Individualized and Intensive Programming, Comprehensive Curriculum, Systematic Instruction and Ongoing Objective Assessment, Structured/Predictable Learning Environment, Specifically Trained Personnel, and Peer Relationships (Connecticut State Department of Education, 2005).

School districts are expected to use The Connecticut Guidelines as a guide when designing and implementing educational programs for students with autism. Specifically, trained personnel are pivotal to the success of children with autism. The Connecticut Guidelines clearly articulated what teachers need to be doing to support students with autism. Teachers need to know how to support children with autism spectrum disorder in school settings through the use of evidence-based education (Yell \& Drasgow, 2005).

In a PowerPoint presentation, Grover J. Whitehurst, Assistant Secretary, Educational Research and Improvement, United States Department of Education, defined Evidence-Based Education (EBE) as "The integration of professional wisdom with the best available empirical evidence in making decisions about how to deliver instruction" (Student Achievement and School Accountability Conference, October 2002). He went on to say that both professional wisdom and empirical evidence are necessary. Professional wisdom is needed to adapt education to local circumstances or operate intelligently in the many areas in which research evidence is absent or incomplete. Empirical research is necessary to determine the effectiveness of competing approaches, generate further understanding, and avoid the latest flights of fancy and fads (Connecticut State Department of Education, 2005).

Benhaven Learning Network, a consultation group that specializes in the field of autism, provides leadership to school districts throughout Connecticut by developing 
competencies in the use of best practices in those who support individuals with ASD.

Benhaven as an agency has provided a wide array of services to the autism community

for 48 years. The consultants employed by Benhaven Learning Network actively strive to support districts to embrace and integrate the components of effective programming identified by the NRC. As the Director and Managing Consultant for Benhaven Learning Network, one of my responsibilities is to provide expertise and insight as a practitioner to state agencies. The Connecticut Guidelines were published ten years ago and due to the changes in the definition of autism in the recently published DSM-5 it is likely the Guidelines will need to be updated. This study provides information on educator's implementation of The Connecticut Guidelines, which could be useful for the revision of the Guidelines and suggestive of further professional development activities.

\section{Statement of the Problem}

The literature has identified components of effective programs for children with autism. The State of Connecticut used the research to develop the Connecticut Guidelines in 2005. The Guidelines were developed for families and service providers for the following purposes:

1. To improve educational outcomes for children and youth with autistic spectrum disorders.

2. To define a consistent statewide base of information that provides clarity and guidance to families, Connecticut school districts, private approved programs, and practitioners.

3. To provide research-based information concerning educational intervention strategies for children and youth with autistic spectrum disorders.

4. To provide smooth transitions for children and youth with autistic spectrum disorders from the Connecticut Birth to Three System through high school (ages 3 through 21).

5. To provide families and practitioners with the information, tools and resources necessary to make informed and cooperative decisions for the education of children and youth with autistic spectrum disorders in public 
schools and community settings. (Connecticut State Department of Education, 2005, p. 4)

As the number of children with autism needing educational support continues to increase, combined with the limited availability of resources, it was critical to examine how educators responsible for teaching children with autism have experienced implementation of the Connecticut Guidelines. At this time there have been no studies done in the State of Connecticut that examine the implementation of the components for effective education of children with autism, as set forth in the Connecticut Guidelines.

\section{Purpose of the Study}

The purpose of this study was to explore educator's experience in implementing the Connecticut Guidelines. The study specifically examined the association between special educators' awareness and implementation of the Connecticut Guidelines and (a) years of experience, (b) assignment, (c) place, (d) Regional Education Service Center (RESC), (e) number of students on caseload, (f) percentage of students with ASD on caseload, or (g) personal relationship.

\section{Research Questions}

The following six research questions guided this study:

1. To what extent are special educators in Connecticut implementing the Connecticut Guidelines for Identification and Education of Children and Youth with Autism for students with autism? Additionally are they implementing the most recognized evidence-based practices recommended for students with autism spectrum disorder? 
2. What rating level of difficulty have special educators in Connecticut experienced in implementing the Connecticut Guidelines for Identification and Education of Children and Youth with Autism for students with autism? Additionally do they find it difficult to implement the most recognized evidence-based practices recommended for students with Autism Spectrum Disorder?

3. What rating of level of importance do special educators in Connecticut place on the Connecticut Guidelines for Identification and Education of Children and Youth with Autism when designing programs for students with autism? Additionally if they are implementing the most recognized evidence-based practices recommended for students with ASD have they found them to be important?

4. Are there associations between special educators' implementation of the Connecticut Guidelines for Identification and Education of Children and Youth with Autism and the independent variables (a) years of experience, (b) assignment, (c) place, (d) RESC, (e) number of students on caseload, (f) percentage of students with ASD on caseload, or $(\mathrm{g})$ personal relationship?

5. Are there associations between special educators' rating of level of difficulty implementing the Connecticut Guidelines for Identification and Education of Children and Youth with Autism and the independent variables (a) years of experience, (b) assignment, (c) place, (d) RESC, (e) number of students on caseload, (f) percentage of students with ASD on caseload, or (g) personal relationship?

6. Are there associations between special educators' rating of importance of the Connecticut Guidelines for Identification and Education of Children and Youth with Autism and the independent variables (a) years of experience, (b) assignment, (c) place, 
(d) RESC, (e) number of students on caseload, (f) percentage of students with ASD on caseload, or (g) personal relationship?

\section{Research Design}

This descriptive correlational study used a self-report survey to address the research questions. Gall, Borg and Gall (1996) identify the use of a survey in educational research as a means to collect and analyze data that is not directly observable. The on-line self-report Autism Needs Survey used in this study collects cross sectional data. The survey consists of 22 questions designed to illicit information on the predictor variables in the categories of participant's (a) years of experience, (b) assignment, (c) place, (d) RESC, (e) number of students on caseload, (f) percentage of students with ASD on caseload, or (g) personal relationship and the dependent variables of the special educator's implementation, the degree of difficulty implementing and the level of importance of the Connecticut Guidelines.

The self-report survey used in this study collected primarily quantitative data. The Needs Assessment for Educating Children with Autism and Other Developmental Disabilities survey designed and implemented by the Connecticut Special Act No. 08-5 feasibility study was the foundation of the survey tool named Autism Need Survey used for this study. The Autism Need Survey collected quantitative data for the purpose of providing descriptive information on teachers' implementation of the Connecticut Guidelines and exploring variables that might predict the probability of an educator's using and valuing the Guidelines. There were 6 open-ended questions included in the survey designed to create a more comprehensive picture and illustration; the qualitative data can enrich the quantitative data (Bryman, 2006). 
Research participants included all certified special education teachers currently employed in Connecticut public and approved private special education facilities, which amount to approximately 6,000 teachers.

\section{Conceptual/Theoretical Framework}

"To improve educational outcomes for children and youth with Autistic Spectrum Disorders" is the first purpose listed for the Connecticut Guidelines (Connecticut State Department of Education, 2005, p. 14). The Connecticut Guidelines are meant to be a formal means of providing guidance and professional development to educators responsible for students with autism on the best evidenced-based practices as defined by the research. Autism and professional development were the two major components of the conceptual design for this study.

\section{Autism Instruction}

The components that have been identified as being critical in designing effective programs for children with ASD are rooted in the principles of applied behavioral analysis.

Applied Behavior Analysis is the science in which procedures derived from the principles of behavior are systematically applied to improve socially significant behavior to a meaningful degree and to demonstrate experimentally that the procedures employed were responsible for the improvement in behavior. (Cooper, Heron \& Heward, 1987, p. 15)

In the 1960's, Ivar Lovaas developed a curriculum and a method of teaching children with autism that applied the science of behavior analysis to the learning of skills; hence the development of applied behavioral analysis. The Behavior Analysis Certification Board (BACB) defines behavioral analysis as: 
The field of behavior analysis grew out of the scientific study of principles of learning and behavior. It has two main branches: experimental and applied behavior analysis. The experimental analysis of behavior (EAB) is the basic science of this field and has over many decades accumulated a substantial and well-respected research literature. This literature provides the scientific foundation for applied behavior analysis (ABA), which is both an applied science that develops methods of changing behavior and a profession that provides services to meet diverse behavioral needs. (2009, para. 1)

J. B. Watson, E. L. Thorndike, and B. F. Skinner delineated the basic principles of behavior, which included reinforcement, prompting, shaping, chaining, and schedules of reinforcement that comprised the pure science of behavior analysis (Coleman, 1985; Cooper et al., 1987). Their elaboration of the principles was an extension of the work of Ivan Pavlov. Pavlov's well-known work with the gastric function and saliva secretion of dogs led to the establishment of the laws of conditioned reflexes which laid the theoretical foundation of behaviorism. Research in the field of autism has established that the most effective strategies for students utilize the structure provided through a behavioral approach.

Current behavioral approaches have become more inclusive of concepts such as teaching in the natural environment, considering antecedents, and direct instruction of social behaviors. There has been a "shift from viewing behavior support as a process by which individuals are changed to fit environments, to one in which environments are changed to fit behavior patterns of people in the environments" (Horner, Carr, Strain, Todd \& Reed, 2000, p. 6). The components from the Connecticut Guidelines that guide the actual teaching of students ( Individualized and Intensive Programming, Comprehensive Curriculum, Systematic Instruction and Ongoing Objective Assessment, Structured/Predictable Learning Environment) are grounded in current behavioral theory. 


\section{Professional Development}

Grant (1996) discusses professional development in terms of going beyond "training" and learning new skills to include formal and informal methods for teachers to develop their own insights into pedagogy by providing resources on content and how to improve their own practices. Positive outcomes for students should be expected as a result of teacher's enhanced job and organizational performance as a result of professional development (Guskey, 2000; Joyce \& Showers, 2002; Killion, 2002). “To improve educational outcomes for children and youth with autistic spectrum disorders" was the first purpose listed for the guidelines (Connecticut State Department of Education, 2005, p. 14). The Connecticut Guidelines were meant to be a formal means of providing guidance and professional development to educators responsible for students with autism.

The literature identifying best practices for the professional development of teachers is extensive (Guskey, 2000; Joyce \& Showers, 2002; Smylie \& Wenzel, 2003). To understand professional development it is helpful to explore the theories of adult learning. The field of research on adult learning dates back to the early 1900s. Constructivist theory and andragogy are two theories.

Constructivism views learning as an active process that is continuously confirmed and re-evaluated which is applicable to professional development. The teacher, as learner, takes in new information that fits or contradicts their knowledge paradigm (Driscoll, 2005). The first assumption, which is key to constructivist theory, is that each learner brings his or her previous knowledge and experience into the learning process (Staits \& Wilke, 2007). The second assumption is that learning is active rather than passive. Hoover (1996) states that the "learner remains active throughout this process: they apply 
current understandings, note relevant elements in new learning experiences, judge the consistency of prior and emerging knowledge, and based on that judgment, they can modify knowledge" ( para. 4).

Malcolm Knowles in his 1970 book, The Modern Practice of Adult Education: Andragogy Versus Pedagogy popularized the concept of andragogy. Knowles' theory focuses on the adults utilizing their life experiences and relating them to what they need or want to learn. His theory is based on the following assumptions, the first four are from his earlier work (1970) and the last two were added in his Andragogy in Action: Applying Modern Principles of Adult Education (1984).

1. Self-concept: As people mature, they move being a dependent personality toward being more self-directed

2. Experience: As people mature, they amass a growing set of experiences that provide a fertile resource for learning

3. Readiness to learn: As people mature, they are more interested in learning subjects that have immediate relevance to their jobs or personal lives

4. Orientation to learning: As people mature, their time perspective changes from gathering knowledge for future use to immediate application of knowledge. As such, adult learners become more problem-centered rather than subject-centered (Knowles, 1970)

5. Motivation to learn: As people mature, they become more motivated by various internal incentives, such as need for self-esteem, curiosity, desire to achieve, and satisfaction of accomplishment

6. Relevance: As people mature, they need to know why they need to learn something. Furthermore, because adults manage other aspects of their lives, they are capable of directing or, at least, assisting in the planning and implementation of their own learning. (Knowles, 1984, p. 12).

Constructivist theory and andragogy are similar, as they both value the experiences and independence of the learner. It would be expected that the application of both of these principles would influence a teacher's perception and use of the professional development experience provided by the Connecticut Guidelines. 


\section{Assumptions}

This research assumed all school districts in Connecticut provide specific services to children identified with autism. Additionally there was an assumption that all school districts are familiar with the Connecticut Guidelines and have attempted to implement what has been established through research as best practice. It was believed districts would participate in this study in order to influence the development of resources in Connecticut for students with autism. Participation in the study was voluntary and responders could choose to withdraw from the study at any time without any consequences. A major assumption of this study was all participants answered the survey questions truthfully based on the knowledge that anonymity and confidentiality would be preserved.

\section{Delimitations}

Given the research questions, the scope of this study was limited to certified special education teachers in approved public and private schools in Connecticut. The rationale for focusing on this group of educators includes their: (a) direct responsibility for providing the educational services delineated in the Connecticut Guidelines to students with autism; (b) participation in training opportunities on effective educational practices for autism; and (c) continued need to see improvement in understanding how to best educate students with autism. Although administrators, general education teachers, related service providers, and paraprofessionals may have a role in supporting students with autism, they are not the primary ones responsible for program development, so their input was not solicited in this study. Focus was on teachers' perception of the 
Connecticut Guidelines, so parents of, or students with autism were not asked to participate in this study.

\section{Limitations}

Participants' experiences with the Connecticut Guidelines were assessed only through the use of the Autism Needs Survey. There were notable limitations inherent in the use of an internet -based survey for this study. It was understood biases are inherent in self-reported information and the possibility of participants concern about the privacy or confidentiality of their response existed.

\section{Significance of the Study}

Findings from this research will inform the practice of school leaders and school consultants working to improve outcomes for children with autism spectrum disorder in Connecticut. The goal is for consultants to work with school leaders to design appropriate and meaningful professional development activities to build the teachers' capacity and skill set and to impact outcomes for individuals with autism. The Connecticut Guidelines were published ten years ago, and due to the changes in the definition of autism in the recently published $D S M-5$ it is likely the Guidelines will need to be updated. This study provides information on educators' perception of the Connecticut Guidelines, which could be useful for their revision. The information from this study will be available to the Connecticut State Department of Education and the Special Education Resource Center (SERC). A presentation of this study will also be shared through a forum sponsored by Benhaven Learning Network to special education directors in Connecticut. This research will add information to the academic field on the effect of research-based interventions being used to educate children with autism. 


\section{Definition of Terms}

Autism: specifically defined in the Individuals with Disabilities Act (IDEA) as a

developmental disability significantly affecting verbal and nonverbal communication and social interaction, generally evident before age 3 that adversely affects a child's educational performance. Other characteristics often associated with autism are engagement in repetitive activities and stereotyped movements, resistance to environmental change or change in daily routines, and unusual responses to sensory experiences. (IDEA, 1997, p. 17)

Autism Spectrum Disorder (ASD): defined in the DSM-5 as a disorder with persistent difficulties in social communication/interaction and restricted/repetitive behaviors which are present from early childhood, although may not be recognized until social demands exceed capacity.

Applied Behavioral Analysis (ABA): the science of applying "principles" of

behavior to shape and change behavior in measurable ways.

Applied Behavior Analysis is the science in which procedures derived from the principles of behavior are systematically applied to improve socially significant behavior to a meaningful degree and to demonstrate experimentally that the procedures employed were responsible for the improvement in behavior.

(Cooper, Heron \& Heward, 1987, p. 15)

Consultative Support: direct support, through scheduled observations and debriefing sessions, provided by highly qualified consultants to educators responsible for teaching children with autism.

The following are definitions of evidence-based practices identified by the National Professional Development Center.

Antecedent-Based Intervention (ABI): Arrangement of events or circumstances that precede the occurrence of an interfering behavior and designed to lead to the reduction of the behaviors. 
Cognitive Behavioral Intervention (CBI): Instruction on management or control of cognitive processes that lead to changes in overt behaviors.

Differential Reinforcement of Alternative Behavior(DRA): Provision of positive/desirable consequences for behaviors or their absence that reduce the occurrence of an undesirable behavior. Reinforcement provided when the learner is engaging in a specific desired behavior other than the inappropriate behavior.

Differential Reinforcement of Incompatible Behavior (DRI): Provision of positive/desirable consequences for behaviors or their absence that reduce the occurrence of an undesirable behavior. Reinforcement provided when the learner is engaging in a behavior that is physically impossible to do while exhibiting the inappropriate behavior.

Differential Reinforcement of Other Behavior (DRO): Provision of positive/desirable consequences for behaviors or their absence that reduce the occurrence of an undesirable behavior. Reinforcement provided when the learner is not engaging in the interfering behavior.

\section{Differential Reinforcement of Alternative, Incompatible, or Other Behavior}

(DRA/I/O): Provision of positive/desirable consequences for behaviors or their absenced that reduce the occurrence of an undesirable behavior. Reinforcement provided: (a) when the learner is engaging ina specific desired behavior other than the inappropriate behavior (DRA), (b) when the learner is engaging in a behavior that is physically impossible to do while exhibiting the inappropriate behavior (DRI), or (c) when the learner is not engaging the the interfering behavior (DRO).

Discrete Trial Teaching (DTT): Instructional process usually involving one teacher/service provider and one student/client and designed to teach appropriate 
behavior or skills. Instruction usually involves massed trials. Each trial consists of the teacher's instruction/presentation, the child's response, a carefully planned consequence, and a pause prior to presenting the next instruction.

Exercise (ECE): Increase in physical exertion as a means of reducing problem behaviors or increasing appropriate behavior.

Extinction (EXT): Withdrawal or removal of reinforcers of interfering behavior in order to reduce the occurrence of that behavior. Although sometimes used as a single intervention practice, extinction often occurs in combination with functional behavior assessment, functional communication training, and differential reinforcement.

Functional Behavior Assessment (FBA): Systematic collection of information about an interfering behavior designed to identify functional contingencies that support the behavior. FBA consists of describing the interfering or problem behavior, identifying antecedent or consequent events that control the behavior, developing a hypothesis of the function of the behavior, and/or testing the hypothesis.

Functional Communication Training (FCT): Replacement of interfering behavior that has a communication function with more appropriate communication that accomplishes the same function.

Modeling (MD): Demonstration of a desired target behavior that results in imitation of the behavior by the learner and that leads to the acquisition of the imitated behavior.

Naturalistic Intervention (NI): Intervention strategies that occur within the typical setting/activities/routines in which the learner participates. Teachers/service providers establish the learner's interest in a learning event through arrangement of the 
setting/activity/routine, provide necessary support for the learner to engage in the targeted behavior, elaborate on the behavior when it occurs, and/or arrange natural consequences for the targeted behavior or skills.

Parent-Implemented Intervention (PII): Parents provide individualized intervention to their child to improve/increase a wide variety of skills and/or to reduce interfering behaviors. Parents learn to deliver interventions in their home and/or community through a structured parent training program.

Peer-Mediated Instruction and Intervention (PMII): Typically developing peers interact with and/or help children and youth with ASD to acquire new behavior, communication, and social skills by increasing social and learning opportunities within natural environments. Teachers/service providers systematically teach peers strategies for engaging children and youth with ASD in positive and extended social interactions in both teacher-directed and learner-initiated activities.

Picture Exchange Communication System (PECS): Learners are initially taught to give a picture of a desired item to a communicative partner in exchange for the desired item. PECS consists of six phases which are: (a) "how" to communicate, (b) distance and persistence, (c) picture discrimination, (d) sentence structure, (e) responsive requesting, and (f) commenting.

Pivotal Response Training (PRT): Pivotal learning variables (i.e., motivation, responding to multiple cues, self-management, and self-initiations) guide intervention practices that are implemented in settings that build on learner interests and initiative. 
Prompting (PP): Verbal, gestural, or physical assistance given to learners to assist them in acquiring or engaging in a targeted behavior or skill. Prompts are generally given by an adult or peer before or as a learner attempts to use a skill.

Psychiatry Diagnostic \& Statistical Manual of Mental Disorders 3rd Edition Revised (DSM-III-R): A book that provides a classification system for mental illness developed by the American Psychiatric Association and published in 1987.

Psychiatry Diagnostic \& Statistical Manual of Mental Disorders 4th Edition (DSM-IV): A book providing a classification system for mental illness developed by the American Psychiatric Association, which was published in 1994.

Regional Educational Service Centers (RESC): school-based partnerships created by school districts and based on legislation enacted over 40 years ago. There are 6 RESCs in Connecticut designed to provide high-quality, cost-effective services to Connecticut's school districts. Based on geographical location a school district is partnered with one of the six RESCs.

Reinforcement $(R+)$ : An event, activity, or other circumstance occurring after a learner engages in a desired behavior that leads to the increased occurrence of the behavior in the future.

Response Interruption/Redirection (RIR): Introduction of a prompt, comment, or other distracters when an interfering behavior is occurring that is designed to divert the learner's attention away from the interfering behavior and results in its reduction.

Scripting (SC): A verbal and/or written description about a specific skill or situation that serves as a model for the learner. Scripts are usually practiced repeatedly before the skill is used in the actual situation. 
Self-Management (SM): Instruction focusing on learners discriminating between appropriate and inappropriate behaviors, accurately monitoring and recording their own behaviors, and rewarding themselves for behaving appropriately.

Social Narratives (SN): Narratives that describe social situations in some detail by highlighting relevant cues and offering examples of appropriate responding. Social narratives are individualized according to learner needs and typically are quite short, perhaps including pictures or other visual aids.

Social Skills Training (SST): Group or individual instruction designed to teach learners with ASD ways to appropriately interact with peers, adults, and other individuals. Most social skill meetings include instruction on basic concepts, role-playing or practice, and feedback to help learners with ASD acquire and practice communication, play, or social skills to promote positive interactions with peers.

Structured Play Group (SPG): Small group activities characterized by their occurrences in a defined area and with a defined activity, the specific selection of typically developing peers to be in the group, a clear delineation of theme and roles by adult leading, prompting, or scaffolding as needed to support students' performance related to the goals of the activity.

Task Analysis (TA): A process in which an activity or behavior is divided into small, manageable steps in order to assess and teach the skill. Other practices, such as reinforcement, video modeling, or time delay, are often used to facilitate acquisition of the smaller steps.

Technology-Aided Instruction and Intervention (TAII): Instruction or interventions in which technology is the central feature supporting the acquisition of a 
goal for the learner. Technology is defined as "any electronic item/ equipment/ application/or virtual network that is used intentionally to increase/maintain, and/or improve daily living, work/productivity, and recreation/leisure capabilities of adolescents with autism spectrum disorders".

Time Delay $(T D)$ : In a setting or activity in which a learner should engage in a behavior or skill, a brief delay occurs between the opportunity to use the skill and any additional instructions or prompts. The purpose of the time delay is to allow the learner to respond without having to receive a prompt and thus focuses on fading the use of prompts during instructional activities.

Video Modeling (VM): A visual model of the targeted behavior or skill (typically in the behavior, communication, play, or social domains), provided via video recording and display equipment to assist learning in or engaging in a desired behavior or skill.

Visual Support (VS): Any visual display that supports the learner engaging in a desired behavior or skills independent of prompts. Examples of visual supports include pictures, written words, objects within the environment, arrangement of the environment or visual boundaries, schedules, maps, labels, organization systems, and timelines (Wong, et al., 2013).

\section{Organization of the Study}

A review of the literature describes the disability of autism and supports the effectiveness of particular components for the effective education of children with autism is presented in Chapter 2. The literature review defines the components and provides an historical perspective that substantiates the effectiveness of identified components for educating children with autism. Chapter 3 describes the research methodology of this 
study. Chapter 4 presents the results. A summary and discussion of the results including implications for the area of autism spectrum disorders within the State of Connecticut is presented in Chapter 5. 


\section{CHAPTER 2}

\section{REVIEW OF RELATED LITERATURE}

\section{Introduction}

“...it would be a mistake to portray the picture as a one-way traffic from research to clinical practice. The reality is more complex interplay, with each feeding into the other and serving to correct the other's mistakes" (Rutter, 1999, p. 169).

This quote by Michael Rutter (1999) shares his insight about the relationship between research and practice in the field of autism. Autism is a lifelong disability that currently affects 1 in every 68 children and is the most frequently diagnosed condition in children (Center for Disease Control, 2014). Research has provided insight into effective treatments for children with autism, however this is still a relatively new field. Highly respected researchers in the field have acknowledged and documented the serious limitations in the existing research. The limitations make it impossible to draw conclusions about the effectiveness on treatments (Lord et al., 2005; Smith et al., 2007). Much still needs to be done in order to improve the quality and availability of interventions and supports. One problem that exists in accomplishing this goal is the lack of coordinated communication between researchers and practitioners, which to this point has been minimal and ineffective (Gabriels \& Hill, 2002; Rutter, 1999).

In 2001 the NRC published Educating Children with Autism. This report was the outcome of a charge given by the U.S. Department of Education's Office of Special 
Education Programs to evaluate the current status of educational practices for children with autism. In this report, the NRC made recommendations for the inclusion of specific core components of interventions and supports in the program design for children with ASD. Their findings were based on empirical research, information from selected autism programs, and findings in the general and developmental literature (National Research Council, 2001). In 2005 when the Connecticut State Department of Education drafted the Connecticut Guidelines, it considered the recommendations made by the NRC (Connecticut State Department of Education, 2005). The Connecticut Guidelines was intended to support school districts in incorporating into their programs the core components which included: Earliest Intervention, Family Involvement and Cooperative Planning, Individualized and Intensive Programming, Comprehensive Curriculum, Systematic Instruction and Ongoing Objective Assessment, Structured/Predictable Learning Environment, Specifically Trained Personnel, and Peer Relationships (Connecticut State Department of Education, 2005).

As the number of children with autism needing educational support increases, it is not enough to know what the components of an effective program are; we must also understand what teachers are able to implement efficiently and effectively in a classroom setting. It is critical to examine teacher's use of the Guidelines. Teachers who are responsible for educating students with autism must demonstrate knowledge of the range of evidence-based practices and ability to implement them effectively, based on the needs of the student (National Research Council, 2001).

Findings from this research can inform the practice of school leaders and school consultants working to improve outcomes for children with autism spectrum disorder in 
Connecticut. Consultants work with school leaders to design appropriate and meaningful professional development activities to build the teachers' capacity and skill set, which will impact outcomes for individuals with autism. Leaders responsible for programs that support children and youth with autism could use this information to determine the best use of resources in order to successfully implement program components. This study provides information on educators' perception of The Connecticut Guidelines, which could be useful for the revision of the guidelines.

In this chapter, the review of the relevant literature initially provides an overview of autism within a theoretical context of the diagnosis. Then the literature review provides information on methodologies and interventions used for educating children with autism. In closing, the components of effective programs as described in the NRC's Educating Children with Autism and incorporated in the 2005 Connecticut State Department of Education Guidelines for the Identification and Education of Children and Youth with Autism are presented along with information on costs of supporting an individual with autism.

\section{Autism}

\section{History of Autism Identification}

Autism is a developmental disorder that was initially described in 1943 by Leo Kanner of John Hopkins Hospital in his paper "Autistic Disturbances of Affective Contact." This famous paper described the behaviors demonstrated by 11 children $(9$ boys and 2 girls) Kanner had seen in his psychiatric practice (Safran, 2001). This group of children shared a variety of unique symptoms including: the desire for sameness, agitation and distress due to changes in environments or routines, failure to develop 
normal relationships, and abnormalities in speech and language (Freeman, 1997; Simpson \& Zionts, 2000). The "autism," or self-centeredness, of these children was recognized as the primary deficit. Similar patterns were soon reported in children throughout the world and researchers began to differentiate autism from other childhood psychoses (Freeman, 1997; Rutter, 1999).

Around the same time as Kanner's initial work, Hans Asperger, an Austrian psychiatrist was describing a similar disorder based on his work with individuals that experienced difficulty with social interactions, but had highly developed expressive language skills and an unusually high level of understanding of factual based knowledge. There is debate as to who came first, but Michael Rutter a leading authority in the field of autism, credits Kanner for creating an organized clinical description. Michael Rutter believes Kanner's paper is the important one:

I don't actually have a very high opinion of Asperger's writings. They were so rambling and disorganized. Which came first? Well, it depends what you mean. Was Darwin the first person to deal with evolution? Of course not. But what Darwin did was provide an organized approach to it. I think the same thing about Kanner. (Feinstein, 2010, p. 24)

Prior to Kanner's work, the introduction of autism to the practice of psychology is credited to the work of E. Bleuler who, in 1911, used the word autism as a description for Schizophrenia.

The schizophrenics who have no more contact with the outside world of their own. They have encased themselves off as much as possible from contact with the external world. The detachment from reality with the relative absolute predominance of the inner life, we term autism. (pp. 131-136)

The name of the disorder was derived from the Greek root autos meaning "self." Leo Kanner was the first to describe autism as a unique disorder separate from other psychoses. In the 50 years since Kanner's initial paper (1943), children with autism have 
been labeled mistakenly with childhood psychosis, severe emotional disability, atypical ego development, childhood schizophrenia, symbiotic psychosis, early (primary) or late (secondary) onset autism, or mental retardation with autistic features (Freeman, 1997).

After its initial description, autism was poorly ascertained during the middle decades of the 20th century. In DSM-I (American Psychiatric Association, 1952) and DSM-II (American Psychiatric Association, 1968), 'psychotic reactions in children manifesting primary autism were classified under the terms schizophrenic reaction or schizophrenia, childhood type. (Rutter, 1999, p. 28)

During the 1950's and 1960's, autism research focused primarily on describing the nature of the disorder, including the behavioral and cognitive characteristics, etiology, and prognosis. Autism was considered to be a psychological disturbance that was caused by uncaring, detached mothers. In 1967 Bruno Bettelheim published the book The Empty Fortress: Infantile Autism and the Birth of the Self, which promoted the theory of the "Refrigerator Mother." The book in part was based on the annual reports he submitted to the Ford Foundation which had awarded him a five-year grant of $\$ 342,000$ in 1956 to study autism. In the early 1960's a few doctors began to challenge this view. Richard Pollack, a journalist who had a brother with autism treated by Bettelheim, which resulted in a negative outcome, wrote the biography The Creation of $\mathrm{Dr}$. B in 1997.

In the book, Pollak investigates Bettelheim's public persona, turning up evidence that Bettelheim had misconstrued his own life story, exaggerated and even invented his credentials and expertise in autism, abused the children under his care, terrorized parents, and popularized the destructive 'refrigerator mother' theory without adequate proof. (Simpson, Hanley \& Quinn, 2002, para. 6)

Bernard Rimland, a doctor of psychology and the father of a child with autism was the most influential in opposing the view of the "refrigerator mother." In 1964, Dr. Rimland provided a definitive review of evidence that established autism as a biological condition thus demonstrating that the earlier theory of uncaring and detached mothering 
was incorrect (National Alliance for Autism Research, 2005). During this time period, treatment initially was focused on psychoanalytic intervention, with some beginning studies of operant-learning techniques (Gabriels \& Hill, 2002; Rutter, 1999).

The second phase in the developing field of autism, 1970s through the mid 1980s, saw diagnostic criteria becoming further defined, and standardized diagnostic tools were utilized. Researchers and practitioners recognized the homogeneity in the presentation of characteristics (Rutter, 1999). Michael Rutter and Lawerence Bartak published "Causes of infantile autism: Some considerations from Research" in 1971 that addressed the prevailing notions of autism at that time (Feinstein, 2010).

Rutter and Bartak were at pains to stress that:

the fact of the matter is that autistic children usually exhibit multiple central defects. At the present time, it is uncertain which of these are necessary and sufficient causes of the disorder. We have suggested that a central defect in the processing of symbolic or sequence information is likely to prove the basic defect, but the evidence is not yet available to decide conclusively between the different types of cognitive or sensory disorders which have been postulated for autism. (Rutter \& Bartak, 1971 p. 27 cited in Feinstein, 2010)

In 1978, the Autism Society of America formulated a "Definition of the Syndrome of Autism" that represented consensus among professionals from all parts of the world (Ritvo \& Freeman, 1978). In 1980, the DSM-III was released and autism was formally recognized under the diagnosis of "infantile autism" (American Psychiatric Association, 1980; Aspy \& Grossman, 2007; Freeman, 1997). The APA (1980) recognized the existence of cases that were similar to autism but failed to meet the diagnostic criteria for the disorder. Such cases were addressed as "pervasive developmental disorder," which encompasses all disorders in which there is qualitative impairment in the development of (a) reciprocal social interaction, (b) communication 
(verbal and non-verbal), and (c) imaginative activity. In 1987 a revised edition of the $D S M$ was released that changed the disorder to "autistic disorder" and refined the criteria (Aspy \& Grossman, 2007). The word "infantile" was removed due to controversy over the descriptor being used with individuals across the age span.

During this time period, medical etiologies for autism were further investigated with some studies yielding a strong genetic component but no clear cause (Gabriels \& Hill, 2002). Treatment saw the development of educational interventions, and psychoanalytic interventions were discarded. According to Turnbull and Turnbull (2000), "early interventions were the exception, not the rule. Placement in private programs was encouraged because it relieved the school of any responsibility for serving children whose families were able or desperate enough to pay for private school opportunities" (p. 19).

In the late 1980s there was a shift in the language used to describe a broader clinical phenotype for autism. Allen (1988) used the phrase "Autistic Spectrum Disorder" and Lorna Wing (1988) used the phrase "Autistic Continuum" to describe her view that, rather than thinking rigidly of autism as a discrete syndrome, it should be viewed as a continuum of autistic disorders (Bishop, 1989). In the years between DSM-III-R and $D S M-I V$ there was a slow consensus that the umbrella of "pervasive developmental disorders" does reflect an "autistic spectrum" (Wing, 1997). "For the first time, DSM-IV criteria included the term qualitative to describe the impairments within the major criteria, defining a range of impairments rather than the absolute presence or absence of a particular behavior as sufficient to meet the criterion for diagnosis" (Filipek et al., 1999, p. 442). In 1994 the $D S M-I V$ listed Autistic Disorder, Asperger disorder, Rett disorder, 
Childhood Disintegrative Disorder, and PDD-NOS under the classification of Pervasive Developmental Disorders (American Psychiatric Association, 1994).

The change from a discrete disorder to a spectrum was indicative of the explosion of work being done both in research and in clinical practice. The gains made in the understanding of the etiology of the disorder and the development of successful interventions became viewed as the result of the exchanges between researcher and practitioner. "However it is still the case that many practitioners do not have easy access to the latest research developments and that many researchers are far removed from the hands-on work of clinical intervention" (Gabriels \& Hill, 2002, p. 18).

In the recently published $D S M-5$ the APA has modified the diagnostic criteria for ASD. The diagnosis will be called Autism Spectrum Disorder, and there no longer will be subdiagnoses (Autistic Disorder, Asperger Syndrome, PDD-NOS, Disintegrative Disorder). The new diagnostic criteria have been consolidated into two areas: (a) social communication/interaction, and (b) restricted and repetitive behaviors (Hyman, 2013). The Neurodevelopmental Work Group, led by Susan Swedo, MD, senior investigator at the National Institute of Mental Health, recommended the $D S M-5$ criteria for ASD to be a better reflection of the state of knowledge about autism. The Work Group believed a single umbrella disorder will improve the diagnosis of ASD without limiting the sensitivity of the criteria, or substantially changing the number of children being diagnosed (American Psychiatric Association, 2013).

\section{Diagnostic Criteria for Autism Spectrum Disorders}

Autism is a developmental disorder of neurobiological origin that is defined on the basis of behavioral and developmental features (National Research Council, 2001). 
Being a developmental disorder, children are either born with the condition or with the potential for developing the condition. Experts agree that autism can be further defined at three different interdependent levels: as a neurological disorder related to brain development: as a psychological disorder of cognitive, emotional, and behavioral development; or as a relationship disorder in which there is a failure of normal socialization (Kusch \& Petermann, 1995).

Uta Frith, a research scientist at the MRC Cognitive Development Unit in London, believes that the current research suggests "we should not just think about 'the' cause for autism, but about a long causal chain" (Frith, 1991, p. 80), and proposes a "hazard, havoc, harm" model: ... The hazard can be of many kinds, including faulty genes, chromosome abnormality, metabolic disorder, viral agents, immune intolerance and anoxia from perinatal problems. We can assume that any of these hazards has the potential to create havoc in neural development. Owing to the upheaval, lasting harm may be done to the development of specific brain systems concerned with higher mental processes. The harm may be mild or severe, but always involves the developmental arrest of a critical system at a critical point in time. It is our hypothesis that only then will autism occur. (Frith, 1991, p. 80 cited in Holmes, 1998)

Autism is a developmental disorder characterized by symptoms in the developmental areas of social reciprocity and interaction, communication, and repetitive behaviors (Wing, 2001). Although authorities agree that autism is a spectrum disorder it cannot be defined simply from mild to severe. Different children demonstrate different combinations of characteristics, but all share a core deficit in forming relationships and communicating (Boutot \& Myles, 2011; Kusch \& Petermann, 1995; Pratt, Vicker \& Davis, 2001). Frequently co-occurring and associated characteristics include problems in sensory processing (Anzalone \& Williamson, 2000; Greenspan \& Wieder, 1997), motor planning (Anzalone \& Williamson, 2000; Prizant, 1996), emotional regulation, and arousal modulation (Cole, Mitchel \& Teti, 1994; Dawson \& Lewy, 1989; Prizant, Shuler, Wetherby \& Rydell, 1997). Levels of intellectual functioning for individuals diagnosed 
with autism spectrum disorders can range from profound mental retardation through the superior range on conventional IQ tests (Filipek et al., 1999). Individuals with autism with above average to superior intelligence may understand and use language fluently yet still demonstrate difficulty with prosody and intonation (Howlin, Savage, Moss, Tempier \& Rutter, 2014).

\section{Core Deficits of Autism Spectrum Disorders}

\section{Social}

By definition, children with autism demonstrate impairments in relationships to peers, the use of nonverbal communicative behaviors within their social exchanges, and the use of imitation and symbolic or dramatic play (National Research Council, 2001, p. 69). "Although the stereotyped child with autism is thought to prefer to be alone and left in his own world, many children with autism express love and affection for familiar people, including parents and teachers. The differences we see in children with autism frequently have to do with the way in which they experience emotions or interact" (Boutot \& Myles, 2011, p. 19). Social interactions of the child with autism are observed to be lacking both in the initiation of a response and in being responsive to other individuals. The social problems in individuals with autism become apparent in situations that require reciprocity. This is most evident in situations focused on sharing experiences or joint attention (Corona, Dissanayake, Arbelle, Wellington \& Sigman, 1998; Mundy, Sigman \& Kasari, 1990; Peterson \& Haralick, 1977; Wetherby \& Prutting, 1984).

Although these children bond and show emotional attachment to their parents and caregivers, their interactions are qualitatively, and sometimes quantitatively, different than their typically developing peers (Capps, Sigman \& Mundy, 1994; Lord, 1994). 
Children with autism seem to pay less attention to others' emotional behaviors and display fewer acts of empathy or shared emotion. This lack of awareness can cause them to behave inappropriately in social situations (Travis \& Sigman, 1998). Imitation, initiation, modulation, and interpretation of others' actions, movements, gestures and vocalizations are impaired which contributes to the social awkwardness (Capps et al., 1994; DeMyer et al., 1972; Sigman, 1994; Stone, Ousley, Yoder, Hogan \& Hepburn, 1997). Social success involves the bringing together of non-verbal and verbal information (O’Conner, 2012). As individuals with autism get older they often misinterpret any verbal communication as friendship (Winter \& Lawrence, 2011). Ruth Aspy and Barry Grossman (2007) developed the list below to highlight the social differences.

\section{Common Social Differences:}

- Has difficulty recognizing the feelings and thoughts of others (mindblindness)

- Uses poor eye contact

- Has difficulty maintaining personal space; physically intrudes on others

- Lacks tact or appears rude

- Has difficulty making or keeping friends

- Has difficulty joining an activity

- Is naïve, easily taken advantage of, or bullied

- Tends to be less involved in group activities than most same- age individuals

- Has difficulty understanding others' nonverbal communication (e.g., facial expressions, body language, tone of voice)

- Has difficulty understanding jokes 


\section{Communication}

The communication difficulties experienced by children with autism are far more complex than a presumed simple speech delay and share some similarities with the deficits seen in children with developmental language disorders or specific language impairments (Allen \& Rapin, 1997). Expressive language use by children with autism ranges from complete mutism to verbal fluency, although the fluency is often accompanied by many semantic (word meaning) and verbal pragmatic (use of language to communication) errors (Filipek et al., 1999). Some children may develop language which is characterized by labeling (instead of requesting), echolalia (echoing speech), abnormal prosody or inflection (unusual tone of voice or inflection), or improper use of pronouns (Corsello, 2013). Most children with autism that learn to speak go through a period of using echolalia (the imitation of speech of others), which may be immediate or delayed (Prizant et al., 1997).

Children with autism who progress beyond echolalia usually acquire more advanced aspects of grammar: that is, they develop grammatical skills in the same general progression as typically developing children, but show persisting problems in following the social rules and shifting between speaker and listener roles of conversation (Baltaxe, 1977; Tager-Flusberg, 1996), which are the pragmatic aspects of language. (National Research Council, 2001, p. 49)

Children with autism often fail to understand the purpose of language as a means to influence their surroundings (Watson, Lord, Schaffer \& Schopler, 1989). Difficulty sustaining a conversation with a partner, and the use of repeated words or idiosyncratic language are characteristics of deficits in the spoken language of children with autism (Plumb \& Wetherby, 2013). This inability to use language as a tool interferes with the child's ability to initiate and maintain a conversation that incorporates the other person's feelings and ideas. Often a child with autism engages in a monologue, telling the 
communication partner information without checking for a response or listening if there is a response (Gabriels \& Hill, 2002). Almost all children with autism, regardless of their verbal skills or intelligence have comprehension deficits, especially in understanding higher-order inferential questions (Filipek et al., 1999).

Additional evidence of a deficit in understanding symbolic meaning in children with autism is their limited ability to develop symbolic or pretend play (National Research Council, 2001). Children with autism show significant difficulty with makebelieve play (i.e., using pretend substitutions for objects - a stick as a magic wand) and limited abilities in functional play (i.e., using objects functionally - rolling a truck along the floor) (Dawson \& Adams, 1984). Some highly verbal children with autism may invent a fantasy scene based on an area of interest that they repeat over and over without any variation, including the need to run through the accompanying script without interruption. Functional and symbolic play-skills have been found to be significantly correlated with receptive and expressive language (Mundy et al., 1990). It is believed that the deficit in imaginative and social play of children with autism further impacts the development of language due to the reduced opportunities to practice language in play situations (Howlin \& Yates, 1989).

Ruth Aspy and Barry Grossman (2007) developed the list below to highlight the communicative differences.

\section{Common Communication Differences}

- Makes sounds repeatedly or states words or phrases repeatedly (non-echolalia) (e.g., humming, "well actually") 
- Displays immediate or delayed echolalia (reciting lines from movies, repeating another person's question or statements, repeating sounds, etc.)

- Interprets words or conversations literally/has difficulty understanding figurative language

- Has difficulty with rules of conversation (e.g., interrupting others, asking inappropriate questions, poor eye contact, and difficulty maintaining conversation)

- Fails to initiate or respond to social greetings

- Has difficulty starting, joining, and/or ending a conversation

- Has difficulty asking for help

- Makes irrelevant comments

- Has difficulty expressing thoughts and feelings

- Speaks in an overly formal way

- Gives false impression of understanding more than actually does

- Talks incessantly

- Uses an advanced vocabulary

- Uses mechanical, "sing-song" voice, or speech sounds that are unusual in other ways (e.g., prosody, cadence, tone)

- Has difficulty following instructions

- Has difficulty understanding language with multiple meanings, humor, sarcasm, synonyms

- Has difficulty talking about others' interests 


\section{Repetitive Behaviors}

Repetitive behaviors engaged in by children with autism that are less verbal often include rocking, moving hands in odd ways, blinking eyes, waving fingers in front of eyes, or other uncommon movements (Stratis \& Lecavalier, 2013). Most of these behaviors displayed by young children with autistic spectrum disorders are observed in typically developing children. However in autistic spectrum disorders, the intensity, frequency, duration, or persistence of the behaviors is more extreme. According to Schroedder "Once moderate to severe problem behaviors become an established part of a child's repertoire, unlike children with typical development, children with autistic spectrum disorders or other disabilities do not usually outgrow them. Without appropriate intervention, these behaviors persist and worsen" (National Research Council, 2001, p. 117; Schroeder, Bickel \& Richmond, 1986).

In higher functioning individuals with autism, the repetitive behavior will show itself as a preoccupation with a specific area or topic of interest. These interests are not typical or shared by same-age typically developing peers (prehistoric animals in preschool, Barney at age 12) or may be unusual at any age (vacuum cleaners, traffic lights). Often these topics become all the child can focus on and distract from social interactions and learning (Aspy \& Grossman, 2007; Winter-Messiers, 2007).

Repetitive behaviors may also take the form of an insistence for sameness. "Routines and rituals become important to many individuals with autism, and they often cling rigidly to sameness in their daily routines" (Gabriels \& Hill, 2002, p. 28). Without intervention, changes or interruptions in their routines can lead to tantrums or other emotional issues (Filipek et al., 1999). Aspy and Grossman (2007) developed the list below to highlight the repetitive behaviors. 


\section{Common Behavioral Differences}

- Expresses strong need for routine or "sameness"

- Expresses desire for repetition

- Has eccentric or intense preoccupations/absorption in own unique interests

- Asks repetitive questions

- Seems to be unmotivated by customary rewards

- Displays repetitive motor movements ("flaps" hands, paces, flicks fingers in front of eyes, etc.)

- Has problems handling transition and change

- Has strong need for closure or difficulty stopping a task before it is completed In addition to social problems, communication impairments, and repetitive behaviors and interests, many children with autism spectrum disorders have other behavioral issues and problems. Some of these difficulties include sleeping and feeding problems, temper tantrums, aggression, self-injurious behaviors, hyperactivity, anxiety, and loud vocalizations and screaming. Many children with autism have difficulty processing and regulating sensory information such as sight, sound, touch, taste, pain, and temperature (Harrison \& Hare, 2004). These behavior problems are not considered diagnostically salient, although they are usually clinically important and require behavioral and educational intervention (Gabriels \& Hill, 2002).

\section{Treatment Options}

"If these [learning disabilities] do not cause the child to lose his zeal or do not force him to flee from them, but activate him, then they will lead to a roundabout path of development” (Rieber \& Carton, 1993, p. 131). In this quote, L. S. Vygotsky, leader of 
Soviet cognitive developmental psychology in the 1920s and 1930s, was referencing children who were physically disabled or challenged. Rieber and Carton (1993) draw comparison between Vygotsky's words and the current thinking of researchers and practitioners responsible for the educational programs of children with autism. Once a child has been identified as eligible for special education and related services because he/she is a child with autism, the most often asked question by parents is "What do we do now?" It is important to remember that children with autism are a heterogeneous group of individuals with unique abilities, talents and needs. As a result, a variety of interventions may be necessary to consider when designing educational programs for children with autism (Mesibov \& Shea, 2010).

The NRC defines education as the fostering and acquisition of skills and knowledge to assist a child to develop independence and personal responsibility; this includes academic learning, socialization, adaptive skills, communication, amelioration of interfering behaviors, and generalization of abilities across multiple environments. Treatment programs should never lose sight of the long-term goal to improve the quality of life indicators for children with ASD. That is, empowerment to live, work, learn, be mobile, and have fun in settings where everyone else does these activities, in natural settings with family, friends, and coworkers. Any evaluation of treatment programs must focus on outcomes and not program specifics (Freeman, 1997).

Comprehensive treatment models and focused intervention practices are the two broad classes of intervention that can be used to describe the interventions discussed in the literature (Smith 2013; Wong et al., 2013). "Comprehensive treatment models (CTMs) consist of a set of practices designed to achieve a broad learning or 
developmental impact on the core deficits of ASD. In contrast, focused intervention practices are designed to address a single skill or goal of a student with ASD” (Odom, Collet-Klingenberg, Rogers \& Hatton, 2010; Wong, et al., 2013, p. 3).

\section{Comprehensive Treatment Models}

The process of education involves assessment, setting goals and objectives, determining teaching strategies, implementing the teaching plan, assessing student progress, and adapting the teaching strategy so the student acquires the skill (Cipani \& Spooner, 1994). There are two theoretical frameworks that provide the structure for how professionals develop goals, design intervention procedures, structure the learning environment, and determine methods of evaluating progress for a child with autism. They are (a) behavioral theory, or (b) developmental/relationship theory. Although these two differing conceptual frameworks influence intervention models in substantial ways, in practice there is considerable overlap between and across the models (National Research Council, 2001). Medical interventions are not the responsibility of the educational system but should be considered by families as possible add-on treatments.

The traditional behavioral approach (Lovaas, 1981) is based on ABA that entails specificity of purpose, goals, and activity structure. The model emphasizes precision and organization during instruction. This includes the adult taking responsibility for structuring the learning environment, utilizing chaining, prompting, and shaping techniques; and the use of reinforcement contingent upon the child's responses. "For each learner, skills to be increased and problem behaviors to be decreased are clearly defined in observable terms and measured carefully by direct observation. Selection of treatment goals for each individual is guided by data from initial assessment, and a curriculum 
scope and sequence that lists skills in all domains (learning to learn, communication, social, academic, self-care, motor, play and leisure, etc.), broken into smaller component skills and sequenced developmentally from simple to complex. The overall goal is to help each learner develop skills that will enable him or her to be as independent as possible and successful in the long run" (Green, 2005, para 2). It is critical to understand that many parents and professionals misunderstand the terms ABA and DTT and use the terms interchangeably. The field of ABA refers to a range of strategies all based on research about how behavior is learned and modified. Of the many teaching methodologies under the umbrella of applied behavior analysis, DTT is only one (Bruey, 2004).

The developmental/relationship approach is based on the premise of typical child development. This type of intervention emphasizes the development of skills while engaging in personally meaningful action-based activities. The model is based on the idea that children acquire skills through social and communicative interactions (Quill, 2000). The emphasis is placed on child-centered activities facilitated by an adult in the natural setting. The core deficits of autism are addressed in natural environments with social partners. The rationale for using a developmental approach to enhance learning in children with autism is based on the belief that developmental growth is the same for all children, thus, using more natural environments can motivate a child to engage in the learning process (Greenspan, 1992).

In the NRC's review of ten representative model programs it found that each was derived from either a behavioral or developmental/relationship approach. The conceptual differences between developmental and behavioral approaches to intervention are real, 
yet the gaps in practice appear to be narrowing (National Research Council, 2001). That is, the developmental/relationship model is increasingly attendant to environmental variables, including the provision of consistent structure, adult attention, and the use of reinforcement. At the same time, contemporary comprehensive behavioral approaches look at antecedents, teaching in the natural environment, and direct instruction of social behaviors (Olley, 1999; Schreibman \& Ingersoll, 2005). There has been a "shift from viewing behavior support as a process by which individuals are changed to fit environments, to one in which environments are changed to fit the behavior patterns of people in the environments" (Horner et al., 2000, p. 6). These types of changes incorporate positive practices from each framework.

As advanced in the 1998 Report of the Connecticut Task Force on Issues for the Education of Children with Autism, there is no single method that guarantees success in the education of children with autism. The diverse needs of this population often dictate a more blended approach to educational programming. Blended is not meant to sanction haphazard, watered-down methodology. It is intended to underscore the need to tailor programming to the individual needs of the child by selecting techniques from different approaches that have known effectiveness for children with autism (Connecticut State Department of Education, 1998). Prizant and Rubin (1999) state that research has supported the effectiveness of a range of approaches that differ in both underlying philosophy and practice, but there is no evidence that any one theoretical approach is more effective than another or that one approach is equally effective for all children. 


\section{Focused Intervention}

The PPT needs to make instructional decisions based upon the needs of the individual child, while keeping in mind evidence-based practices. The key to any child's educational program lies in the contents of the Individualized Education Plan (IEP); the specified goals and objectives, the intervention strategies matched to the objectives and the student profile, and the identified appropriate instructional accommodations. Effective services

will, and should, vary considerably across individual children, depending on a child's age, cognitive and language levels, social profile, behavioral needs, and family priorities (National Research Council, 2001). Intervention and instruction should focus on developing functional skills that will be of immediate and ongoing value in the context of the child's daily life. The National Professional Development Center on Autism Spectrum Disorders (NPDC) reviewed the autism intervention literature and published Evidence-Based Practices for Children, Youth, and Young Adults with Autism Spectrum Disorder 2013. Table 1 presents the 27 focused interventions that met the criteria for evidence-based and are recommended for teaching students with autism spectrum disorder (Wong, et al., 2013). The focus should be on teaching strategies that will enhance the individual's ability to communicate, understand language, and get along socially in complex home, school, work and community environments (Dunlap, Carr, Horner, Zarcone \& Schwartz, 2008). 
Table 1

Effective Evidence-Based Practices

Antecedent-Based Interventions

Cognitive Behavior Intervention

Differential Reinforcement of Other Behaviors

Discrete Trial Teaching

Exercise

Extinction

Functional Behavior Assessment

Functional Communication Training

Modeling

Naturalistic Intervention

Parent-Implemented Intervention

PECS

Peer-Mediated Instructional and Intervention

Pivotal Response Training

Prompting

Reinforcement

Response Interruption/Redirection

Scripting

Self-Management

Social Narrative

Social Skills Training

Structured Play Group

Task Analysis

Technology-Aided Instruction and Intervention

Time Delay

Video Modeling

Visual Support 


\section{Reviews of Effective Practices}

The literature reflects that the number of interventions and programs for children with autism has exploded in the last 10 to 20 years (Heflin \& Simpson, 1998a). "Presented with an array of treatment options, parents and professionals are left with minimal guidelines to determine which approaches are 'fringe therapy' and which are empirically supported and efficacious" (Iovannone, Dunlap, Huber \& Kincaid, 2003, p. 151). Although researchers have not identified one approach that is better than all the others, there is documented support identifying essential components of effective educational programs for children with autism (Prizant \& Rubin, 1999; Rogers, 1999). There have been six comprehensive reviews of the literature to identify effective practices for individuals with ASD: (a) Powers (1992), (b) Dawson \& Osterling (1997), (c) Hurth, Shaw, Izeman, Whaley \& Rogers (1999), (d) NRC (2001), (e) Ikeda (2002), and (f) Iovannone et al. (2003).

In the book Autism: Identification, Education and Treatment, Dr. Powers (1992) contributed a chapter on early intervention for children with autism. He reviewed early intervention programs and concluded there was no one program that was effective for all. He did identify a set of best practices that should be included in programs for students with autism. These identified components included structured treatment, using principles of ABA; parent involvement in the school, community, and home; early intervention; intensive treatment; programming for generalization; specified curricula emphasizing social and communication skills; and integration with peers when possible.

In 1997 Dr. Dawson and Dr. Osterling contributed a chapter in The Effectiveness of Early Intervention (Guralnick, 1997) that reviewed highly regarded programs and 
identified several elements that were present in all programs reviewed. These elements included specific curriculum content focusing on core deficits of autism: highly supportive and structured teaching environment; predictability and routine; functional approach to problem behavior; planned transitions between pre-school and kindergarten/first grade; and family involvement.

The Office of Special Education Programs (OSEP) and the U.S. Department of Education funded The National Early Childhood Technical Assistance System (NECTAS) to examine seven effective programs for children with autism and identify similarities across programs (Hurth, Shaw, Izeman, Whaley \& Rogers, 1999). Six areas of agreement were recognized as common to all programs reviewed: earliest possible start to intervention; individualization of services for children and families; systematic, carefully planned teaching; specialized curriculum; intensity of engagement; and family involvement. Three additional elements were presented as common to some, but not all, programs: structured environment, developmentally appropriate practices, and intervention in settings with typical children or in natural environments.

In 2001 the NRC, as part of their work on the state of the art in autism, examined ten model programs for "points of convergence and divergence" (National Research Council, 2001, p. 140). The programs they reviewed provided educational services to children eight years and younger. Common elements identified included: participation in early intervention programs; active engagement in intensive instructional programming, use of planned teaching opportunities, sufficient amount of adult attention to meet individualized goals, and active family involvement. They also noted priority areas for 
instructional focus: functional spontaneous communication, social interaction, cognitive development, play skills, and proactive approaches to behavior challenges.

Iovannone et al. (2003) presented a comparison of the essential elements as identified in the previous reviews. Based on this comparison and further research review, they identified common core elements for effective programs. The six essential themes or components for educating students with autism were: individualized supports and services for students and families; systematic instruction; comprehensible and/or structured environments; specialized curriculum content; a functional approach to problem behaviors; and family involvement.

Ikeda (2002) also examined best practices for the implementation and design of effective treatment programs for children with autism. Ikeda identified the critical program components: self-help skills; self-management; proactive interventions to address compliance issues; a structured environment to minimize physical distractions; predictable routines; effective transitioning; highly trained staff; collaboration with family; and outside resources.

The New York Autism Network (NYAN), a consortium of four Regional Education Service Centers (RESC) responsible for promoting effective educational approaches for students with autism, was requested by the New York State Education Department to develop a means of evaluating the services provided for children with autism in the State of New York. In response to the request NYAN designed the Autism Program Quality Indicators (APQI), a tool that is meant to be a self-review and quality improvement guide. The APQI is a compilation of research-based components that are anchored in best practices and derived from a review of the scientific literature, 
professional experience, as including input and review by national experts in the field of autism (New York State APQI, 2001). The APQI identified 14 areas: individual evaluation, development of the Individualized Education Program, curriculum, instructional activities, instructional methods, instructional environments, review and monitoring of progress and outcomes, family involvement and support, inclusion, planning the move from one setting to another, challenging behavior, community collaboration, personnel, and program evaluation.

In 2009 the National Standards Project, sponsored by the National Autism Center, did a comprehensive review of the literature and yielded 775 studies of treatments for individuals with autism to evaluate. The studies were evaluated and rated, based on the evidence, to determine the efficacy of the research (National Autism Center, 2009).

They identified 11 practices as established treatments. In addition, they identified 22 practices as emerging treatments, meaning that there was some evidence but it was not strong enough to meet the established criteria. Also, they found five practices for which researchers demonstrated, experimentally, that there were no effects, and no practices they would characterize as ineffective/harmful" (Wong, et al., 2013, p. 5).

A second project, sponsored by the Office of Special Education Programs in the U.S. Department of Education, provided funding to the NPDC to identify those practices with sufficient evidence, of efficacy, for children and youth with autism spectrum disorder. The NPCD also conducted a review of the literature, focused on research published between 1997 to 2007 which yielded 175 articles that met criteria for review. The NPDC reviewed practices considered focused interventions and identified 24 interventions that met criteria of having evidence in the research of their efficacy (The National Professional Development Center, 2007). 
Table 2 presents the findings regarding evidence-based practices from both projects to demonstrate where there are similarities. Table 3 presents the evidence-based practices from both projects highlighting the differences.

Table 2

Overlap in Evidence-Based Practices Comparing NPDC on ASD and NSP

\begin{tabular}{ll}
\hline NPDC & NSP \\
\hline Prompting and Modeling & Antecedent and Modeling \\
Antecedent-Based Intervention & Antecedent \\
Time Delay & Antecedent \\
Reinforcement & Behavioral Package \\
Task Analysis & Behavioral Package \\
Discrete Trial Training & Behavioral Package \\
Functional Behavior Analysis & Behavioral Package \\
Functional Communication Training & Behavioral Package \\
Response Interruption/Redirection & Behavioral Package \\
Differential Reinforcement & Behavioral Package \\
Social Narratives & Story-Based Intervention Package \\
Video Modeling & Modeling \\
Naturalistic Interventions & Naturalistic Teaching Strategies \\
Peer Mediated Intervention & Peer Training Package \\
Pivotal Response Training & Pivotal Response Treatment \\
Visual Supports & Schedules \\
Structured Work Systems & Schedules \\
Self-Management & Self-Management \\
\hline
\end{tabular}


Table 3

Differences in Evidence-Based Practices Between NPDC on ASD and NSP

Identified Practice

Comments

Parent Implemented

Intervention

The NSP did not consider Parent Implemented Intervention as a category of evidence-based practice. However, 24 of the studies reviewed by the NSP under intervention categories involve parents implementing the intervention.

Social Skills Training Group

Social Skills Training Groups (Social Skills Package) was identified as an emerging practice by the NSP.

Speech Generating Devices

Speech Generating Devices (Augmentative and Alternative Communication Device) was identified as an emerging practice by the NSP.

Computer Aided

Instruction

Computer Aided Instruction (Technology-based Treatment) was identified as an emerging practice by the NSP.

Picture Exchange

Communication

Picture Exchange Communication was identified as an emerging practice by the NSP.

Extinction

Extinction (Reductive Package) was identified as an emerging practice by the NSP.

Comprehensive Behavioral Treatment

The NPDC on ASD did not review Comprehensive Treatment models of Components of The Comprehensive Treatment of Young Children overlap with many NPDC identified practices.

Joint Attention

Intervention

The NPDC of ASD considers Joint Attention to be an outcome rather than an intervention. Components of Joint Attention Interventions overlap with NPDC identified practices.

From: The National Professional Development Center on Autism Spectrum Disorders. Evidence Base Practices. (2007). Retrieved from http://autismpdc.fpg.unc.edu/content/nationalstandards-project)

\section{Key Components of Effective Programs}

Based on the research, The Connecticut Guidelines identified eight components for this framework: earliest intervention, family involvement and cooperative planning, individualized and intensive programming, comprehensive curriculum, systematic instruction and ongoing objective assessment, structured/predictable learning 
environment, specifically trained personnel, and peer relationships (Connecticut State Department of Education, 2005).

\section{Earliest Intervention}

Early intervention for children with autism is one of the most effective ways to impact long-term outcomes, both academically and socially for the individual (National Research Council, 2001). Providing intensive early intervention can amplify the effect, and evidence suggests that the earlier the intense intervention begins the better the result (Woods \& Wetherby, 2003). Early intervention appears to impact the child's ability to be successful with peers later in school, therefore allowing the child and their family to experience a more positive educational and life experience (Odom \& McLean, 1996). The 1998 Report of the Connecticut Task Force on Issues for Education of Children with Autism articulated benefits of early intervention not only for the child, but also for the family:

- The opportunity for family members and educators to intervene prior to the development of behaviors that interfere with functioning.

- The opportunity for family members and educators to begin teaching functional communication strategies prior to the development of idiosyncratic communicative patterns and/or aberrant behaviors.

- The opportunity for educators to assist family members in the development of effective teaching strategies for use in the home and community where the need is often greatest and the deficits are most acutely felt.

- The opportunity for family members and teachers, working together, to support the healthy adjustment of the family with respect to the child's autistic spectrum disorder, and to facilitate the formation and maintenance of social networks in the community. (Report of the Connecticut Task Force on Issues for the Education of Children with Autism, 1998, p. 39) 


\section{Family Involvement and Cooperative Planning}

Since the 1980s, parent involvement for a child with autism has been viewed as paramount for success. Family members are the constant in the child's life. Schopler and Reichler (1971) advocated that parents be considered "co-therapists" in programming for their child with autism. Parents can offer a unique insight into the intervention plan, based on the time they spend with their child. When families are provided guidance on how to engage their child, the outcome is evident in the child's ability to successfully generalize and maintain skills. Families are essential partners in the education of children with autism (Dawson \& Osterling, 1997; Dunlap \& Fox, 2002).

Family involvement as described by Hurth et al., 1999:

Ways that families are involved in high-quality programs for young children with ASD are as follows: family involvement in their own child's program such as participation of family members as key decision makers and collaborators in determining appropriate services for their child, planning meetings and evaluating their child's progress; services provided to families primarily because their child has ASD such as information, training and education, assistance with activities of daily living, and strategies of addressing child goals during home and community activities; services provided to families and are not directly related to ASD but may impact on overall family functioning such as obtaining or applying for housing assistance, food stamps, Medicaid, counseling or psychiatry referrals; family support and networking such as parent to parent support, family resource centers, family and professional collaboration and support groups; and family involvement in the overall program such as taking part in program evaluation, serving on advisory committees, and participating in social and recreational activities. (p. 21)

\section{Individualized and Intensive Programming}

Children with autism are a heterogeneous group of individuals with unique abilities, talents, learning styles, and needs; and as such require individualized instructional supports. The IDEA amendments of 1997 requires that a continuum of 
placement options, services, and supports be made available to students with disabilities. These options range from inclusion in general education with supports and services to suit the students' needs to highly specialized services in secluded settings. The types and levels of support are addressed through an IEP. In order to program for success, school personnel should match specific practices, supports, and services with each student's unique profile and the family's characteristics (Iovannone et al., 2003).

Individualized supports and services include the following:

1. Considering family preferences when determining the goals to be taught and the methods by which instruction will be delivered,

2. Incorporating the child's preferences and special interests into the instructional program (Hurth et al., 1999),

3. Focusing on the child's strengths and weaknesses to determine the most appropriate intensity and level of instruction to meet the child's individual goals (National Research Council, 2001).

Intensity can take into account a variety of factors such as length of time in instruction (hours per week, days per year); student-to-teacher ratio; the number and/or types of learning environments; and the educational validity of the interventions provided (Connecticut Task Force on Issues for Education of Children with Autism, 1998; New Jersey Department of Education, 2004). Wolery and Garfinkle (2000) caution that intensity cannot be simply measured in terms of the number of hours a child attends a program. The child with autism has to be actively engaged in programming in order to benefit. "Engagement" is defined by the NRC (2001) as "sustained attention to an activity or person" (p 160). The NRC recommends that "educational services should include a 
minimum of 25 hours a week, 12 months a year, in which the child is engaged in systematically planned, developmentally appropriate educational activity aimed toward identified objectives" (National Research Council, 2001, p. 220). Due to the severity of the needs of a child with autism, it is often necessary and appropriate to provide instruction with a student-to-teacher ratio ranging from one to three students per teacher.

\section{Comprehensive Curriculum}

Children with autism display an extremely wide and unique pattern of development and learning styles. The NRC discussed the positive effects gained by programs having a systematic core curriculum designed to meet the specific needs of children with autism. The curriculum must then be individualized to meet each child's age, cognitive level, interests, and needs. The core curriculum should provide instruction in social engagement skills, including initiating and responding to social interactions, appropriate recreation and leisure, increasing the student's independence in demonstrating skills, language comprehension, and communication in addition to appropriate academic skills. The what and how to teach the child should be based on assessing the individual child and consideration of the family's preference for targeting goals (Olley, 1999). It is also important to take into account the functionality of a skill being taught. As the child's program is planned the team should "focus on those skills that (a) are most likely to be useful in the student's life to control his or her environment, (b) will increase the student's independence and quality of life, and (c) will increase the student's competent performance" (Dunlap \& Robbins, 1991, p. 184). It is necessary and important to provide the child with autism a means to communicate and engage socially in order to improve the quality of his/her life and control their environment. A good test 
of determining the need to teach a skill is to ask: if the child isn't taught the skill, will he/she have to depend upon others to do the skill for him/her?

The NRC (2001) states that six kinds of interventions should have priority:

- Functional, spontaneous communication should be the primary focus of early education. For very young children, programming should be based on the assumption that most children can learn to speak. Effective teaching techniques for both verbal language and alternative modes of functional communication, drawn from the empirical and theoretical literature, should be vigorously applied across settings.

- Social instruction should be delivered throughout the day in various settings, using specific activities and interventions planned to meet age-appropriate, individualized social goals (e.g., with very young children, response to maternal imitation; with preschool children, cooperative activities with peers).

- The teaching of play skills should focus on play with peers, with additional instruction in appropriate use of toys and other materials.

- Other instruction aimed at goals of cognitive development should also be carried out in the context in which the skills are expected to be used, with generalization and maintenance in natural contexts being as important as the acquisition of new skills. Because new skills have to be learned before they can be generalized, the documentation of rates of acquisition is an important first step. Methods of introduction of new skills may differ from teaching strategies to support generalization and maintenance.

- Intervention strategies that address problem behaviors should incorporate information about the contexts in which the behaviors occur; positive, proactive 
approaches; and the range of techniques that have empirical support (e.g., functional assessment, functional communication training, reinforcement of alternative behaviors).

- Functional academic skills should be taught when appropriate to the skills and needs of a child.

\section{Systematic Instruction and Ongoing Objective Assessment}

"Systematic teaching is instruction or intervention that is carefully thought out, logical, and consistent with a conceptual or theoretical basis" (Hurth, et al., 1999, p. 21). Instruction is planned by identifying valid educational goals, delineating teaching procedures, evaluating the effectiveness of the procedures, and modifying the instruction based on data (Hurth et al., 1999; Westling \& Fox, 2000). Children with autism have demonstrated progress when the instruction is well designed and implemented systematically (Heflin \& Alberto, 2001; Simpson, 2001). Plans for generalization across environments and maintenance of previously learned skills are also built into the instructional plan. How to structure the learning to maintain the child's attention and engagement is considered in the plan design.

Applied behavior analysis strategies have been shown to be effective in the acquisition of new skills for children with autism. As previously mentioned, it is critical to keep in mind that this does not mean just DTT, but rather that DTT incorporates the range of teaching strategies that are classified under the "umbrella" of applied behavior analysis (Dunlap, 1999). A well-designed program will utilize strategies that provide intense structure (e.g., discrete trial training), naturalistic strategies (e.g., incidental teaching, pivotal response training), and self- management procedures (Iovanne et al., 2003). 
In summary, systematic, well-planned instruction is an essential component of all classrooms including students with ASD. By carefully targeting meaningful skills to be taught, planning specifically when and how to provide instruction based on the unique characteristics of the specified student, determining data collection methods to gauge student progress and effectiveness, and using data to make sound instructional decisions, educational personnel should have effective programs. (Iovanne et al., 2003, p. 158)

\section{Structured/Predictable Learning Environment}

One of the characteristics of autism is the need for sameness and predictability.

Studies have shown that children with autism respond better to social interactions and are better able to attend in environments that are highly structured, and, conversely, their behavior is severely disrupted when environments and interventions are unpredictable (Dawson \& Lewy, 1989; Ferrara \& Hill, 1980). It has been theorized that the need for predictability and structure, in part, is due to difficulties in arousal levels and modulation (Dawson \& Lewey, 1989), impairments in memory (Klinger \& Dawson, 1996), and in processing temporal information.

A structured program is one that allows the child and staff to know what is expected of them in terms of activities, schedule, and setting. Eliciting, facilitating, enhancing or supporting the child in acquiring skills to meet their communication, social, behavioral, and academic goals is more likely to occur if the classroom is designed with an understanding of the child's learning style (Earles, Carlson \& Bock, 1998; Hurth et al., 1999). A well structured environment allows the student and staff to (a) know what is currently expected of them and what will happen next in their schedule, (b) understand what is expected of them in specific settings, and (c) learn and generalize skills (Earles et al., 1998; Gresham, Beebe-Frankenberger \& MacMillan, 1999; Volmer, 1997).

Iovannone et al. (2003) cites the following: 
examples of strategies that assist in structuring the environment include visual cues or supports that;

1. organize the instructional setting (Heflin \& Alberto, 2001);

2. provide a schedule of activities (Rogers, 1999; Simpson \& Myles, 1998);

3. carefully plan and provide choice-making opportunities (Dalrymple, 1995);

4. provide behavioral support (Earles et al., 1998);

5. define specific areas of the classroom and school settings (Heflin \& Alberto, 2001; Volmer, 1997);

6. provide temporal relations, (Earles et al., 1998; Heflin \& Alberto, 2001);

7. facilitate transitions, flexibility and change (Simpson \& Myles, 1998). (Iovannone et al., 2003, p. 58)

\section{Specifically Trained Personnel}

The NRC (2001) has produced a set of principles that include:

Teachers must be familiar with theory and research concerning best practices for children with autism spectrum disorders, including methods of applied behavior analysis, naturalistic learning, incidental teaching, assistive teaching, assistive technology, socialization, communication, inclusion, adaptation of the environment, language interventions, assessment and the effective use of data collection systems. Specific problems in generalization and maintenance of behaviors also affect the need for training in methods of teaching children with autistic spectrum disorders. The wide range of IQ scores and verbal skills associated with autistic spectrum disorders, from profound mental retardation and severe language impairments to superior intelligence, make the need for training of personnel ever greater. To enable teachers to adequately work with parents and with other professionals to set appropriate goals, teachers need familiarity with the course of autism and the range of possible outcomes. (p. 184).

School systems can contribute significantly to the growth and development of children with autism by providing teachers who are well trained, committed to meeting the needs of students with autism, and familiar with methods of and procedures of working with students with autism (Simpson \& Zoints, 2000). Although this is understood to be best practice, it is difficult to provide in a public school setting, due to the fact that special education teachers are typically responsible for providing support to children with a variety of disabilities and are not trained to be autism specialists. To address this concern, when designing the Connecticut State Guidelines for Children and 
Youth with Autism (2005) it was agreed that the child's PPT (i.e., special educator,

general educator, speech/language pathologist, occupational therapist, physical therapist,

psychologist, social worker, autism consultant, administrator) should have a collective

knowledge of autism. Gallagher and Clifford (2000) discuss that there is a need for a

supportive infrastructure that can provide the direct service instructor with the needed

assistance.

The Connecticut Guidelines identified that the team's collection of working

knowledge should include the following:

Knowledge of ASD, including etiology, incidence, range of symptoms and characteristics, strengths, possible medical concerns, and assessment tools. Knowledge of early intervention, including its rationale, the importance of family involvement, and suggested treatment strategies.

Knowledge of cooperative planning and family involvement, including team roles and responsibilities, the importance of teamwork and how to plan for generalization, and regularly scheduled meetings.

Knowledge of individualized and intensive programming, including how to match educational approaches to the unique learning styles of students in the child's IEP, principles of responsible inclusive practice, the importance of ensuring high levels of engagement, and optimal treatment hours.

Knowledge of comprehensive curriculum, including emphasis on the importance of individualized curricula to improve quality of life, addressing core deficits in ASD how to provide access to Connecticut's curricular frameworks and the school district's core curriculum, and how to facilitate generalization.

Knowledge of systematic instruction and ongoing objective assessment, including how to conduct assessments, develop goals and objectives, implement and evaluate the effectiveness of intervention procedures with systematic data collection, program for generalization, and validate new procedures.

Knowledge of how to provide structured predictable learning environments, including how to use visual supports, physical arrangement of the classroom, time allocation and sequence of activities, and optimal staff-tostudent ratios.

Knowledge of evidenced-based instructional strategies, including:

(a) Strategies to teach new behaviors that fall on a continuum of child-directed activities in natural contexts to adult-directed activities in structured, distraction-free contexts (Anderson \& Romanczyk, 1999), and are provided through repeated, planned teaching opportunities (National Research Council, 
2001). These include pivotal response training, incidental teaching, peermediated strategies, and discrete trial training. Also included are strategies to decrease or alter existing behaviors such as functional analysis, differential reinforcement of other behaviors, extinction, and antecedent manipulation. (b) Developmental strategies such as developmental sequencing curricula, child-centered teaching, and the use of natural internal consequences.

(c) Augmentative and alternative communication strategies, such as the PECS, sign language, and vocal output communication devices.

Knowledge of how to facilitate peer relationships, including assessment of social behavior, development of play and leisure skills, and intervention resources, such as Circle of Friends, the Lunch Bunch, Social Stories and Sixth Sense.

Knowledge of transition planning, including person-centered planning, legal requirements, practices to promote home-to-school, school-to school, and school-to-adulthood transitions. (2005, p. 54)

Personnel preparation remains one of the weakest areas of effective programming for children with autism. Teachers need on-going support, consultation and hands-on opportunities to observe, practice, and be provided with feedback to develop the competencies necessary to teach children with autism. Findings suggest that the district's administrative and leadership personnel's attitudes and supports are critical to improving success for the child (National Research Council, 2001).

\section{Peer Relationships}

The social skills necessary for interactions with others, particularly peers, are inherently complex and difficult for children with autism. A qualitative impairment in social interactions is a core feature of autism, as evidenced by difficulties using nonverbal communicative behaviors during social exchanges by using imitation and symbolic or dramatic play. "Peer interactions, and indeed social interactions are characterized by low rates of both initiation and response" (National Research Council, 2001, p. 69). Children with autism often have interests that are dissimilar to those of their peers, which makes it difficult for them to engage in a joint activity. Typically children are grouped by age for 
social activities and this may create an "insurmountable challenge" for children with autism (Aspy \& Grossman, 2007, p. 245).

Although children with autism can exhibit a range of communication abilities, research supports that engaging children in social situations does not require a particular level of language or speech to be a prerequisite. Children with autism benefit from instruction in the process of initiation, response, play and interaction (Gerber, Brice, Capone, Fujiki \& Timler, 2012). It is critical that social skills training is individualized, based on the needs, abilities and interests of the child (Aspy \& Grossman, 2007; Henry \& Myles, 2007). Adults must provide prompts and instruction in order for children with autism to acquire social communication skills (Kim, 2015; Willey, 2015). Children with autism need to learn social skills in the same way they learn academic and functional skills; through direct instruction followed by practice with generalization. "Strategies that teach peers to initiate and persist in physical engagement (Odom \& Strain, 1984) are quite important for preverbal children with autism, while strategies that teach a child with autism to make verbal initiations to peers (Krantz \& McClannahan, 1993) target children with some speech" (National Research Council, 2001, p. 71). An effective means of teaching specific skills is to have the child learn the skill with an adult and then generalize to a peer. Many programs also understand the benefit of having peers as social facilitators for modeling appropriate social behaviors (Strain \& Cordisco, 1994).

"All of us need to become better at listening, conversing, respecting one another's uniqueness because they are essential to strong relationships. The era of the rugged individual has been replaced by the era of the team player" (Wheatley, 1999, p. 39) Relationships are critical for success, which necessitates social cognition as a critical 
component of programming for children with autism. "All children, regardless of their unique characteristics or gifts, have the intrinsic need to play and make friends. Children with AS are no different - they just express this need differently" (McCracken, 2004, p. 1). In order to help meet this need, typical peers must also be provided instruction in how to interact with the child with autism. "The key to friendship for children with ASD is to build awareness, understanding and empathy in peers, siblings and classmates in an ageappropriate and sensitive manner" (McCracken, 2004, p. 1).

\section{Cost}

As the incidence of autism increases, the cost to society to care and educate a child with autism is having a significant impact on communities. A study completed in 2006 by Michael Ganz, an Assistant Professor of Society, Human Development, and Health at Harvard School of Public Health, found the approximate cost of caring for an individual with autism over the course of his or her lifetime to be 3.2 million dollars (Ganz, 2006). A similar study, conducted by Jarbrink and Knapp (2001) in the United Kingdom, found the lifetime cost for a person with autism to be approximately 4.2 million US dollars. Jacobson and Mulick (2000) estimated the cost for a child with autism who had little or no early behavioral intervention to be a 4.4 million dollars lifetime cost. The Autism Society of America estimates the lifetime cost for care to be between 3.5 million to 5 million for an individual with ASD which totals to an annual cost of close to $\$ 90$ billion annually for the United States in funding for autism services (Lindgren \& Doobay, 2011).

Jacobson, Mulick and Green (1998) ask, "How does one, after all, set the price of a bright future?" (p. 586). The question that needs to be answered is how do we ensure 
that the monies being spent for programming are being spent on the right things? As educators, now more than ever, it is critical to explore the relationship between researchbased practices and the outcomes of a child's learning. In order to measure the outcome, we can look to the progress on a student's IEP.

\section{Summary}

This chapter presented a review of the literature on the evolution and theoretical foundations of the diagnosis of autism and effective practices. Research on the specific components of effective programming, individualized educational plans, and costs associated with autism were reviewed.

In the Connecticut educational system, the PPT is responsible for developing an IEP, the contents of which is the key to any child's educational program. The IEP delineates goals and objectives, supports, and services that the child will receive for the school year. Intervention strategies are matched to the objectives and student's profile, and appropriate instructional accommodations are described. The PPT must make instructional decisions based upon the needs of the individual child while keeping in mind evidence-based practices. The Connecticut Guidelines were designed to be a tool to assist the PPT in the decision making process.

The research has identified specific components that should be in place in a child's program to support progress. The Connecticut Guidelines, which were published ten years ago, translate the research into practice for educators in the State of Connecticut. Many of the components recommended in the Guidelines require resources in talent, time, and money to implement. Due to the problematic combination of increased incidence of autism and limited availability of resources, it was critical to 
examine the implementation of the Connecticut Guidelines to determine if they are effective. 


\section{CHAPTER 3}

\section{METHODOLOGY}

\section{Introduction}

This chapter provides a description of the methodology and procedures used to conduct the study, Educator's Implementation of the Connecticut Guidelines. The chapter reviews the purpose of this study and discusses the appropriateness of a descriptive correlation study using a self-report survey to address the research questions. Next, the chapter describes the population and the instrument used in the study. It then continues with a detailed explanation of the procedure and research question/hypothesis. It concludes with a section on data analysis which explains the treatment of the data and the rationale for the analytical techniques used.

Autism is a lifelong disability that is currently reported to affect 1 in every 68 children (Center for Disease Control, 2014). In 2001, the NRC published the report, Educating Children with Autism. This report was generated as the outcome of a charge given by the U.S. Department of Education's Office of Special Education Programs. The function was to evaluate the current status of educating children with autism. It outlined specific research-based components for effective programs for students diagnosed with autism. In 2005, the Connecticut State Department of Education utilized the findings from the NRC report to draft Guidelines for the Identification and Education of Children 
and Youth with Autism (Connecticut State Department of Education, 2005) that identified benchmarks for appropriate educational supports for children with autism.

The purpose of this study was to explore special educators' experiences with the Connecticut Guidelines. Specifically, the study examined the association between special educators' experience, education, assignment, caseload, relationships, self-reported proficiency, and view of importance, implementation, and degree of difficulty in relation to implementing the Guidelines. Due to the problematic combination of increased number of students with autism requiring an effective education and limited availability of resources, it is critical to examine teacher's use of the Guidelines. Teachers who are responsible for educating students with autism must demonstrate knowledge of the range of evidence-based practices and ability to implement them effectively, based on the needs of the student (National Research Council, 2001). At this time, there have been no studies conducted in the State of Connecticut that have examined the implementation of the components for effective education of children with autism, as identified in the Connecticut Guidelines, published in 2005.

\section{Research Questions}

The following 6 research questions guided this study:

1. To what extent are special educators in Connecticut implementing the Connecticut Guidelines for Identification and Education of Children and Youth with Autism for students with autism? Additionally are they implementing the most recognized evidence-based practices recommended for students with autism spectrum disorder? 
2. What rating level of difficulty have special educators in Connecticut experienced in implementing the Connecticut Guidelines for Identification and Education of Children and Youth with Autism for students with autism? Additionally do they find it difficult to implement the most recognized evidence-based practices recommended for students with autism spectrum disorder?

3. What rating of level of importance do special educators in Connecticut place on the Connecticut Guidelines for Identification and Education of Children and Youth with Autism when designing programs for students with autism? Additionally if they are implementing the most recognized evidence-based practices recommended for students with autism spectrum disorder have they found them to be important?

4. Are there associations between special educators' implementation of the Connecticut Guidelines for Identification and Education of Children and Youth with Autism and the independent variables: (a) years of experience, (b) assignment, (c) place, (d) RESC, (e) number of students on caseload, (f) percentage of students with ASD on caseload, or $(\mathrm{g})$ personal relationship?

5. Are there associations between special educators' rating of level of difficulty implementing the Connecticut Guidelines for Identification and Education of Children and Youth with Autism and the independent variables: (a) years of experience, (b) assignment, (c) place, (d) RESC, (e) number of students on caseload, (f) percentage of students with ASD on caseload, or (g) personal relationship?

6. Are there associations between special educators' rating of importance of the Connecticut Guidelines for Identification and Education of Children and Youth with Autism and the independent variables: (a) years of experience, (b) assignment, (c) place, 
(d) RESC, (e) number of students on caseload, (f) percentage of students with ASD on caseload, or (g) personal relationship?

\section{Research Design}

The research design for this study was a non-experimental, descriptive correlation study. Kerlinger and Lee (2000) stated, "Non-experimental research is systematic empirical inquiry in which the scientist does not have direct control of independent variables because their manifestation has already occurred" (p. 558). Data for the study was collected through the use of a self-report survey. Gall et al. (1996) identifies research by survey as being a systematic method of data collection and analysis used extensively in educational research to collect information that is not directly observable. Creswell (2009) describes a survey design as one that "provides a quantitative or numeric description of trends, attitudes, or opinions of a population by studying a sample of the population” (p. 145). Data obtained from self-assessments yield reliable and accurate measures of teacher practices (Blank, Alas \& Smith, 2008; Smithson \& Porter, 1994). A survey allows the researcher to make inferences about the sample populations' behaviors, attitudes or characteristics (Fink, 2002). The cross-sectional data collected through the survey explored the relationship between the dependent or outcome variables and the independent predictor variables.

\section{Population and Sample}

During the 2013-2014 school year there were 6555 special education teachers employed in the 223 public and approved private special education facilities in Connecticut. The Directors of the 223 school districts were made aware of the study and requested to encourage teachers to participate in the study. The list of special education 
teachers employed in the State of Connecticut was provided by the Connecticut State Department of Education in response to a request through the Freedom of Information Act. Special education teachers were selected as the participants due to their direct responsibility of program design and implementation for students with autism.

Connecticut does not have a specific autism certification, therefore, all special education teachers are expected to have the knowledge necessary to support a student with autism. Participants were assured of complete anonymity. Approval of research involving human subjects secured by the Institutional Review Board of Andrews University was included in the survey packet.

\section{Instrumentation}

\section{Description and Development}

In 2008, the State of Connecticut commissioned a feasibility study through the Department of Developmental Services (DDS) to identify needs and possible solutions in regards to educating individuals with autism. The survey entitled, Needs Assessment for Educating Children with Autism and Other Developmental Disabilities was designed and implemented as part of the Connecticut Special Act No. 08-5 study. The Connecticut Autism Needs Survey was created for the purpose of this study. The foundation for the survey questions for this research was the Needs Assessment for Educating Children with Autism and Other Developmental Disabilities with modifications based on the professional literature and the researcher's own experience. The professional literature on appropriate educational programs based on evidenced based strategies was discussed in Chapter 2 of this dissertation. 
The researcher has been in the field of autism for more than 30 years as a teacher, administrator, consultant, presenter, trainer, and mentor. She is the founder and Director of the Benhaven Learning Network, which is comprised of 3 programs: Benhaven Academy, the Social Learning Center, and the Benhaven Consultative Network. Benhaven Academy is a school for students with social, communication, coping, and organizational skill deficits. The Social Learning Center is a center that provides services to promote and support effective methods for social thinking. Benhaven Consultative Network is a professional network that provides services in educational and behavioral consultation to local school systems in order to improve their capabilities for serving students with autism.

The Benhaven Learning Network won a business plan award from the 2003 Yale School of Management-Goldman Sachs Foundation Partnership for Nonprofit Ventures and the 2004 Fast Company Social Capitalist Award. The researcher has held a leadership role in the following initiatives: the Interactive Collaborative Autism Network (ICAN), a project developed in 2000 and supported by a U.S. Department of Education. Interactive Collaborative Autism Network was a collaborative effort among three states, the Connecticut State Department of Education Guidelines for Identification and Education of Children and Youth with Autism, and the Connecticut Department of Developmental Services Autism Training Services.

The Connecticut Autism Needs Survey is an on-line self-report survey consisting of 20 questions designed to illicit information in the categories of participant's: (a) education; (b) experience; (c) assignment; (d) caseload; (e) relationship; (f) self-reported proficiency of knowledge of evidence-based practices for educating children with Autism 
Spectrum Disorder; (g) special educator's experience with the implementation of the Connecticut Guidelines. The first 16 questions are closed ended with multiple choice or ordered response using a Likert scale. The last 4 questions are open ended and ask the respondent to provide a one word response. Detailed information regarding survey questions is displayed in Table 4.

\section{Validity}

To assist the researcher in the design of the Connecticut Autism Needs Survey, three individuals who are esteemed in the State of Connecticut for their expertise in the field of autism and were involved in the development of the Connecticut State Guidelines, were asked to review the survey for the purpose of assessing content validity. Experts included: Ruth Eren, Ed.D., David Cormier, Ph.D., and Kathryn Reddington. Dr. Eren serves as the Director for The Center of Excellence on Autism Disorders. Through her role as a Professor of Special Education at Southern Connecticut State University (SCSU), she oversees the M.S. program in teacher preparation for educating children with Autism. Additionally, she has consulted with public school districts in Connecticut for more than fifteen years, focusing on individual and system program development and curriculum design for children with Autism. Dr. David Cormier specializes in working with organizations to design and implement effective leadership strategies. Dr. Cormier merges leadership theory with contemporary tools and tactics to encourage leaders at all levels to support coordinated, ongoing organizational improvement. Prior to his leadership consulting, Dr. Cormier served as the Assistant Director for Program Development for a statewide resource and training organization. In this role, Dr. Cormier was the lead consultant in the area of autism. Kathryn Reddington is currently a 
Table 4

Description of Survey

\begin{tabular}{|c|c|c|}
\hline Variable & $\begin{array}{l}\text { Number } \\
\text { of Items }\end{array}$ & Descriptor \\
\hline $\begin{array}{l}\text { Importance of } \\
\text { Guidelines }\end{array}$ & 1 & - Rating on importance \\
\hline $\begin{array}{l}\text { Implementation } \\
\text { of Guidelines }\end{array}$ & 1 & - Rating on implementation \\
\hline $\begin{array}{l}\text { Ease of } \\
\text { Implementation } \\
\text { of Guidelines }\end{array}$ & 1 & - Rating on degree of difficulty of implementation \\
\hline $\begin{array}{l}\text { Teacher's score } \\
\text { of Proficiency }\end{array}$ & 3 & $\begin{array}{l}\text { - Frequency of implementation of evidence base } \\
\text { practices } \\
\text { - Rating on degree of difficulty implementing } \\
\text { evidence base practices } \\
\text { - Training needs }\end{array}$ \\
\hline $\begin{array}{l}\text { Teacher's } \\
\text { Assignment }\end{array}$ & 3 & $\begin{array}{ll}\text { - } & \text { Role } \\
\text { - } & \text { Setting } \\
\text { - } & \text { Area of state }\end{array}$ \\
\hline $\begin{array}{l}\text { Teacher's } \\
\text { caseload }\end{array}$ & 2 & $\begin{array}{l}\text { - Number of students on caseload } \\
\text { - Percentage of students with autism on caseload }\end{array}$ \\
\hline Education & 3 & $\begin{array}{ll}\text { - } & \text { Degree } \\
\text { - } & \text { Types of training } \\
\text { - } & \text { Topic of trainings }\end{array}$ \\
\hline Relationship & 2 & $\begin{array}{l}\text { - Relationship with a person with autism } \\
\text { - Type of relationship }\end{array}$ \\
\hline Experience & 1 & - Years teaching \\
\hline
\end{tabular}


behavioral and educational consultant with the Benhaven Learning Network, providing consultative services for individuals diagnosed with an ASD. She is the past Division Director of Autism, Family Support and Employment Services for the State of Connecticut Department of Developmental Services. In this role, she developed and prepared applications for three home and community-based Medicaid waivers to serve the needs of children and adults with autism. She initiated and completed an outcome study regarding services to adults with autism and developed a state system of service provision for adults with ASD. Ms. Reddington holds degrees in Special Education, School Psychology, School Administration and Supervision, and Applied Behavioral Analysis. She is a Board Certified Behavior Analyst. Based on their credentials and experiences, these individuals meet the criteria that DeVellis (2011) describes as "such experts presumably have a theoretical frame of reference that supports their judgment" (p. 71).

\section{Variables}

The on-line self-report Autism Needs Survey used in this study collects crosssectional data. The survey consists of 22 questions designed to illicit information on the predictor variables in the categories of participant's: (a) years of experience, (b) assignment, (c) place, (d) RESC, (e) number of students on caseload, (f) percentage of students with ASD on caseload, or (g) personal relationship and the dependent variables of the special educator's awareness and implementation of the Connecticut Guidelines.

The purpose of the quantitative data collected through the Connecticut Autism Needs Survey is to provide descriptive information on teachers' implementation of the Connecticut Guidelines and to explore relationships between the independent and 
dependent variables. The 4 open-ended questions included in the study are designed to create a more comprehensive picture; the qualitative data can enrich the quantitative data (Bryman, 2006).

\section{Procedure}

One week prior to contacting Connecticut special education teachers regarding the survey, the researcher contacted the Director of Special Education for the public school districts and the administrator for private schools throughout Connecticut. An email was sent to: inform them of purpose of the study, assure them of confidentiality of participants and district information, and to request their assistance in encouraging special education teachers to participate in the study by completing the Connecticut Autism Needs Survey (Appendix A). During the following week, a request to participate in the Connecticut Autism Needs Survey was sent via email to all special education teachers in the State of Connecticut. The invitation included an introductory statement, assurance of confidentiality, and a direct link to the survey hosted by Survey Monkey. Special education teachers were able to access the Connecticut Autism Needs Survey online for two weeks. At the end of the first week, the researcher sent a second email to the Director of Special Education for public school districts and the administrator for private schools asking them to contact special education teachers to encourage them to complete the survey. Special education teachers were sent a reminder regarding the study at the beginning of the second week. In an effort to facilitate the highest possible response rate, a final email to potential participants was sent out the day before the link is closed. At the end of the second week, the access to the Connecticut Autism Needs Survey was removed from the platform 
The Connecticut Autism Needs Survey should take approximately 20 to 25 minutes to complete. McCroskey stated in a presentation "Self report measures are most appropriate when they are directed toward matters of affect and/or perception in circumstances where the respondent has no reason to fear negative consequences for any given answer." (as cited in McCroskey \& McCroskey 1988). No information regarding the identity of the individual or the district in which they are employed was requested on the survey. The assurance of confidentiality was given to both administrators and teachers to encourage participation. Upon accessing the Connecticut Autism Needs Survey, participants were asked to provide informed consent before beginning the survey.

\section{Treatment of Data}

All data were reviewed for accuracy and completeness. Any survey that was not finished was discarded before analysis. The Connecticut Autism Needs Survey consists of 16 closed questions and 4 open-ended questions. The closed questions yielded data that was either ordinal or nominal. Data for demographic information reflected the answers as given by respondents. In order to answer the research questions and analyze the data in a meaningful manner, responses to certain questions were recoded. The original responses and the recoded responses are presented in Table 5. 
Table 5

Original and Recoded Responses

\begin{tabular}{|c|c|c|c|}
\hline Question & Measure & Original Value & Recoded Value \\
\hline 1 & Assignment & $\begin{array}{l}1=\text { Special Education Teacher }- \text { Preschool } \\
2=\text { Special Education Teacher- Elementary } \\
3=\text { Special Education Teacher }- \text { Middle School } \\
4=\text { Special Education Teacher }- \text { High School } \\
5=\text { Special Education Teacher }- \text { Other } \\
6=\text { Early Childhood Educator } \\
7=\text { Autism Specialist } / \text { Consultant }\end{array}$ & $\begin{array}{l}\text { 1, } 2,6,=\text { Pre/Elem } \\
\quad \text { School } \\
2=\text { Middle School } \\
3=\text { High School } \\
4=\text { Other }\end{array}$ \\
\hline $11(\mathrm{~A})(1)$ & $\begin{array}{l}\text { Plan and implement systematic } \\
\text { instruction based on learner } \\
\text { characteristics and previous on-going } \\
\text { assessment }\end{array}$ & $\begin{array}{l}1=\text { No need } \\
2=\text { Low need } \\
3=\text { Moderate low need } \\
4=\text { Need } \\
5=\text { Priority need } \\
6=\text { High priority need }\end{array}$ & $\begin{array}{l}4,5,6=1 \text { Need } \\
1,2,3=2 \text { Low } / \text { No Need }\end{array}$ \\
\hline $11(\mathrm{~A})(9)$ & $\begin{array}{l}\text { Foster social skill development through } \\
\text { peer interactions, direct instruction, } \\
\text { role playing, video modeling, etc. }\end{array}$ & $\begin{array}{l}1=\text { No need } \\
2=\text { Low need } \\
3=\text { Moderate low need } \\
4=\text { Need } \\
5=\text { Priority need } \\
6=\text { High priority need }\end{array}$ & $\begin{array}{l}4,5,6=1 \text { Need } \\
1,2,3=2 \text { Low } / \text { No Need }\end{array}$ \\
\hline
\end{tabular}


Table 5-Continued

\begin{tabular}{|c|c|c|c|}
\hline Question & Measure & Original Value & Recoded Value \\
\hline $11(\mathrm{~A}, 10)$ & $\begin{array}{l}\text { Implement evidenced based strategies } \\
\text { that promote the development of self- } \\
\text { help, independent living, } \\
\text { transportation, community } \\
\text { participation, safety and nutrition }\end{array}$ & $\begin{array}{l}1=\text { No need } \\
2=\text { Low need } \\
3=\text { Moderate low need } \\
4=\text { Need } \\
5=\text { Priority need } \\
6=\text { High priority need }\end{array}$ & $\begin{array}{l}4,5,6=1 \mathrm{Need} \\
1,2,3=2 \text { Low } / \text { No Need }\end{array}$ \\
\hline 11(B) & $\begin{array}{l}17 \text { Evidence-based Interventions } \\
\text { Level of Difficulty Implementing }\end{array}$ & $\begin{array}{l}1=\text { Too difficult } \\
2=\text { Moderately difficult } \\
3=\text { Difficult } \\
4=\text { Minimally difficult } \\
5=\text { Not difficult } \\
6=\text { Not implemented }\end{array}$ & $\begin{array}{l}1,2,3=1 \text { Difficult } \\
4,5=2 \text { Not difficult } \\
6=\text { Excluded from } \\
\text { analysis }\end{array}$ \\
\hline $11(\mathrm{C})$ & $\begin{array}{l}17 \text { Evidence-based Interventions } \\
\text { Level of Importance }\end{array}$ & $\begin{array}{l}1=\text { Extremely important } \\
2=\text { Moderately important } \\
3=\text { Important } \\
4=\text { Minimally important } \\
5=\text { Not important }\end{array}$ & $\begin{array}{l}1,2,3=2 \text { Important } \\
4,5=1 \text { Not important }\end{array}$ \\
\hline
\end{tabular}


Table 5-Continued

\begin{tabular}{|c|c|c|c|}
\hline Question & Measure & Original Value & Recoded Value \\
\hline 14 & Implement Guidelines & $\begin{array}{l}1=\text { Fully implemented } \\
2=\text { Implemented adequately for all students } \\
3=\text { Implemented adequately for a few students } \\
4=\text { Minimal implementation } \\
5=\text { Not implementing }\end{array}$ & $\begin{array}{l}1,2,3=1 \text { Yes } \\
4,5=0 \mathrm{No}\end{array}$ \\
\hline 15 & $\begin{array}{l}\text { Level of difficulty implementing } \\
\text { Guidelines }\end{array}$ & $\begin{array}{l}1=\text { Very difficult } \\
2=\text { Moderately difficult } \\
3=\text { Difficult } \\
4=\text { Minimally difficult } \\
5=\text { Not difficult } \\
6=\text { Not familiar with }\end{array}$ & $\begin{array}{l}1,2,3=0 \text { Difficult } \\
4,5=1 \text { Not difficult } \\
6=\text { Excluded from } \\
\text { analysis }\end{array}$ \\
\hline 13 & Level of importance of guidelines & $\begin{array}{l}1=\text { Extremely important } \\
2=\text { Aware they exist and on occasion have found } \\
\quad \text { them helpful } \\
3=\text { Know they exist but have not used } \\
4=\text { Tried to use them but have not found them } \\
\quad \text { helpful } \\
5=\text { Didn't know they existed } \\
6=\text { No need to know }\end{array}$ & $\begin{array}{l}1,2=1 \text { Important } \\
3,4,5=0 \text { Not Important }\end{array}$ \\
\hline
\end{tabular}




\section{Data Analysis}

Quantitative data were analyzed using SPSS Statistics 21. The first three questions of the study asked participants to report on their experience with level of importance, degree of implementation, and level of difficulty implementing the Connecticut Guidelines for Identification and Education of Children and Youth with Autism. The responses to the questions were analyzed using descriptive statistics to determine frequency distribution and measure of central tendency of the data. The purpose of these questions was to present a description of special education teachers' experience with the Connecticut Guidelines for Identification and Education of Children and Youth with Autism.

The last three questions address the association between the dependent variables reported on in the first three questions and the predictor variables of: (a) years of experience, (b) assignment, (c) place, (d) RESC, (e) number of students on caseload, (f) percentage of students with ASD on caseload, or (g) personal relationship. The dependent variable for each question and the 7 predictor variables were analyzed using logistic regression. The dependent variable for questions 4-6 of the study had two categories, so binary logistic regression analysis was selected. Additionally logistic regression was the appropriate tool, because it allowed analysis of predictor variables that were a mixture of categorical and ordinal. Logistic regression is able to predict group membership and to provide knowledge of the relationships and strengths among the variables. A summary of analysis is presented in Table 6. 
Table 6

Data Analysis of Research Questions

\begin{tabular}{|c|c|c|c|}
\hline Question & Independent Variable & Dependent Variable & Analysis \\
\hline 1 & Special education teachers & $\begin{array}{l}\text { 1. Level of implementation of Guidelines } \\
\text { 2. Level of implementation of } 17 \text { recommended } \\
\text { evidence-based practices }\end{array}$ & $\begin{array}{l}\text { Descriptive } \\
\text { Statistics }\end{array}$ \\
\hline 2 & Special education teachers & $\begin{array}{l}\text { 1. Level of difficulty in implementation of } \\
\text { Guidelines } \\
\text { 2. Level of difficulty in implementation of } 17 \\
\text { recommended evidence-based practices }\end{array}$ & $\begin{array}{l}\text { Descriptive } \\
\text { Statistics }\end{array}$ \\
\hline 3 & Special education teachers & $\begin{array}{l}\text { 1. Level of importance of Guidelines } \\
\text { 2. Level of importance of } 17 \text { recommended } \\
\text { evidence-based practices }\end{array}$ & $\begin{array}{l}\text { Descriptive } \\
\text { Statistics }\end{array}$ \\
\hline 4 & $\begin{array}{l}\text { - } \text { Experience } \\
\text { - Assignment } \\
\text { - Place } \\
\text { - RESC } \\
\text { - Number of students on caseload } \\
\text { - Percentage of students with ASD on caseload } \\
\text { - Relationship }\end{array}$ & Level of implementation of Guidelines & $\begin{array}{l}\text { Logistic } \\
\text { Regression }\end{array}$ \\
\hline
\end{tabular}


Table 6-Continued

\begin{tabular}{|c|c|c|c|}
\hline Question & Independent Variable & Dependent Variable & Analysis \\
\hline 5 & $\begin{array}{ll}\text { - } & \text { Experience } \\
\text { - } & \text { Assignment } \\
\text { - } & \text { Place } \\
\text { - } & \text { RESC } \\
\text { - Number of students on caseload } \\
\text { - Percentage of students with ASD on caseload } \\
\text { - Relationship }\end{array}$ & $\begin{array}{l}\text { Level of difficulty in implementation of } \\
\text { Guidelines }\end{array}$ & $\begin{array}{l}\text { Logistic } \\
\text { Regression }\end{array}$ \\
\hline 6 & $\begin{array}{l}\text { - Experience } \\
\text { - Assignment } \\
\text { - Place } \\
\text { - RESC } \\
\text { - Number of students on caseload } \\
\text { - Percentage of students with ASD on caseload } \\
\text { - Relationship }\end{array}$ & Level of importance of Guidelines & $\begin{array}{l}\text { Logistic } \\
\text { Regression }\end{array}$ \\
\hline
\end{tabular}


The purpose of the qualitative data from the open-ended questions is to enrich the analysis of the quantitative data. The questions were structured to provide single-word responses, which support ease of text analysis. The information provided by the analysis of the qualitative data will be used in the discussion of the findings presented in Chapter 5.

\section{Role of the Researcher}

I have been involved in the education of individuals with autism spectrum disorders for over 30 years. Roles throughout this time period have included special education teacher, consultant, and principal. Currently, I am the director and managing consultant for Benhaven Learning Network, a consultation group that specializes in the field of autism and provides leadership to school districts throughout Connecticut by developing competencies in the use of best practices in those who support individuals with ASD. The consultants employed by Benhaven Learning Network and supervised by myself, actively strive to support districts to embrace and integrate the components of effective programming identified by research to constitute best practice. Additionally, it is my responsibility to provide expertise and insight as a practitioner to state agencies. Ten years ago I served as a lead member of the task force that developed the Connecticut Guidelines. As the number of children with autism needing educational support continues to increase, combined with the limited availability of resources, it is critical that educators are being given the information and support in order to provide effective education to students with autism spectrum disorder. My personal passion for supporting individuals with autism was a driving force in the development of this study. 
A non-experimental, descriptive correlation study design was selected for the study in order to minimize any personal influence or bias. Participants received an email invitation to participate in the on-line survey. The invitation was sent from an unidentifiable email address to mask the identity of the researcher from the participants. The invitation did not identify the researcher. Surveys did not require any identifiable information from the participants, which protected their identities as well.

\section{Summary}

At this time there have been no studies done in Connecticut to examine the implementation of the components for effective education of children with autism, identified in the Connecticut Guidelines published in 2005. This study provides information on educator's implementation of the Connecticut Guidelines which could be useful for the revision of the Guidelines and suggestive of further professional development activities. 


\section{CHAPTER 4}

\section{RESULTS}

\section{Introduction}

Autism is a complex lifelong neuro-developmental disorder characterized by problems with social communication/interaction and restricted and repetitive behaviors, which currently affects 1 in every 68 children (Center for Disease Control, 2014). Autism affects more than just the child with the disorder. The family and community feel the responsibility of providing support to someone who experiences the world so differently. Interventions and services for individuals with autism are, however, intensive and significantly impact the educational resources of school districts. Unfortunately, the high cost of education is not yielding high quality of life outcomes for individuals with autism. As leaders in the field of education, we must take responsibility to implement effective programs to address the specific social, communication, and behavioral needs of individuals with autism in order to improve the outcomes of their adult lives. The Connecticut State Department of Education commissioned a task force in 2005 to provide guidance to educators on how to meet the needs of students with autism. The task force drafted the Guidelines (Connecticut State Department of Education, 2005), which identified benchmarks for appropriate educational supports for children with autism. The expectation was that school districts would use the Connecticut Guidelines as a guide when designing and implementing educational programs for students with autism. 
The Connecticut Guidelines were published ten years ago and due to the changes in the definition of autism in the recently published fifth edition of the $D S M-5$, it is likely the Guidelines will need to be updated. As the number of children with autism needing educational support continues to increase, combined with the limited availability of resources, it is critical to examine how educators responsible for teaching children with autism have experienced implementation of the Connecticut Guidelines (2005). At this time there have been no studies done in the State of Connecticut that have examined the implementation of the components for effective education of children with autism, as set forth in the Connecticut Guidelines.

The purpose of this study was to explore educators' experience in implementing the Connecticut Guidelines. The study specifically examined the association between special educators' implementation, difficulty of implementing, and perspective on importance of the Connecticut Guidelines and variables related to: (a) years of experience; (b) assignment; (c) place; (d) RESC; (e) number of students on caseload; (f) percentage of students with ASD on caseload; or (g) personal relationship. This descriptive correlational study used a self-report survey to address the research questions. This chapter presents the results related to the research questions.

\section{Description of the Sample}

A survey questionnaire was sent electronically to special educators currently employed in the State of Connecticut. The survey was received by 713, but 128 opted not to participate. The individuals who opened the survey, resulted in 568 completing some part of the survey. A total of 377 surveys were fully completed and 161 were partially completed. After examination of the data, 377 surveys were included in the analysis. 
The demographic characteristics of the respondents are presented in Table 7. Almost two thirds (63\%) of the teachers had taught for under 20 years, and almost one third (36\%) had taught for 20 years or more. Respondents had primarily (85.4\%) taught in a public school. Only a small number of teachers (8.2\%) had a only a Bachelor's/ Special Education degree; predominantly the teachers had a Master's degree or higher. Teachers from the Central (27.9\%) and South Central (21.5\%) parts of the state accounted for almost half of the responses (49.4\%). There were surveys where a respondent checked more than one geographic option, therefore there are higher number of responses for education demographic.

Specific responses from the participants regarding ASD-related experiences are summarized in Table 8. Almost half (43.5\%) of the teachers taught children in pre/elementary school classrooms. About two thirds (68.7\%) of the respondents had 10 or more students on their caseload, and of that number one third (34.2\%) were responsible for more than 15 students. About half (53.3\%) of the teachers responded that $1-25 \%$ of their caseload were students identified with ASD. About one third (36.6\%) of teachers had a personal relationship with an individual with ASD.

There were three questions from the survey which addressed self-reported proficiency. They included: focus on plan and implement instruction based on learner characteristics; plan and implement appropriate social skills instruction; plan functional life skills instruction for individuals with autism. The responses were slightly higher for there being low/no need rather than a need for training in the areas of planning and implementing program (55.7\%) and foster social skills (50.9\%). In the area of teaching 
Table 7

Demographic Characteristics

\begin{tabular}{lll}
\hline Variable & $n$ & $\%$ \\
\hline
\end{tabular}

$\underline{\text { Years employed as a special educator }}$

$\begin{array}{lrr}0-5 \text { years } & 52 & 13.8 \\ \text { 6-10 years } & 62 & 16.4 \\ 11-15 \text { years } & 62 & 16.4 \\ 16-20 \text { years } & 62 & 16.4 \\ 21-25 \text { years } & 36 & 9.5 \\ \text { 26-30 years } & 45 & 11.9 \\ \text { Over } 30 \text { years } & 55 & 14.6\end{array}$

Education

$\begin{array}{lrr}\text { Bachelor's SPED } & 31 & 8.2 \\ \text { Master's SPE } & 215 & 57.0 \\ \text { Master's ASD } & 20 & 5.3 \\ \text { Behavior Analyst } & 8 & 2.1 \\ \text { Sixth Year } & 93 & 24.7 \\ \text { Admin } & 29 & 7.7 \\ \text { PhD } & 3 & 0.8\end{array}$

Current place of employment

$\begin{array}{lll}\text { Public School } & 322 & 85.4\end{array}$

$\begin{array}{lll}\text { Private School } & 42 & 11.1\end{array}$

Area of state where employed

\begin{tabular}{lrr} 
Central & 105 & 27.9 \\
Northeast & 30 & 8.0 \\
South Central & 81 & 21.5 \\
Northwestern & 33 & 8.8 \\
Southwestern & 60 & 15.9 \\
Southeastern & 29 & 7.7 \\
Don't Know & 33 & 8.8 \\
\hline
\end{tabular}


Table 8

ASD Related Experiences

\begin{tabular}{|c|c|c|c|}
\hline Variable & $N$ & $\%$ & Additional Comments \\
\hline \multicolumn{4}{|l|}{ Primary teaching role } \\
\hline Pre/Elem & 164 & 43.5 & \\
\hline Middle School & 71 & 18.8 & \\
\hline High School & 74 & 19.6 & \\
\hline Other/Specialist & 45 & 11.9 & \\
\hline \multicolumn{4}{|c|}{ Number of students on caseload } \\
\hline $1-3$ & 6 & 1.6 & \\
\hline 4-6 & 40 & 10.6 & \\
\hline 7-9 & 68 & 18.0 & \\
\hline $10-12$ & 73 & 19.4 & \\
\hline $13-15$ & 57 & 15.1 & \\
\hline More than 15 & 129 & 34.2 & \\
\hline \multicolumn{4}{|c|}{ Percentage of caseload identified as ASD } \\
\hline $0 \%$ & 39 & 10.3 & \\
\hline $1-25 \%$ & 201 & 53.3 & \\
\hline $26-50 \%$ & 55 & 14.6 & \\
\hline $51-75 \%$ & 27 & 7.2 & \\
\hline $76-99 \%$ & 27 & 7.2 & \\
\hline $100 \%$ & 23 & 6.1 & \\
\hline
\end{tabular}


Table 8-Continued

\begin{tabular}{|c|c|c|c|}
\hline Variable & $N$ & $\%$ & Additional Comments \\
\hline \multicolumn{4}{|l|}{ Personal relationship } \\
\hline No & 236 & 62.6 & \\
\hline Yes & 138 & 36.6 & \\
\hline$\underline{\text { Plan and implement systematic instruction }}$ & & & $\begin{array}{l}\text { based on learner characteristics and previous on- } \\
\text { going assessment }\end{array}$ \\
\hline \multirow{2}{*}{$\begin{array}{l}\text { Low need/No need } \\
\text { Need }\end{array}$} & 210 & 55.7 & \\
\hline & 158 & 41.9 & \\
\hline$\underline{\text { Foster social skill development }}$ & & & $\begin{array}{l}\text { through peer interactions, direct instruction, role } \\
\text { playing, video modeling, etc. }\end{array}$ \\
\hline \multirow{2}{*}{$\begin{array}{l}\text { Low need/No need } \\
\text { Need }\end{array}$} & 192 & 50.9 & \\
\hline & 169 & 44.8 & \\
\hline$\underline{\text { Implement evidenced based strategies }}$ & & & $\begin{array}{l}\text { promoting the development of self-help, } \\
\text { independent living, transportation, community } \\
\text { participation, safety and nutrition }\end{array}$ \\
\hline Low need/No need & 171 & 45.4 & \\
\hline Need & 196 & 52.0 & \\
\hline
\end{tabular}


life skills to students with autism, teachers identified the need for training as slightly higher $(52 \%)$.

\section{Results by Questions}

The following 6 research questions guided this study:

1. To what extent are special educators in Connecticut implementing the Connecticut Guidelines for Identification and Education of Children and Youth with Autism for students with autism? Additionally are they implementing the most recognized evidence-based practices recommended for students with autism spectrum disorder?

2. What rating level of difficulty have special educators in Connecticut experienced in implementing the Connecticut Guidelines for Identification and Education of Children and Youth with Autism for students with autism? Additionally do they find it difficult to implement the most recognized evidence-based practices recommended for students with autism spectrum disorder?

3. What rating of level of importance do special educators in Connecticut place on the Connecticut Guidelines for Identification and Education of Children and Youth with Autism when designing programs for students with autism? Additionally if they are implementing the most recognized evidence-based practices recommended for students with autism spectrum disorder have they found them to be important?

4. Are there associations between special educators' implementation of the Connecticut Guidelines for Identification and Education of Children and Youth with Autism and the independent variables: (a) years of experience, (b) assignment, (c) place, 
(d) RESC, (e) number of students on caseload, (f) percentage of students with ASD on caseload, or $(\mathrm{g})$ personal relationship?

5. Are there associations between special educators' rating of level of difficulty implementing the Connecticut Guidelines for Identification and Education of Children and Youth with Autism and the independent variables: (a) years of experience, (b) assignment, (c) place, (d) RESC, (e) number of students on caseload, (f) percentage of students with ASD on caseload, or (g) personal relationship?

6. Are there associations between special educators' rating of importance of the Connecticut Guidelines for Identification and Education of Children and Youth with Autism and the independent variables: (a) years of experience, (b) assignment, (c) place, (d) RESC, (e) number of students on caseload, (f) percentage of students with ASD on caseload, or (g) personal relationship?

\section{Research Question One}

Research Question 1 examined the rating that Connecticut special educators assign to their implementation of the Connecticut Guidelines. Question 16 on the Connecticut Autism Needs Survey asked teachers: "Rate the level which best describes how you implement the recommendations of the Connecticut Guidelines for the Identification and Education of Children and Youth with Autism 2005?" Teachers rated their experience using a Likert Scale rating of 0 through 6. Table 9 presents the response choices and the frequency count as well as the percentage of the sample who responded for each option. As represented by the mode, the highest frequency response was teachers are not implementing the Guidelines. Based on the data from this sample $4.2 \%$ of teachers have fully implemented the recommendations of the Guidelines, $25.2 \%$ have 
implemented adequately for all students, and $20.4 \%$ have implemented adequately for a few students which represents $50 \%$ cumulatively implemented the Guidelines. The remaining teachers' response to this question reflect that $19.4 \%$ have minimally implemented and $30.2 \%$ have not implemented the recommendations of the Guidelines.

Table 9

Teacher Responses for Implementing Connecticut Guidelines

\begin{tabular}{lrr}
\hline Level Description & $\mathrm{N}$ & $\%$ \\
\hline Fully Implemented & 16 & 4.2 \\
Implemented adequately for all students & 95 & 25.2 \\
Implemented adequately for a few students & 77 & 20.4 \\
Minimal Implementation & 73 & 19.4 \\
Not Implementing & 114 & 30.2 \\
Total & 375 & 99.5 \\
Missing & 2 & 0.5 \\
Total & 377 & 100 \\
\hline
\end{tabular}

The Connecticut Guidelines provide information and advocate for the use of evidence-based education when designing and implementing educational programs for students with autism. To further explore implementation, Question 11 on the Connecticut Autism Needs Survey asked teachers if they have implemented 17 of the most effective evidence-based practices for students with autism. Teachers responded with either yes or no for implementation of each of the 17 practices. 
The three evidence-based practices most frequently implemented by Connecticut special education teachers included: interventions based on behavioral principles, $88.6 \%$; visual supports, 78.0\%; and functional behavior assessment, 69.8\%. The interventions implemented the least by teachers included: pivotal response training, $17.60 \%$; video modeling, $19.4 \%$; voice output communication aide, $22.5 \%$. Table 10 presents the frequency count and percentage of the sample implementing or not implementing the 17 evidence-based interventions that are recommended for teaching students with autism.

\section{Research Question Two}

Research Question 2 provided information on Connecticut special educators' perception of the difficulty level of implementing the Connecticut Guidelines. Question 17 on the survey asked teachers: "Rate the level of difficulty implementing the recommendations of the Connecticut Guidelines for the Identification and Education of Children and Youth with Autism 2005? Teachers rated their experience using a Likert Scale rating of 0 through 6 . Teachers who rated the level of difficulty, but had responded that they had not implemented the Guidelines, were excluded in the analysis of this question. Table 11 shows the response choices and the frequency count as well as the percentage of the sample who responded for each option. As represented by the mode, the highest frequency response found that $35.0 \%$ of teachers were not familiar with the Guidelines. 
Table 10

Implementation of Evidence-Based Practices

\begin{tabular}{|c|c|c|c|c|c|c|}
\hline \multirow[t]{2}{*}{ Variable } & \multicolumn{2}{|c|}{ Implemented } & \multicolumn{2}{|c|}{ Not Implemented } & \multicolumn{2}{|c|}{ Missing } \\
\hline & $N$ & $\%$ & $n$ & $\%$ & $n$ & $\%$ \\
\hline Interventions based on behavioral principles & 344 & 88.6 & 33 & 8.8 & 10 & 2.7 \\
\hline Computer aided instruction & 234 & 62.1 & 129 & 34.2 & 14 & 3.7 \\
\hline Discrete trial training & 138 & 36.6 & 222 & 58.9 & 17 & 4.5 \\
\hline Parent implemented interventions & 102 & 27.1 & 259 & 68.7 & 16 & 4.2 \\
\hline Peer mediated interventions & 178 & 47.2 & 182 & 48.3 & 17 & 4.5 \\
\hline Picture exchange communication systems & 152 & 40.3 & 209 & 55.4 & 16 & 4.2 \\
\hline Pivotal response training & 64 & 17.0 & 296 & 78.5 & 17 & 4.5 \\
\hline Functional behavior assessment & 263 & 69.8 & 99 & 26.3 & 15 & 4.0 \\
\hline Functional communication training & 120 & 31.8 & 238 & 63.1 & 19 & 5.0 \\
\hline Antecedent based interventions & 195 & 51.7 & 166 & 44.0 & 16 & 4.2 \\
\hline Self-Management & 213 & 56.5 & 144 & 38.2 & 20 & 5.3 \\
\hline Social Narratives & 226 & 59.9 & 134 & 35.5 & 17 & 4.5 \\
\hline Social skills groups & 198 & 52.5 & 160 & 42.4 & 19 & 5.0 \\
\hline Structured work systems & 169 & 44.8 & 191 & 50.7 & 17 & 4.5 \\
\hline Video modeling & 73 & 19.4 & 285 & 75.6 & 19 & 5.0 \\
\hline Visual supports & 294 & 78.0 & 68 & 18.0 & 15 & 4.0 \\
\hline Voice Output Communication Aide & 85 & 22.5 & 271 & 71.9 & 21 & 5.6 \\
\hline
\end{tabular}


Based on the data from this sample, cumulatively $57.8 \%$ of the teachers found the Guidelines difficult to implement as evidenced by the following ratings: $2.1 \%$ for very difficult; $12.2 \%$ moderately difficult; $19.4 \%$ difficult, and $24.1 \%$ minimally difficult. A small percentage, $5.8 \%$, of teachers did not find it difficult to implement the Guidelines. In summary $92.8 \%$ of respondents were either not familiar with the Guidelines or found them difficult to implement and 5.8\% do not find them difficult to implement.

Table 11

Level of Difficulty Implementing Recommendations

\begin{tabular}{|c|c|c|}
\hline Description & $\mathrm{n}$ & $\%$ \\
\hline Very Difficult & 8 & 3.0 \\
\hline Moderately Difficult & 45 & 17.1 \\
\hline Difficult & 71 & 27.0 \\
\hline Minimally Difficult & 90 & 34.2 \\
\hline Not Difficult & 19 & 7.2 \\
\hline Not Familiar with Guidelines & 26 & 9.9 \\
\hline Total & 259 & 98.4 \\
\hline Missing & 4 & 1.5 \\
\hline Total & 263 & 100.0 \\
\hline
\end{tabular}


To further explore the level of difficulty implementing prescribed practices, Question 11 on the Connecticut Autism Needs Survey asked teachers to rate the degree of difficulty in implementation of 17 of the most effective evidence-based interventions for students with autism. Teachers' responses to degree of difficulty implementing was recoded from 5 responses to 2 responses to create a dichotomous variable for analysis. Minimally difficult, not difficult were coded as not difficult and too difficult, moderately difficult and difficult were coded as difficult to implement for the purpose of analysis.

Table 12 shows the frequency count and percentage of the sample, rating the 17 evidence-based interventions as not difficult or difficult to implement. It is critical to consider that the degree of difficulty was only rated if the intervention was being implemented by the responder. If an intervention was not implemented it would be in the count as missing. In question 1 the practice most frequently implemented by teachers (88.6\%) was intervention based on behavioral principles. In this section it had the highest response rate of $64.7 \%$ of teachers rating it as not difficult to implement. Visual supports was also rated high as not difficult to implement at $64.5 \%$. Computer-aided instruction with a $48.0 \%$ and social narratives with $47.2 \%$ of teachers rating not difficult to implement. These results appear to be not difficult, yet the $32.9 \%$ and $40.6 \%$ of missing values respectively, reflect that a significant number of teachers were not implementing the intervention. Video modeling (9.3\%), pivotal response training,(11.7\%) and voice output communication aide $(11.7 \%)$ had the lowest ratings as being difficult to implement, yet the missing values of $79.0 \%, 81.2 \%$ and $76.1 \%$ respectively reflect that the majority of respondents did not answer the question. 
Table 12

Difficulty of Evidence-Based Practices

\begin{tabular}{|c|c|c|c|c|c|c|}
\hline \multirow[t]{2}{*}{ Variable } & \multicolumn{2}{|c|}{ Not Difficult } & \multicolumn{2}{|c|}{ Difficult } & \multicolumn{2}{|c|}{ Missing } \\
\hline & $n$ & $\%$ & $N$ & $\%$ & $n$ & $\%$ \\
\hline $\begin{array}{l}\text { Interventions based on behavioral } \\
\text { principles }\end{array}$ & 244 & 64.7 & 87 & 23.1 & 44 & 11.7 \\
\hline Computer aided instruction & 181 & 48.0 & 65 & 17.1 & 124 & 32.9 \\
\hline Discrete trial training & 91 & 24.1 & 48 & 12.7 & 212 & 56.2 \\
\hline Parent implemented interventions & 39 & 10.3 & 77 & 20.4 & 233 & 61.8 \\
\hline Peer mediated interventions & 108 & 28.6 & 79 & 21.0 & 167 & 44.3 \\
\hline $\begin{array}{l}\text { Picture exchange communication } \\
\text { systems }\end{array}$ & 106 & 28.1 & 48 & 12.7 & 204 & 54.1 \\
\hline Pivotal response training & 27 & 7.2 & 44 & 11.7 & 306 & 81.2 \\
\hline Functional behavior assessment & 147 & 39.0 & 112 & 29.7 & 107 & 28.4 \\
\hline $\begin{array}{l}\text { Functional communication } \\
\text { training }\end{array}$ & 57 & 15.1 & 65 & 17.2 & 228 & 60.5 \\
\hline Antecedent based interventions & 114 & 30.2 & 82 & 21.8 & 161 & 42.7 \\
\hline Self-Management & 98 & 26.0 & 117 & 31.0 & 145 & 38.5 \\
\hline Social Narratives & 178 & 47.2 & 46 & 12.2 & 153 & 40.6 \\
\hline Social skills groups & 143 & 37.9 & 57 & 15.1 & 177 & 46.9 \\
\hline Structured work systems & 117 & 31.0 & 51 & 13.5 & 187 & 49.6 \\
\hline Video modeling & 44 & 11.7 & 35 & 9.3 & 298 & 79.0 \\
\hline Visual supports & 243 & 64.5 & 48 & 12.7 & 82 & 21.8 \\
\hline $\begin{array}{l}\text { Voice Output Communication } \\
\text { Aide }\end{array}$ & 46 & 12.2 & 44 & 11.7 & 287 & 76.1 \\
\hline
\end{tabular}




\section{Research Question Three}

Research Question 3 provided information on how Connecticut special educators rated the importance of the Connecticut Guidelines for the Identification and Education of Children and Youth with Autism. Question 15 on the Connecticut Autism Needs Survey asked teachers: "How important have the Connecticut Guidelines for the Identification and Education of Children and Youth with Autism 2005 been to you in designing programs for students with ASD?" Teachers rated their experience using a Likert Scale rating of 0 through 6 . The response choices and the frequency count as well as the percentage of the sample which responded for each option are listed in Table 13. As represented by the mode, the highest frequency of response was that teachers are aware that the Guidelines exist and reference them when they have a question. Based on the data, $6.1 \%$ of teachers used them to design programs, $41.6 \%$ had an awareness of the Guidelines and may reference them when they have a question which represents $47.7 \%$ cumulatively used Guidelines. The remaining teacher responses reflect that $21.8 \%$ know the Guidelines exist but have not used them, and $0.8 \%$ have not found them important. Cumulatively the remaining $25.5 \%$ either did not know they existed or did not need to know. In summary it appears in this sample that $47.7 \%$ of the special education teachers believe the Guidelines are important to use, and $48.1 \%$ of special education teachers did not rate them as important.

The final section of Question 11 asked teachers to rate their perception of the level of importance that each of the 17 specific practices had on improving students' progress. 
Table 13

Importance in Designing Programs for Students With ASD

\begin{tabular}{lrr}
\hline Description & $n$ & $\%$ \\
\hline Extremely Important & 23 & 6.1 \\
Aware they exist and have referenced them & 157 & 41.6 \\
Know they exist but have not used them & 95 & 25.2 \\
Tried to use them but have not found them & 3 & 0.8 \\
important & & \\
I didn't know they existed & 82 & 21.8 \\
No need to know & 14 & 3.7 \\
Total & 360 & 95.5 \\
Missing & 17 & 4.5 \\
Total & 377 & 100.0 \\
\hline
\end{tabular}

Teachers' responses to degree of importance was recoded from 5 ratings to 2 ratings to create a dichotomous variable in order to analyze the data. Extremely important, moderately important, important were coded as important and minimally important and not important were coded as not important for the purpose of analysis.

Table 14 shows the frequency count and percentage of the sample rating of the 17 evidence-based interventions as important or not important with respect to positively impacting student performance. Once again, it is critical to consider that the degree of importance was only rated if the intervention was being implemented by the responder. If an intervention was not implemented, it would be in the count as missing. In question 1 the practice most frequently implemented by teachers $(88.6 \%)$ was intervention based on 
behavioral principles therefore in this section it has the highest response rate of $87.0 \%$ of teachers rating it as important to implement.

Table 14

Importance of Evidence-Based Practices

\begin{tabular}{lrrrrrr}
\hline Variable & \multicolumn{2}{c}{ Important } & \multicolumn{3}{c}{ Not Important } & \multicolumn{2}{c}{ Missing } \\
Description & \multicolumn{1}{c}{$N$} & $\%$ & $n$ & $\%$ & $n$ & $\%$ \\
\hline Interventions based on behavioral & 328 & 87.0 & 0 & 0.0 & 49 & 13.0 \\
principles & 242 & 64.2 & 0 & 0.0 & 135 & 35.8 \\
Computer aided instruction & 143 & 37.9 & 7 & 1.9 & 227 & 60.2 \\
Discrete trial training & 133 & 35.0 & 2 & 0.5 & 245 & 64.5 \\
Parent implemented interventions & 190 & 50.4 & 7 & 1.9 & 180 & 47.7 \\
Peer mediated interventions & & & & & & \\
Picture exchange communication & 151 & 40.1 & 6 & 1.6 & 220 & 58.4 \\
systems & 80 & 21.2 & 7 & 1.9 & 290 & 76.9 \\
Pivotal response training & 246 & 65.3 & 9 & 2.4 & 122 & 32.4 \\
Functional behavior assessment & 124 & 32.9 & 4 & 1.1 & 249 & 66.0. \\
Functional communication training & 190 & 50.4 & 8 & 2.1 & 179 & 47.5 \\
Antecedent based interventions & 216 & 57.3 & 3 & 0.8 & 158 & 41.9 \\
Self-Management & 212 & 56.2 & 13 & 3.4 & 152 & 40.3 \\
Social Narratives & 202 & 53.6 & 3 & 0.8 & 172 & 45.6 \\
Social skills groups & 168 & 44.6 & 10 & 2.7 & 199 & 52.8 \\
Structured work systems & 85 & 22.5 & 13 & 3.4 & 279 & 74.0 \\
Video modeling & 278 & 75.3 & 6 & 1.6 & 93 & 24.7 \\
Visual supports & 94 & 24.9 & 10 & 2.7 & 273 & 72.4 \\
Voice Output Communication Aide & & & & & & \\
\hline
\end{tabular}


Visual supports (75.3\%), functional behavior assessment (65.3\%), and computer-aided instruction (64.2\%) were the other evidence-based interventions rated as important by the teachers. The three practices with the lowest percentage of responders rating as important were: pivotal response training, $21.2 \%$; video modeling $22.5 \%$; voice output communication aide, $24.9 \%$. The rating of importance should be viewed with the awareness that these techniques, as already presented in Table 10, were the ones with the least amount of teachers implementing with an $n$ of 64,73 , and 85 respectively.

\section{Research Question Four}

Research Question 4 examined the association between implementation of the Connecticut Guidelines for Identification and Education of Children and Youth with Autism by special educators and the predictor variables: (a) years of experience, (b) assignment, (c) place, (d) RESC, (e) number of students on caseload, (f) percentage of students with ASD on caseload, or (g) personal relationship. Description of each of the predictor variables was provided in Chapter 3 and frequency data was provided previously in this chapter. Teachers' responses for degree of implementation were recoded from 5 responses to 2 responses to create a dichotomous variable in order to use binary logistic regression to analyze the data. Fully implemented, adequately implemented for all students and adequately for a few students were coded as implemented, and minimal implementation and not implementing were coded as not implemented for the purpose of analysis.

Direct logistic regression was performed to predict the probability of a special educator implementing the Connecticut Guidelines for Identification and Education of Children and Youth with Autism, based on a number of factors. The full model containing 
all predictors as a set was statistically significant, $X^{2}(14, N=308)=45.76, p<.001$, indicating that the model was able to distinguish between special educators who reported implementation of the Guidelines and those who reported they had not implemented the Guidelines. The model as a whole explained between $13.8 \%\left(\right.$ Cox and Snell $R^{2}$ ) and $18.4 \%$ (Nagelkerke $R^{2}$ ) of the variance in implementation. Overall the model was able to classify $68 \%$ of the cases, $64.2 \%$ for implement and $73.1 \%$ for not implement.

Table 15 shows the logistic regression coefficient, Wald test, significance, and odds ratio for each of the predictors. Employing a .05 criterion for statistical significance, the Wald criterion demonstrated caseload per cent, experience, relationship, and one regional area of the state made a significant contribution for prediction of implementation of the Guidelines by teachers. The strongest predictor of implementation was the percentage of students with autism on the special educator's caseload. Teachers with a higher percentage of students with autism on their caseload were more likely to implement the Guidelines than teachers with no students with autism on their caseload, recording an odds ratio of 1.437 . More-experienced teachers were slightly more likely to implement the Guidelines than less-experienced teachers with an odds ratio of 1.205. Teachers who responded yes to having a personal relationship with a person with autism were almost twice as likely to implement the Guidelines as teachers not having a personal relationship, with an odds ratio of 1.949 . The region of the state where the teacher is employed as represented by the RESC variable was dummy coded using Project Learn as the reference group. 
Table 15

Variables in the Equation for Implementation

\begin{tabular}{lcccc}
\hline Variable & $B$ & Wald & Sig. & $\operatorname{Exp}(B)$ \\
\hline Experiences & 0.186 & 8.059 & 0.005 & 1.205 \\
Assignment & - & 6.662 & 0.155 & - \\
Assignment(1) & 1.124 & 3.656 & 0.056 & 3.077 \\
Assignment(2) & 0.39 & 0.615 & 0.433 & 1.477 \\
Assignment(3) & 0.028 & 0.003 & 0.957 & 1.028 \\
Assignment(4) & 0.063 & 0.015 & 0.901 & 1.065 \\
Place & -0.842 & 2.967 & 0.085 & 0.431 \\
RESC & - & 8.176 & 0.147 & - \\
RESC(1) & -1.016 & 4.659 & 0.031 & 0.362 \\
RESC(2) & -0.367 & 0.407 & 0.523 & 0.693 \\
RESC(3) & -0.51 & 1.137 & 0.286 & 0.601 \\
RESC(4) & 0.004 & 0 & 0.995 & 1.004 \\
RESC(5) & -0.831 & 2.684 & 0.101 & 0.436 \\
Number on caseload & -0.092 & 0.883 & 0.347 & 0.913 \\
Caseload percent ASD & 0.363 & 10.893 & 0.001 & 1.437 \\
Relationship exists & 0.667 & 6.461 & 0.011 & 1.949 \\
Constant & -1.036 & 0.743 & 0.389 & 0.355 \\
& & & & \\
\hline$R^{2}$ (Negelkerke's) $=.184, X^{2}(14, N=308)$ & $=45.76, p<.001$ & &
\end{tabular}

The Capitol Region Education Council (CREC), variable was slightly significantly to be less likely to implement the Guidelines than Project Learn, with a recorded odds ratio of .362 .

\section{Research Question Five}

Research Question 5 examined the association between special educators' rating of difficulty level of implementation of the Connecticut Guidelines for Identification and 
Education of Children and Youth with Autism and the predictor variables: (a) years of experience, (b) assignment, (c) place, (d) RESC, (e) number of students on caseload, (f) percentage of students with ASD on caseload, or (g) personal relationship. Description of each of the predictor variables was provided in Chapter 3 and frequency data was provided previously in this chapter. Teachers' responses to degree of difficulty implementing was recoded from 5 responses to 2 responses to create a dichotomous variable, in order to use binary logistic regression to analyze the data. Minimally difficult and not difficult were coded as not difficult and very difficult, moderately difficult, and difficult were coded as difficult to implement for the purpose of analysis.

Direct logistic regression was performed to predict the probability of a special educator's rating of difficulty level of implementing the Connecticut Guidelines based on a number of factors. The full model containing all predictors as a set was statistically significant, $X^{2}(14, N=195)=31.76, p<.005$, indicating that the model was able to distinguish between special educators who reported that it was difficult to implement the Guidelines and those who reported they did not find it difficult to implement the Guidelines. The model as a whole explained between $14.9 \%\left(\right.$ Cox and Snell $\left.R^{2}\right)$ and $19.8 \%$ (Nagelkerke $R^{2}$ ) of the variance in implementation. The model was able to correctly classify $58.2 \%$ of those who found the Guidelines not difficult to implement and $71.2 \%$ of those who found them difficult to implement, for an overall success rate of $65 \%$.

Table 16 shows the logistic regression coefficient, Wald test, significance, and odds ratio for each of the predictors. 
Table 16

Variables in the Equation for Level of Difficulty

\begin{tabular}{|c|c|c|c|c|}
\hline Variable & $B$ & Wald & Sig. & $\operatorname{Exp}(B)$ \\
\hline Experiences & -0.105 & 1.609 & 0.205 & 0.900 \\
\hline Assignment & - & 3.356 & 0.500 & - \\
\hline Assignment(1) & 0.310 & 0.172 & 0.678 & 1.364 \\
\hline Assignment(2) & 0.681 & .979 & 0.322 & 1.976 \\
\hline Assignment(3) & 1.071 & 2.165 & 0.141 & 2.917 \\
\hline Assignment(4) & 0.843 & 1.411 & 0.235 & 2.324 \\
\hline Place & 2.240 & 7.593 & 0.006 & 9.394 \\
\hline RESC & - & 12.298 & 0.031 & - \\
\hline RESC(1) & 0.770 & 1.598 & 0.206 & 2.160 \\
\hline $\operatorname{RESC}(2)$ & 1.428 & 3.928 & 0.047 & 4.169 \\
\hline $\operatorname{RESC}(3)$ & 0.044 & 0.005 & 0.943 & 1.045 \\
\hline $\operatorname{RESC}(4)$ & 0.194 & 0.068 & 0.794 & 1.214 \\
\hline $\operatorname{RESC}(5)$ & 1.418 & 4.611 & 0.032 & 4.127 \\
\hline Number on caseload & -0.036 & 0.088 & 0.767 & 0.964 \\
\hline Caseload percent ASD & -0.449 & 9.602 & 0.002 & 0.638 \\
\hline Relationship exists & -0.170 & 0.271 & 0.603 & 0.843 \\
\hline Constant & -1.799 & 1.272 & 0.259 & 0.165 \\
\hline
\end{tabular}


Employing a .05 criterion for of statistical significance the Wald criterion demonstrated that caseload percent, place of employment, and one regional area of the state made a significant contribution to prediction. The strongest predictor of implementation was the percentage of students with autism on the special educator's caseload; teachers with a higher percentage of students with autism on their caseload were more likely to rate it as difficult to implement the Guidelines than teachers with no students with autism on their caseload, recording an odds ratio of .638. Special education teachers in private schools were 9 times less likely to find it difficult to implement the Guidelines than teachers in public schools, with an odds ratio of 9.394. The region of the state where the teacher is employed as represented by the RESC variable was dummy coded using Project Learn as the reference group. Two of the RESCs, East Conn, and Cooperative Educational Services were 4 times less likely to find implementing the Guidelines difficult than Project Learn with recorded odds ratio of .047 and .032.

\section{Research Question Six}

Research Question 6 examined the association between special educators' rating of importance of the Connecticut Guidelines for Identification and Education of Children and Youth with Autism and the predictor variables: (a) years of experience, (b) assignment, (c) place, (d) RESC, (e) number of students on caseload, (f) percentage of students with ASD on caseload, or (g) personal relationship. Description of each of the predictor variables was provided in Chapter 3, and frequency data was provided previously in this chapter. Teachers' responses to degree of importance were recoded from 5 responses to 2 responses to create a dichotomous variable in order to use binary logistic regression to analyze the data. Extremely important and have used for designing 
programs was coded as important and aware they exist, and on occasion have referenced them, know they exist but have not used them, tried to use them but have not found them important, and didn't know they existed were coded as not important for the purpose of analysis.

Direct logistic regression was performed to predict the probability of a special educator's rating of importance of the Connecticut Guidelines based on a number of factors. The full model containing all of the predictors as a set was not statistically significant, $X^{2}(14, N=297)=20.67, p<.110$, indicating that as a whole, this set of predictors are not significant in predicting teachers' rating of importance. The 6.7\% (Cox and Snell $\mathrm{R}^{2}$ ) and $17.3 \%$ (Nagelkerke $\mathrm{R}^{2}$ ) confirm the weakness of the model in explaining the variance for predicting rating of importance. Overall the model was able to correctly classify $93 \%$ of the responses, $0 \%$ for important and $100 \%$ for not important.

Table 17 shows the logistic regression coefficient, Wald test, significance, and odds ratio for each of the predictors. Employing a .05 criterion for of statistical significance, the Wald criterion demonstrated that the two variables, years of experience and caseload percent were significant on their own in contributing to prediction. The strongest predictor of importance was the percentage of students with autism on the special educator's caseload. Teachers with a higher percentage of students with autism on their caseload were almost twice as likely to rate the Guidelines as more important than teachers with no students with autism on their caseload, recording an odds ratio of 1.813. Special education teachers with more years of experience were slightly more likely to rate the Guidelines as important than less experienced teachers with an odds ratio of 1.373. 
Table 17

Variables in the Equation for Importance

\begin{tabular}{|c|c|c|c|c|}
\hline Variable & $B$ & Wald & Sig. & $\operatorname{Exp}(B)$ \\
\hline Experiences & 0.317 & 5.668 & 0.017 & 1.373 \\
\hline Assignment & - & 4.104 & 0.392 & - \\
\hline Assignment(1) & 1.883 & 1.823 & 0.177 & 6.573 \\
\hline Assignment(2) & 1.889 & 2.055 & 0.152 & 6.612 \\
\hline Assignment(3) & 0.666 & 0.214 & 0.644 & 1.946 \\
\hline Assignment(4) & 0.99 & 0.553 & 0.457 & 2.69 \\
\hline Place & -0.243 & 0.037 & 0.847 & 0.785 \\
\hline RESC & - & 2.208 & 0.82 & - \\
\hline $\operatorname{RESC}(1)$ & 0.137 & 0.014 & 0.906 & 1.147 \\
\hline $\operatorname{RESC}(2)$ & 1.064 & 0.666 & 0.414 & 2.898 \\
\hline $\operatorname{RESC}(3)$ & 0.33 & 0.077 & 0.781 & 1.392 \\
\hline $\operatorname{RESC}(4)$ & 1.073 & 0.746 & 0.388 & 2.925 \\
\hline $\operatorname{RESC}(5)$ & 0.327 & 0.074 & 0.786 & 1.386 \\
\hline Number on caseload & 0.334 & 2.166 & 0.141 & 1.396 \\
\hline Caseload percent ASD & 0.595 & 8.735 & 0.003 & 1.813 \\
\hline Relationship exists & 0.561 & 1.211 & 0.271 & 1.752 \\
\hline Constant & -9.525 & 8.926 & 0.003 & - \\
\hline
\end{tabular}




\section{Qualitative Responses}

The purpose of the qualitative data from the 4 open-ended questions was to enrich the analysis of the quantitative data. The questions were structured to provide singleword responses, which support ease of text analysis. The information provided by the analysis of the qualitative data will be used in the discussion of the findings presented in Chapter 5. Table 18 contains the data collected from the first open-ended question: "Please use ONE word to describe what you believe is the key to success for educating a student with ASD." Table 19 displays the data collected from the second open-ended question: "Please use ONE word to describe what you believe is the most significant barrier to educating a student with ASD.”

Table 18

Key to Success for Students With ASD

\begin{tabular}{llc}
\hline Word & $N$ & $\%$ \\
\hline Consistency & 65 & 18.11 \\
Patience & 44 & 12.26 \\
Understanding & 26 & 7.24 \\
Communication & 19 & 5.29 \\
Structure & 18 & 5.01 \\
Flexibility & 17 & 4.74 \\
\end{tabular}


Table 19

Significant Barrier to Educating a Student with ASD

\begin{tabular}{llr}
\hline Word & $\mathrm{N}$ & $\%$ \\
\hline Communication & 38 & 10.67 \\
Behavior & 22 & 6.18 \\
Resources & 30 & 8.43 \\
Understanding & 14 & 3.93 \\
Support & 13 & 3.65 \\
Ignorance & 11 & 3.09 \\
\hline
\end{tabular}

Table 20 contains the data collected from the third open-ended question: "Please use ONE word to describe the Connecticut Guidelines for the Identification and Education of Children and Youth with Autism 2005."

Table 20

Description of the Connecticut Guidelines

\begin{tabular}{lcc}
\hline Word & $\mathrm{N}$ & $\%$ \\
\hline Unknown & 48 & 15.90 \\
Outdated & 11 & 3.64 \\
Difficult & 11 & 3.64 \\
Useful & 8 & 2.65 \\
Necessary & 6 & 1.99 \\
Important & 5 & 1.66 \\
\hline
\end{tabular}


Table 21 displays the data collected from the fourth open-ended question: "Please use ONE word to describe what you want from the Connecticut Guidelines for the Identification and Education of Children and Youth with Autism 2005."

Table 21

What is Desired From the Connecticut Guidelines

\begin{tabular}{lcc}
\hline Word & $\mathrm{N}$ & $\%$ \\
\hline Simplified & 17 & 6.36 \\
Guidance & 6 & 2.24 \\
Flexibility & 3 & 1.12 \\
Implementation & 3 & 1.12 \\
Knowledge & 3 & 1.12 \\
\hline
\end{tabular}

\section{Summary}

This chapter provided the data and analyses of the six research questions for the study. Descriptive data identifies that $89.2 \%$ of the participants completing the Connecticut Autism Needs Survey, that was used in this study, were public school teachers with the highest number of them, $32.9 \%$ employed in elementary schools. Case management for more than 15 students with a frequency of $34.3 \%$ was the most frequent response, and $53.4 \%$ of the respondents stated the number of students with autism on their caseload was in the range of $1-25 \%$ percent.

Analysis of the respondents' view of the Connecticut Guidelines reveal that 47.6 $\%$ of the special education teachers believe the Guidelines are important to use, and 52.4 $\%$ of special education teachers did not rate them as important. Additionally half of the 
sample have implemented the Guidelines to varying degrees and $30.6 \%$ have not implemented them at all. In terms of level of difficulty implementing the Guidelines, $58.5 \%$ of the responders rated the Guidelines difficult to implement.

\section{Major Findings}

The following were the key findings from the research.

- $89.5 \%$ of respondents were either not familiar with the Connecticut Guidelines or find them difficult to implement.

- The strongest predictor of teacher implementing and rating the Connecticut Guidelines as important was the number of students with autism on their caseload.

- Teachers with more years of experience were slightly more likely to implement and rate the Connecticut Guidelines as important as teachers with less years of teaching experience.

- Special education teachers in private schools were nine times less likely to rate the Connecticut Guidelines as more difficult to implement than teachers in public schools.

- Teachers having a personal relationship with an individual with autism were twice as likely to implement Connecticut Guidelines than those that didn't have a relationship with an individual with autism.

- Three of the most critical evidence-based strategies for educating students with autism have a low percentage of implementation and are perceived as not important. 


\section{CHAPTER 5}

\section{DISCUSSION AND CONCLUSIONS}

\section{Introduction}

Autism is a lifelong disability that currently affects one in every sixty-eight children (Center for Disease Control, 2014). As the number of children with autism who require educational support continues to increase, it is critical to explore the effectiveness of providing guidance to educators, especially when considering the limited availability of resources. In 2005, the Connecticut State Department of Education drafted the Guidelines for the Identification and Education of Children and Youth with Autism, which identified benchmarks for appropriate educational supports for children with autism. The first purpose listed in the Connecticut Guidelines is "To improve educational outcomes for children and youth with autistic spectrum disorders" (Connecticut State Department of Education, 2005, p. 14). The Guidelines were designed to function as a formal framework to provide guidance and professional development to educators responsible for students with autism. Said Guidelines are based on evidenced-based best practices as defined by the research. This chapter summarizes the current study and presents implications from the findings, based on the data presented in Chapter 4.

\section{Purpose}

At this time, no studies have been done in the State of Connecticut that examine the implementation of the components for effective education of children with autism, as 
set forth in the Connecticut Guidelines. The purpose of this study was to explore educators' experience with implementing the Connecticut Guidelines. Specifically, the study examined the association between special educators' awareness and implementation of the Connecticut Guidelines and: (a) years of experience, (b) assignment, (c) place, (d) RES,; (e) number of students on caseload, (f) percentage of students with ASD on caseload, or (g) personal relationship.

\section{Overview of the Literature}

The Connecticut Guidelines utilized research to identify a framework for educating students with autism. The components identified as critical in designing effective programs for children with ASD are rooted in the principles of applied behavioral analysis.

Applied Behavior Analysis is the science in which procedures derived from the principles of behavior are systematically applied to improve socially significant behavior to a meaningful degree and to demonstrate experimentally that the procedures employed were responsible for the improvement in behavior. (Cooper, Heron \& Heward, 1987, p. 15)

Current behavioral approaches have begun to include concepts such as teaching in the natural environment, considering antecedents, and direct instruction of social behaviors. There has been a "shift from viewing behavior support as a process by which individuals are changed to fit environments, to one in which environments are changed to fit behavior patterns of people in the environments" (Horner et al., 2000, p. 6). The components from the Connecticut Guidelines that guide the actual teaching of students (Individualized and Intensive Programming, Comprehensive Curriculum, Systematic Instruction, and Ongoing Objective Assessment, Structured/Predictable Learning Environment) are grounded in current behavioral theory. 
As the number of children with autism who need educational support increases, it is not enough to be familiar with the components of an effective program. Teachers must have knowledge of evidence-based practices and demonstrate the ability to implement such methods effectively, based on the needs of the student with autism (National Research Council, 2001). The NPDC reviewed the literature on autism intervention, and as a result, published Evidence-Based Practices for Children, Youth, and Young Adults with Autism Spectrum Disorder in 2013. Table 22 presents the twenty-seven specific interventions that met the criteria for evidence-based practices and are definitions of evidence-based practices identified by the NPDC. In addition, these interventions are recommended for educating students with autism spectrum disorder (Wong, et al., 2013). In order to attain optimal results, the focus of educational interventions should be on teaching strategies that will enhance the individual's ability to communicate, understand language, and navigate social complexities at home, school, work and in community environments (Dunlap et al., 2008).

The Connecticut Guidelines were designed to function as a formal framework to provide guidance and professional development to educators in relation to both the "what" and "how" to teach students with autism. Grant (1996) discussed professional development in relation to going beyond "training" and learning new skills. Grant suggests including formal and informal methods for teachers in order to support the development of their own insights into pedagogy through providing resources for content and ideas about how to improve their own practices. 
Table 22

Effective Evidence-Based Instruction - National Professional Development Center

1. Antecedent-Based Intervention (ABI)

2. Cognitive Behavioral Intervention (CBI)

3. Differential Reinforcement of Alternative, Incompatible, or Other Behavior (DRA/I/O)

4. Discrete Trial Teaching (DTT)

5. Exercise (ECE)

6. Extinction (EXT)

7. Functional Behavior Assessment (FBA)

8. Functional Communication Training (FCT)

9. Modeling (MD)

10. Naturalistic Intervention (NI)

11. Parent-Implemented Intervention (PII)

12. Peer-Mediated Instruction and Intervention (PMII)

13. Picture Exchange Communication System (PECS)

14. Pivotal Response Training (PRT)

15. Prompting (PP)

16. Reinforcement $(\mathrm{R}+)$

17. Response Interruption/ Redirection (RIR)

18. Scripting (SC)

19. Self-Management (SM)

20. Social Narratives (SN)

21. Social Skills Training (SST)

22. Structured Play Group (SPG)

23. Task Analysis (TA)

24. Technology-Aided Instruction and Intervention (TAII)

25. Time Delay (TD)

26. Video Modeling (VM)

27. Visual Support (VS) 
With the enhancement of teacher jobs, organizational performance, and increased professional development, positive outcomes for students should be expected (Guskey, 2000; Joyce \& Showers, 2002; Killion, 2002).

Constructivist theory and androgyny are similar, as they both value the experience of the learner and the relevance of information for the learner. The application of both of these principles should influence a teacher's perception and use of the professional development experience provided by the Connecticut Guidelines. It would be expected, teachers primarily responsible for teaching students with autism, would be more likely to have used the Guidelines and rated them as important.

\section{Methodology of the Study}

The research design for this study was a non-experimental, descriptive correlation study. Data for the study was collected through the use of a self-report survey. The data obtained from the self-assessments reflected special education teachers' practices and attitudes towards educating students with autism and the Connecticut Guidelines. The cross-sectional data collected through the survey explored the relationship between the dependent or outcome variables and the independent predictor variables.

The Connecticut Autism Needs Survey was created for the purpose of this study. The foundation for the survey questions for this research was the Needs Assessment for Educating Children with Autism and Other Developmental Disabilities with modifications based on the professional literature and the researcher's own experience. The Connecticut Autism Needs Survey consists of 16 closed questions that are answered with a multiple choice or ordered response using a Likert scale and 4 open-ended 
questions that ask the respondent to provide a one word response. The closed questions yielded data which was either ordinal or nominal.

Special education teachers were selected as the participants due to their direct responsibility of program design and implementation for students with autism.

Connecticut does not have a specific autism certification, therefore, all special education teachers are expected to have the knowledge necessary to support a student with autism. The survey was received by 713, 128 opted not to participate. After examination of the data 377 surveys were included in the analysis.

Quantitative data was analyzed using SPSS Statistics 21. The first three research questions of this the study ask participants to report on their experience with level of importance, degree of implementation and level of difficulty implementing the Connecticut Guidelines. The Guidelines advocate for the use of evidence-based education when designing and implementing educational programs for students with autism. To further explore implementation, level of difficulty implementing and importance the data was examined specifically for teachers practice with the recommended 17 evidence based practices for students with autism. The responses to the questions were analyzed using descriptive statistics to determine frequency distribution.

The last three questions address the association between the dependent variables reported on in the first three questions and the predictor variables of: (a) years of experience, (b) assignment, (c) place, (d) RESC, (e) number of students on caseload, (f) percentage of students with ASD on caseload, or (g) personal relationship. The dependent variable for each question and the 7 predictor variables were analyzed using logistic 
regression. The dependent variable for questions 4-6 of the study had two categories so binary logistic regression analysis was selected.

\section{Summary of Major Results}

The following were the key findings from the research.

- $89.5 \%$ of respondents were either not familiar with the Connecticut Guidelines or find them difficult to implement.

- The strongest predictor of teacher implementing and rating the Connecticut Guidelines as important was the number of students with autism on their caseload.

- Teachers with more years of experience were slightly more likely to implement and rate the Connecticut Guidelines more important than teachers with less years of teaching experience.

- Special education teachers in private schools were nine times less likely to rate the Connecticut Guidelines as difficult to implement than were teachers in public schools.

- Teachers having a personal relationship were twice as likely to implement Connecticut Guidelines than those that didn't have a relationship with an individual with autism.

- Three of the most critical evidence-based strategies for educating students with autism have a low percentage of implementation and are perceived as not important.

\section{Discussion of Major Findings}

The first finding revealed that $89.5 \%$ of respondents were either not familiar with the Connecticut Guidelines or found them difficult to implement. Clearly this statistic reflects the ineffectiveness of the Guidelines in helping teachers develop effective programs based on evidence-based practice for students with autism. The three most 
frequent responses to the survey question that asked teachers to describe the Guidelines with one word were: unknown, outdated, and difficult. The qualitative data supports the findings of the quantitative data.

The next three findings suggest there is an association between a special educator's use of the Connecticut Guidelines and the specificity of their role and tenure. The strongest predictor of teacher's implementation and rating the Guidelines as "important" was the number of students with autism on their caseload. Teachers who are primarily responsible for students with autism were more likely to use the Guidelines than were teachers who were responsible for providing specialized instruction to students with a range of disabilities. It appears that when a teacher is supporting students who primarily have autism, the information presented in the Guidelines is used and valued.

Additionally, the research found that special education teachers in private schools were nine times less likely to rate the Connecticut Guidelines as difficult to implement than were teachers in public schools. Teachers in specialized schools are focused only on the needs of students with autism, therefore, their exposure to the Guidelines and to methodologies described therein, is more likely. Logically, if your primary role is to teach students with autism, you are more likely to have professional development experiences that are focused on supporting individuals with autism.

The findings suggest teachers with more experience were slightly more likely to implement the Connecticut Guidelines. The longer an educator has been teaching, the more their likelihood of supporting a student with autism increases. This may lead such educators to look to the State Department of Education for support. The Guidelines are 
the primary resource for professional development provided by the State Department of Education for special educators in the area of ASD.

The significance of the predictor variables of a specificity of role and experience reflect the learning of the teacher. Malcolm Knowles in his book from 1970, The Modern Practice of Adult Education: Andragogy versus Pedagogy, popularized the concept of androgyny. Knowles' theory focuses on adults utilizing their life experiences and relating them to what they need or want to learn. Four of his assumptions support why an association was found between the predictor variables, years of experience and assignment, and implementation and perceived difficulty level of implementation.

1. Experience: As people mature, they amass a growing set of experiences that provide a fertile resource for learning

2. Readiness to learn: As people mature, they are more interested in learning subjects that have immediate relevance to their jobs or personal lives

3. Orientation to learning: As people mature, their time perspective changes from gathering knowledge for future use to immediate application of knowledge. As such, adult learners become more problem-centered rather than subject-centered (Knowles, 1980)

4. Relevance: As people mature, they need to know why they need to learn something. Furthermore, because adults manage other aspects of their lives, they are capable of directing or, at least, assisting in the planning and implementation of their own learning. (Knowles, 1984, p. 12).

The data from this study found an association between the predictor variable of having a personal relationship with someone with autism and implementation of the 
Connecticut Guidelines. Teachers who have a personal relationship were twice as likely to use the Guidelines as those who did not. Parents of a child with autism spectrum disorder are often overwhelmed by the challenge of meeting their child's needs. These difficulties force family members of children with autism to quickly become experts on not only the child's needs, but also on what treatments and methodologies are available.

I've had to stand my ground with psychologists and educators, and even family. I am no expert on parenting, on autism, or on homeschooling. But I am an expert on Henry. I know him best. I know, unequivocally, I'm the most qualified person for the job. (Mackin, 2013, p. 1).

Autism affects every member of a family and there is a constant search for the answer. Parents and family members are determined to investigate every option available. Elaine Hall, the mother of a child with autism shares, "They say it takes a village to raise a child. I think it takes a child with autism or other special needs to raise the consciousness of a village" (Hosseini, 2012, p. 28). Once you have been touched by a child with autism you become invested, therefore, it is not surprising that teachers who have family members affected by autism were twice as likely to implement the Connecticut Guidelines.

A significant finding of the study identifies that three of the most critical evidence-based strategies for educating students with autism had the lowest percentage of implementation and were also perceived as "not important" by teachers. The interventions implemented the least by teachers included: pivotal response training, $17.60 \%$; video modeling, $19.4 \%$; voice output communication aide, $22.5 \%$.

The research validates the importance and effectiveness of PRT. "Many children with autism show very little interest in academic assignments and exhibit disruptive behavior when assignments are presented" (Koegel, Singh \& Koegel, 2010, p. 1057). 
Pivotal Response Training involves incorporating specific motivational variables such as choice, interspersal of maintenance tasks, and natural reinforcers during intervention. The research suggests the use of PRT can lead to improvements in core symptoms of autism, and may prove to be effective in academic areas. (Koegel et al., 2010). Teachers have the opportunity to implement this extremely effective methodology all day, every day to develop a child's motivation and understanding of how to learn. Yet, a lack of knowledge and understanding of the practice leads to the absence of its implementation.

It is concerning that educators are not using voice output communication with students with autism. In the last generation, people with autism have, as a group, decreased from $50 \%$ non-verbal to $25 \%$ percent non-verbal. The evidence strongly suggests when appropriate interventions are provided to children, particularly young children with autism, dramatic gains can be made. Access to technology which can produce speech output has become more accessible and easier to use. Thus, it is disappointing that teachers are not implementing voice output.

Video modeling uses video recordings to provide a visual model to instruct a student on how to perform a targeted skill or behavior. Videos can be shown to pre teach the skill immediately before the behavior is to be performed or at a later time. This strategy can be used to teach skills in many different domains including social, functional life skills, academic, and vocational. The research literature suggests that video modeling and video self-modeling are effective interventions for working with children and adolescents with autism spectrum disorders (Bellini \& Akullian, 2007; Buggey, Hoomes, Sherberger \& Williams, 2011). Teaching through video modeling can help individuals with autism understand the expectation through the modality that is their strength, thus 
reducing frustration and expediting learning. Video prompting a type of video modeling can be used to develop functional life skills (Gardner \& Wolfe, 2013). Video modeling is an easy intervention to implement, requiring limited materials and time to create. The ready availability of a video camera on cell phones and iPads makes it difficult to understand why teachers are not using this intervention.

The three evidence-based practices most frequently implemented by Connecticut special education teachers included: interventions based on behavioral principles, $88.6 \%$; visual supports,78.0\%; and functional behavior assessment, $69.8 \%$. Two of the three are focused on behavioral principles and involve shaping behaviors rather than focusing on the methodologies to help a child with autism develop relationships and their ability to think. Additionally, in Connecticut, functional behavioral assessments and interventions based on behavioral principles implemented in educational settings are often developed and monitored by a Behavior Analyst through a consultative model to the teacher. The current practice does not set an expectation that the teacher will be responsible for the plan nor do they have to have expertise in understanding behavioral principles. It is important to be aware of this practice when interpreting teachers' response for implementation of practices based on behavioral principles.

When teachers were asked, "what is key to success for educating students with autism?", the top three responses were: consistency, patience, and understanding. All of which reflected teacher behaviors rather than teacher skills. The responses are indicative of a tendency for teachers to focus on attributes that impact how students with autism behave rather than what is required for students to learn. It appears that although the Connecticut Guidelines are clear in recommending effective methodologies, teachers 
have not been provided the opportunity to learn, implement, and to be held accountable for utilizing evidence-based practices.

In 2005, when the task force was assembled, there had been a dramatic increase in the number of students with autism in the state. As the number of students increased, so did the number of therapies and requests from parents to incorporate these therapies into their child's educational program. Parents in Connecticut were strong advocates, and their demands forced the state to examine educational services for children with autism. The task force considered critical issues and current research with the purpose of developing Guidelines to improve educational outcomes for children with autism. The intent was to define a consistent statewide standard of service, provide information on research-based interventions, and identify resources to be utilized by those who provide support to individuals with autism. Once the Guidelines were completed, they were presented to parents and educators through a series of forums offered in each region of the state. Unfortunately, the presentations were attended by parents and district administrators rather than the teachers responsible for implementation. The extent to which the teachers became familiar with and received professional development for the use of the methodologies in the Connecticut Guidelines became the responsibility of district administrators. As reflected in both the quantitative and qualitative data, it does not appear that the information was shared with teachers in an effective manner.

\section{Limitations of the Study}

Participant experiences with the Connecticut Guidelines were only assessed through the use of the Autism Needs Survey. There are notable limitations inherent in the 
use of an internet-based survey for this study. It is understood that biases are inherent in self-reported information.

Only special educators were asked to participate in the study. Experience with the Guidelines by other professionals who are responsible for educational support to students with autism, such as administrators, psychologists, social workers, speech/language pathologist, and general education teachers, was not included in this study.

The number of questions and the length of time it took to complete the survey may have impeded the rate of responses. A total of 568 individuals opened the survey, however, 161 participants only partially completed the survey, and for the purpose of analysis had to be excluded. If the survey was simplified, the likelihood of finishing it may have improved, consequently increasing the size of the sample.

The sole focus of the survey concentrated on teacher's experience with the Connecticut Guidelines. There is no assessment that measures whether teachers who reported more positive experiences actually saw improved behavior or educational gains for students with autism, based on what they gained from the Guidelines.

\section{Implications for Practice}

Three of the six major findings suggest there is an association between a special educator's use of the Connecticut Guidelines and the specificity of their role and tenure. Teachers who are primarily responsible for students with autism aree more likely to use the Guidelines than teachers who aree responsible for providing specialized instruction to students with a range of disabilities. Teachers in specialized schools for students with autism rated their understanding and ability to implement evidence-based practices as less difficult. Logically, if your primary role is to teach students with autism, you are 
more likely to have professional development experiences focused on understanding and using methodologies known to be effective for students with autism. School systems can significantly contribute to the growth and development of children with autism by providing teachers who are well trained, committed to meeting the needs of students with autism, and familiar with methods and procedures of working with students with autism (Simpson \& Zoints, 2000). Although this is understood to be best practice, it is difficult to provide in a public school setting, due to the fact that special education teachers are typically responsible for providing support to children with a variety of disabilities. These findings, as well as the research on effective practices for students with autism, should be considered by school districts when assigning roles and responsibilities to special educators.

"That the number of new autism diagnoses is dramatically increasing is generally accepted and not a point of debate" (Novella, 2008, para. 3). Autism affects more than just the child with the disorder. The family and community are responsible for providing support to individuals who experience the world so differently. Interventions and services for children with autism are intensive, and significantly impact the educational resources of school districts. It would be valuable to produce a measure to assess the relationship between educator's practices and attitudes towards educating students with autism and the outcomes for the student. This information would be important to consider when determining how to best use financial resources.

\section{Recommendations for Further Study}

The information provided by the survey outcomes was insightful and would prove helpful for updating the Connecticut Guidelines. The information would be more 
informative if a greater number of special educators and other professionals participated in the study. It is recommended that the study be replicated by a task force from the State Department of Education. A study conducted by an official body with authority and responsible for change could potentially be perceived by professionals as more valuable, leading to an expectation of participation that could be established and tracked.

It would be beneficial for the Connecticut State Department of Education to conduct a study employing a convergent mixed-method design. Mixed-method research uses both quantitative and qualitative data in a single study. This design is used "to obtain different but complementary data on the same topic" (Morse, 1991, p. 122) to better understand the research problem.

It would be helpful to use a simplified version of the Autism Needs Survey to assess the dependent variable of special educator's awareness and implementation of the Connecticut Guidelines. This could also illicit information on the independent variables of participant education, experience, and proficiency with evidence-based practices for educating children with autism spectrum disorder. The purpose of the quantitative data collected through the survey would serve to provide descriptive information on teacher implementation of the Connecticut Guidelines, as well as explore variables which may predict educator behavior and attitudes towards the Guidelines.

Concurrent to the quantitative data collection, professional focus groups would be formed to gather qualitative data. It is suggested to establish focus groups of teachers to gain a better understanding of factors that impact the professionals experience with the Guidelines. The purpose of employing this method is to ensure completeness to the study, 
by creating a more comprehensive picture in which the qualitative data can enrich the quantitative data (Bryman, 2006).

\section{Conclusion}

The results of this study show the Connecticut Guidelines are not being used or viewed as important by the majority of special education teachers in Connecticut. The Guidelines were written 10 years ago and much has changed in the field of autism over that time period. It seems that it is time to reexamine and make changes to the Connecticut Guidelines for the Identification and Education of Children and Youth with Autism. The findings of this study would suggest that the Guidelines need to be simplified, and thought should be given to whom they are being developed to inform. The study also makes it apparent that it may be necessary for new guidelines to consider the qualifications and diversity of the caseload of a teacher responsible for the education of a student with autism. Clearly if new guidelines are developed, discussion and study of how to more effectively share them with teachers needs to occur. The five most frequent responses to the survey question that asked teachers to describe in one word what they wanted from the Guidelines were: simplified, guidance, flexibility, implementation, and knowledge. Teachers are looking for answers and hopefully new guidelines can provide them. 
APPENDIX A

IRB Approval Letter 


\title{
Andrews University
}

August 8, 2014

Linda Grimm

Tel: (888) 717-6247

Email: grimmbln@gmail.com

\begin{abstract}
RE: APPLICATION FOR APPROVAL OF RESEARCH INVOLVING HUMAN SUB.JECTS IRB Protocol \#:14-070 Application Type: Original Dept.: Leadership Review Category: Exempt Action Taken: Approved Advisor: Shirley Freed Title: A descriptive study of special educators implementation of the Connecticut guidelines for the identification of children and youth with autism.
\end{abstract}

Your IRB application for approval of research involving human subjects entitled: " $A$ descriptive study of special educators implementation of the Connecticut guidelines for the identification of children and youth with autism" IRB protocol \# 14-070 has been evaluated and determined exempt from IRB review. You may now proceed with your research.

Please note that any future changes made to the study design and/or informed consent form require prior approval from the IRB before such changes can be implemented. Incase you need to make changes please use the attached report form.

While there appears to be no more than minimum risks with your study, should an incidence occur that results in a research-related adverse reaction and/or physical injury, this must be reported immediately in writing to the IRB. Any research-related physical injury must also be reported immediately to the University Physician, Dr. Reichert, by calling (269) 473-2222.

We ask that you reference the protocol number in any future correspondence regarding this study for easy retrieval of information.

Best wishes in your research.

Sincerely,

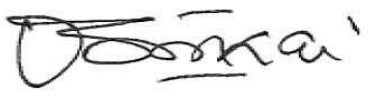

Mordekai Ongo

Research Integrity \& Compliance Officer 
APPENDIX B

Survey CT ASD 


\section{Connecticut Autism Needs Survey}

Thank you for taking the time to complete this survey.

The survey has 20 questions and should only take about 20 minutes of your time

If you have any questions about the survey, please contact Linda Grimm at Benhaven (203) 774-0008 ext. 305, or via email at grimmbln@gmail.com.

In order to progress through this survey, please use the following navigation buttons:

- Click the Next button to continue to the next page.

- Click the Previous button to return to the previous page.

- Click the Exit the Survey Early button if you need to exit the survey.

- Click the Submit button to submit your survey.

By completing this survey, you are indicating you had read the consent email sent to you, have had any questions answered, and voluntarily agree to take part in this research study.

\section{What is your primary role in educating students with ASD?}

Special Education Teacher - Preschool

Early Childhood Educator (Birth-5)

Special Education Teacher - Elementary School

$\bigcirc$ Autism Specialist/Consultant

$\bigcirc$ Special Education Teacher - Middle School

$\bigcirc$ Speech Language Pathologist

Special Education Teacher - High School

$\bigcirc$ School Social Worker

Special Education Teacher - Other

$\bigcirc$ school Psychologist

Other (please specify)

\section{Current place of employment. Check ONE only.}

$\square$ Public School

$\square$ Private School

$\square$ Regional Education Service (RESC)

$\square$ Private Consultative Agency

Self Employed

Other (please specify) 


\section{Connecticut Autism Needs Survey}

3. Years employed as a special education teacher.

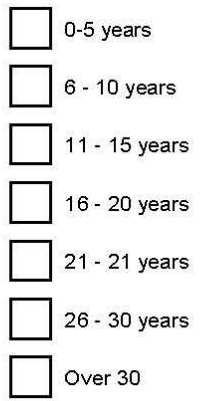

\section{What is the highest degree you have received?}

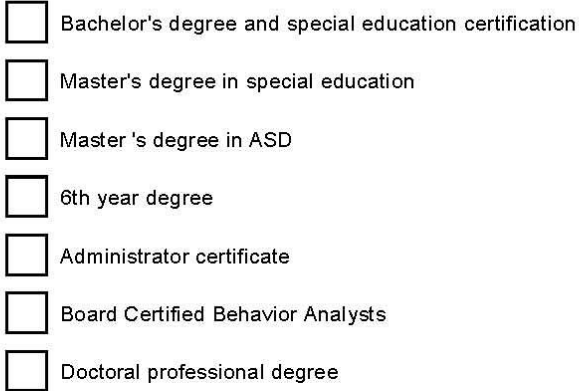

\section{Select the RESC/area of CT where you are currently employed:}

$\square$ CREC (Central)
$\square$ EASTCONN (Northeast)
$\square$ ACES (South Central)
$\square$ EDUCATION CONNECTION (Northwestern)

$\square$ CES (Southwestern)
$\square$ Project LEARN (Southeastern)
$\square$ Don't know

\section{How many students are on your current caseload?}
1.3
4.6
7-9
10-12
13-15
More than 15 


\section{Connecticut Autism Needs Survey}

7. What percentage of students on your caseload are identified with Autism Spectrum Disorder?

${ }_{100 \%}$

$76-99 \%$

${ }_{51-75 \%}$

26-50\%

${ }_{1-25 \%}$

$0 \%$ 
Connecticut Autism Needs Survey

\title{
8. Please answer yes if you have for implemented the practice in this school year. If you have implemented rate the level of difficulty to implement. If you have not implemented the practice please select no.
}

\author{
to \\ 1. INTERVENTIONS BASED ON BEHAVIORAL PRINCIPLES (including prompting, reinforcement, task \\ analysis, time delay, differential reinforcement, extinction/response interruption) \\ 2. COMPUTER AIDED INSTRUCTION (use of computers to teach academic skills and to promote \\ communication and language development and skills. It includes computer modeling and computer \\ 3. DISCRETE TRIAL TRAINING (one to one instructional approach used to teach skills in a planned, \\ controlled, and systematic manner. DTT is used when a learner needs to learn a skill best taught in small \\ repeated steps) \\ 4. PARENT IMPLEMENTED INTERVENTIONS (entails parents directly using individualized intervention
} practices with their child to increase positive learning opportunities and acquisition of important skills. Parents learn to implement such practices in their home and/or community through a structured parent training program)

5. PEER MEDIATED INTERVENTIONS (used to teach typically developing peers ways to interact with and help learners with ASD acquire new social skills by increasing social opportunities within natural environments)

6. PICTURE EXCHANGE COMMUNICATION SYSTEMS (designed to teach young children to communicate in a social context. Using PECS, learners are taught to give a picture of a desired item to a communicative partner in exchange for the item)

7. PIVOTAL RESPONSE TRAINING (method of systematically applying the scientific principles of applied behavior analysis (ABA) to teach learners with ASD. PRT builds on learner initiative and interests, and is particularly effective for developing communication, language, play, and social behaviors)

8. FUNCTIONAL BEHAVIOR ASSESSMENT (systematic set of strategies that is used to determine the underlying function or purpose of a behavior, so that an effective intervention plan can be developed)

9. FUNCTIONAL COMMUNICATION TRAINING (a systematic practice used subsequent to a Functional Behavior Assessment to replace inappropriate behavior or subtle communicative acts with more appropriate and effective communicative behaviors or skills.

10. ANTECEDENTBASED INTERVENTIONS (used to address both interfering and on task behaviors. This practice is most often used after a functional behavior assessment (FBA) has been conducted to identify the function of the interfering behavior)

11. SELFMANAGEMENT (helps learners with ASD learn to independently regulate their own behaviors and act appropriately in a variety of home, school, and community based situations)

12. SOCIAL NARRATIVES (interventions that describe social situations in some detail by highlighting relevant cues and offering examples of appropriate responding)

13. SOCIAL SKILLS GROUPS (teachs individuals with ASD ways to appropriately interact with typically developing peers)

14. STRUCTURED WORK SYSTEMS (instructional strategy that emphasizes visual supports. Its aims are to increase and maximize independent functioning and reduce the frequent need for teacher correction and reprimand)

15. VIDEO MODELING (uses video recording and display equipment to provide a visual model of the targeted behavior or skill)

16. VISUAL SUPPORTS (any tool presented visually that supports an individual as he/she moves through the day. Visual supports might include, but are not limited to, pictures, written words, objects within the environment, arrangement of the environment or visual boundaries, schedules, maps, labels, organization systems, timelines, and scripts)
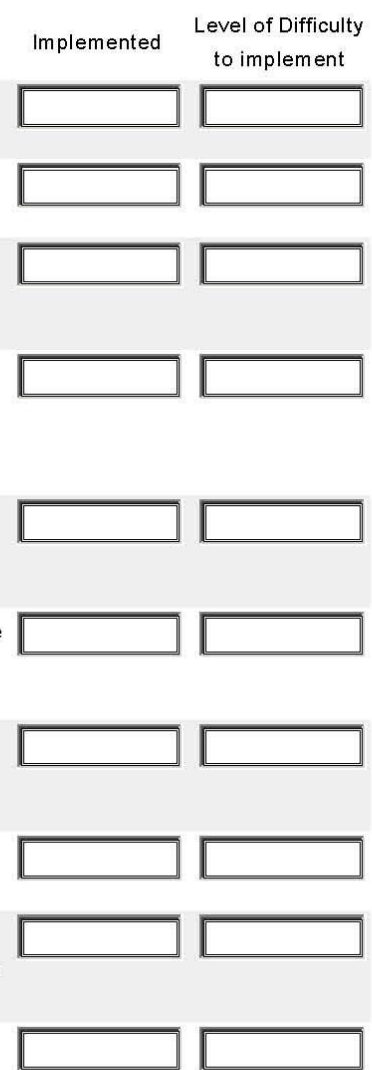

\section{西}
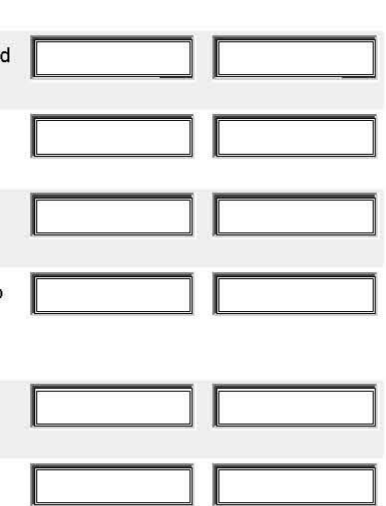


\section{Connecticut Autism Needs Survey}

17. VOICE OUTPUT COMMUNICATION AIDE (electronic devices that are portable in nature and can produce either synthetic or digital speech for the user. SGD may be used with graphic symbols, as well as

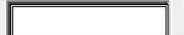

with alphabet keys)

9. What trainings have you participated in or received in the past 3 years related to ASD? Check ALL that apply

$\square$ SERC Workshops

Lecture

$\square$ Mentoring/coaching

$\square$ Consultation

Video Instruction

In District Workshops

Statewide conferences

Other (please specify)

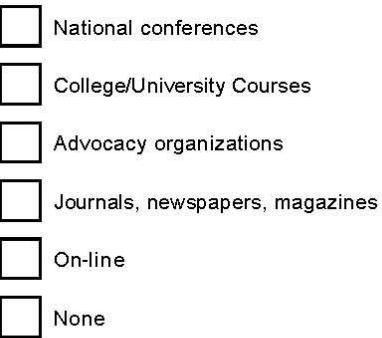

\section{IF YOU CHECKED ANY ITEMS IN THE PREVIOUS QUESTION, which topics were} included in those training opportunities? Check ALL that apply

\footnotetext{
$\square$ Academic Instruction

$\square$ Social Skills

$\square$ Assessment/Evaluation

Communication

$\square$ Assistive Technology

Behavioral Strategies

Inclusion Strategies

Other (please specify)
}

$\square$ Transition
$\square$ Independent Living
$\square$ Self Management \& Emotional Regulation
$\square$ Nutrition
$\square$ Accommodations
$\square$ Family School Partnerships
$\square$ Not Applicable




\section{Connecticut Autism Needs Survey}

\section{As it pertains to students with ASD my need for training in order to feel confident in my}

ability to....

1. Plan and implement systematic instruction based on
learner characteristics and previous on-going assessment.

2. Evaluate and implement assistive technology options.

3. Implement instructional programs that improve social skills and interactions between peers and adults.

4. Implement instructional programs that address transition needs between grades and schools and across all settings.

5. Collect and interpret data to document progress on outcomes and adjust programs as indicated by data.

6. Provide training for parents and families to understand, work and interact more effectively.

7. Provide environmental and structural accommodations across environments in order to ensure generalization of learning.

8. Write specific behavioral plans based on a FBA

9. Foster social skill development through peer interactions, direct instruction, role playing, video modeling, etc

10. Implement evidenced based strategies that promote the development of self-help, independent living, transportation, community participation, safety and nutrition.

11. Teach the unstated rules and customs that help regulate social behavior.

12. Assist in understanding of sexuality and sexual behavior at home, school and community.

13. Design and implement instructional programs that promote effective communication skills using appropriate
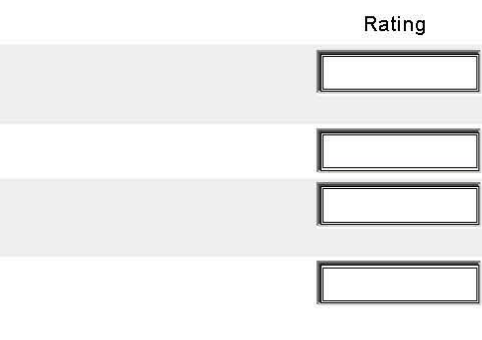

verbal, augmentative, and alternative communication

systems.

14. Use evidenced based assessment procedures and

evidenced based instruments to screen and evaluate for ASD/DD.

15. Listen to families in a non-judgmental manner and incorporate the information they contribute into the overall assessment data.

16. Explain to students, parents and professionals the assessment results and their implication for program development.

17. Interpret assessment results and to design appropriate 


\section{Connecticut Autism Needs Survey}

12. Rate your knowledge of the Connecticut Guidelines for the Identification and Education of Children and Youth with Autism 2005?

Very Knowledgeable

Moderately Knowledgeable

Knowledgeable

MinimallyKnowledgeable

Not Knowledge

13. How helpful have the Connecticut Guidelines for the Identification and Education of Children and Youth with Autism 2005 been to you in designing programs for students with ASD?

I have found them extremely helpful when designing programs for students with ASD

I am aware they exist and on occasion have referenced them when I have a question

I know they exist but have not used them

I have tried to use them but have not found them to be helpful

I didn't know they existed

No need to know

14. Rate the degree to which you implement the recommendations of the Connecticut Guidelines for the Identification and Education of Children and Youth with Autism 2005?

Fully implemented

Implemented adequately for all students

Implemented adequately for a few students

Minimal Implementation

Not implementing

15. Rate the degree of difficulty implementing the recommendations of the Connecticut Guidelines for the Identification and Education of Children and Youth with Autism 2005?

$\bigcirc$ very Difficult

Moderately Difficult

$\bigcirc$ Difficult

$\bigcirc$ Minimally Difficult

$\bigcirc$ Not Difficult

Not familiar with the Guidelines 


\section{Connecticut Autism Needs Survey}

16. I have a personal relationship with an individual with autism spectrum disorder

Y Yes

No

17. If you checked yes in the previous question, please identify the relationship? Check all that apply

$\square$ My own child
$\square$ Sibling
$\square$ Spouse
$\square$ Grandparent
$\square$ Niece/nephew
$\square$ Close friend
$\square$ Not applicable

Other (please specify)

18. Please use ONE word to describe what you believe is the key to success for educationg a student with ASD

19. Please use ONE word to describe what you believe is the most significant barrier to educating a student with ASD

20. Please use ONE word to describe the Connecticut Guidelines for the Identification and Education of Children and Youth with Autism 2005

21. Please use ONE word to describe what you would want from the Connecticut Guidelines for the Identification and Education of Children and Youth with Autism if they were revised 


\section{REFERENCE LIST}

Allen, D. A. (1988). Autism spectrum disorders: Clinical presentation in preschool children. Journal of Child Neurology, 3(1) [Supplemental],, S48-S56.

Allen, D. A., \& Rapin, I. (1997). Questioning the validity of the semantic-pragmatic syndrome diagnosis. Autism, 1(1), 37-55.

American Psychiatric Association. (1952). Diagnostic and statistical manual of mental disorders. Washington, DC: Author.

American Psychiatric Association. (1968). Diagnostic and statistical manual of mental disorders (2nd ed.). Washington, DC: Author.

American Psychiatric Association. (1980). Diagnostic and statistical manual of mental disorders (3rd ed.). Washington, DC: Author.

American Psychiatric Association. (1987). Diagnostic and statistical manual of mental disorders (3rd ed., text revision.). Washington, DC: Author.

American Psychiatric Association. (1994). Diagnostic and statistical Manual of Mental Disorders (4th ed.). Washington, DC: Author.

American Psychiatric Association. (2000). Diagnostic and statistical manual of mental disorders, (4th ed., text rev.). Washington, DC: Author.

American Psychiatric Association. (2013). Diagnostic and statistical manual of mental disorders, (5th ed.). Washington, DC: Author.

Anderson, S. R., \& Romanczyk, R. G. (1999). Early intervention for young children with autism: Continuum-based behavioral models. Journal of the Association for People with Special Handicaps, 24(3), 162-173.

Anzalone, M., \& Williamson, G. (2000). Sensory processing and motor performance in autism spectrum disorders. In A. Wetherby, \& B. Prizant (Eds.), Autism spectrum disorders: A transactional developmental perspective (pp. 143-166). Baltimore, MD: Paul Brookes.

Aspy, R., \& Grossman B. G. (2007). The ziggurat model. Shawnee Mission, KS: Autism Asperger.

Baltaxe, C. (1977). Pragmatic deficits in the language of autistic adolescents. Journal of Pediatric Psychology, 2(4), 176-180. 
Behavior Analysis Certification Board. (2009). About behavioral analysis. Retrieved from http://www.bacb.com/index.php?page=2

Bellini, S., \& Akullian, J. (2007). A meta-analysis of video modeling and video selfmodeling interventions for children and adoloscents with autism spectrum disorders. Exceptional Children, 73(3), 261-284.

Bettelheim, B. (1967). The empty fortress. Infantile autism and the birth of the self. New York: The Free Press.

Bishop, D. V. M. (1989). Autism, Asperger's syndrome and semantic-pragmatic disorder: What are the boundaries? British Journal of Disorders of Communication, 24(2), 107-121.

Blank, R. K., de las Alas, N., \& Smith, C. (2008). Does teacher professional development have effects on teaching and learning? Analysis of evaluation findings from programs for mathematics and science teachers in 14 states. Washington, DC: Council of Chief State School Officers.

Bleuler, E. (1911).Dementia Praecox oder Gruppe der Schizophrenien. Leipzig. Germany: Deuticke.

Boutot, A., \& Myles, B. S. (2011). Autism spectrum disorders: Foundations, characteristics, and effective strategies. Upper Saddle River, NJ: Pearson Education.

Bruey, C. T. (2004). Topics in autism: Demystifying autism spectrum disorders. A guide to diagnoses for parents and professionals. Bethesda, MD: Woodbine House.

Bryman, A. (2006). Paradigm peace and the implications for quality. International Journal of Social Research Methodology. 9(2), 111-126.

Buggey, T., Hoomes, G., Sherberger, M. E., \& Williams, S. (2011). Facilitating social initiations of preschoolers with autism spectrum disorders using video selfmodeling. Focus on Autism and Other Developmental Disabilities, 26(1), 25-36.

Capps, L., Sigman, M., \& Mundy, P. (1994). Attachment security in children with autism. Development and Psychopathology, 6(02), 249-261.

Center for Disease Control. (2014). Data and Stastics. Autism Spectrum Disorder (ASD). www.cdc.gov/ ncbddd/autism

Cipani, E., \& Spooner, F. (1994). Curricular and instructional approaches for persons with severe disabilities. Boston: Allyn and Bacon.

Cole, P. M., Mitchel, M. K., \& Teti, L. O. D. (1994). The development of emotion regulation and dysregulation: A clinical perspective. Monographs of the Society for Research in Child Development, 59(2-3), 73-102. 
Coleman, S. R. (1985). B.F. Skinner, 1926-1928: From literature to psychology. The Behavior Analyst, 8(1), 77-92.

Cooper, J. O., Heron, T. E., \& Heward, W. L. (1987). Applied behavior analysis. Upper Saddle River, NJ: Merrill, Prentice-Hall.

Connecticut State Department of Education. (1998). Report of the Connecticut task force on issues for the education of children with autism. Hartford: Author.

Connecticut State Department of Education. (2005). Guidelines for identification of children and youth with autism working draft. Hartford: Author.

Corona, R., Dissanayake, C., Arbelle, S., Wellington, P., \& Sigman, M. (1998). Is affect aversive to young children with autism? Behavioral and cardiac responses to experimenter distress. Child Development, 69(6), 1494-1502.

Corsello, C. (2013). Diagnostic Instruments in Autistic Spectrum Disorders. In Encyclopedia of Autism Spectrum Disorders (pp. 919-926). New York: Springer.

Creswell, J. W. (2009). Research design. Qualitative, quantitative, and mixed methods approaches. Thousand Oak, CA: SAGE.

Dalrymple, N. J. (1995). Environmental supports to develop flexibility and independence. In K. Quill (Ed.), Teaching children with autism (pp. 234-264). New York: Delmar.

Dawson, G., \& Adams, A. (1984). Imitation and social responsiveness in autistic children. Journal of Abnormal Child Psychology, 12(2), 209-226.

Dawson, G., \& Lewy, H. (1989). Arousal, attention and socioemotional impairments of individuals with autism. In G. Dawson (Ed.). Autism: Nature, diagnosis and treatment (pp. 49-74). New York: Guilford Press.

Dawson, G., \& Osterling, J. (1997). Early intervention in autism. In M. Guralnick (Ed.), The effectiveness of early intervention (pp. 307-326). ERIC Number: ED414694

DeMyer, M. K., Alpern, G. D., Barton, S., DeMyer, W. E., Churchill, D. W., Hingtgen, J. N., ... \& Kimberlin, C. (1972). Imitation in autistic, early schizophrenic, and nonpsychotic subnormal children. Journal of Autism and Childhood Schizophrenia, 2(3), 264-287.

DeVellis, R. F. (2011). Scale development: Theory and applications (3rd ed.). Thousand Oaks, CA: SAGE.

Driscoll, M. P. (2005). Psychology of learning for instruction. Toronto, ON: Pearson. 
Dunlap, G. (1999). Consensus, engagement, and family involvement for young children with autism. Research and Practice for Persons with Severe Handicaps, 24(3), 222-225.

Dunlap, G., Carr, E.G., Horner, R.H., Zarcone, J., \& Schwartz, I. (2008). Positive behavior support and applied behavior analysis: A familial alliance. Behavior Modification, 32(5), 682-698.

Dunlap, G., \& Fox, L. (1999). Teaching students with autism. Reston, VA: ERIC Clearinghouse on Disabilities and Gifted Education. (ED: 582).

Dunlap, G., \& Fox, L. (2002). The challenge of autism from a large system perspective. Unpublished manuscript, University of South Florida, Tampa.

Dunlap, G., \& Robbins, F. R. (1991). Current perspectives in service delivery for young children with autism. Comprehensive Mental Health Care, 1(3), 177-194.

Earles, T. L., Carlson, J. K., \& Bock, S. J. (1998). Instructional strategies to facilitate successful learning outcomes for students with autism. In R. L. Simpson, \& B. S. Myles (Eds.), Educating children and youth with autism: Strategies for effective practice (pp. 55-111). Austin: PRO-ED.

Feinstein, A. (2010). A History of Autism. Weat Sussex, UK: Wiley-Blackwell.

Ferrara, C., \& Hill, S. (1980). Intensive interaction and autism: some theoretical concerns. Children \& Society, 14(2), 98-109.

Filipek, P. A., Accardo, P. J., Baranek, G. T., Cook Jr, E. H., Dawson, G., Gordon, B., ... \& Minshew, N. J. (1999). The screening and diagnosis of autistic spectrum disorders. Journal of Autism and Developmental Disorders, 29(6), 439-484.

Fink, A. (2002). How to Ask Survey Questions (2nd edition). Thousand Oaks, CA: Sage.

Fombonne, E. (2003). The prevalence of autism. Journal of the American Medical Association, 289(1), 87-89.

Freeman, B. J. (1997). Guidelines for evaluating intervention programs for children with Autism. Journal of Autism and Developmental Disorders, 27(6), 641-659.

Frith, U. (1989). Autism: Explaining the enigma. Oxford, UK: Blackwell.

Gabriels, R. L., \& Hill, D. E. (2002). Autism - from research to individualized practice. London: Jessica Kingsley.

Gall, M. D., Borg, W. R., \& Gall, J. P. (1996). Educational research: An introduction (6 ${ }^{\text {th }}$ ed.). White Plains, NY: Longman. 
Gallagher, J., \& Clifford, R. (2000). The missing support infrastructure in early childhood. Early Childhood Research and Practice, 2(1), n1.

Ganz, M. (2006). Autism Has High Costs to U.S. Society. Retrieved from http://archive.sph.harvard.edu/press-releases/2006-releases/press04252006.html

Gardner, S. J., \& Wolfe, P. S. (2013). Use of video prompting interventions for teaching daily living skills to individuals with autism spectrum disorders: A review. Research and Practice for Students With Severe Disabilities, 38(2), 73-87.

Gerber, S., Brice, A., Capone, N., Fujiki, M., \& Timler, G. (2012). Language use in social interactions of school-age children with language impairments: An evidence-based systematic review of treatment. Language, Speech, and Hearing Services in Schools, 43(2), 235-249.

Grandin, T. (1996). Thinking in pictures. New York: Doubleday.

Grant, C. M. (1996). Professional development in a technological age: Old challenges, new resources. Technology Infusion and School Change. TERC.

Green, G. (2005). Autism and ABA: Applied behavior analysis for autism. Cambridge Center for Behavioral Studies. Retrieved April 7, 2005, from www.behavior.org/autism.

Greenleaf, R. K. (1977). Servant leadership: A journey into the nature into legitimate power and greatness. New York: Paulist Press.

Greenspan, S. (1992). Infancy and early childhood: The practice of clinical assessment and intervention with emotional and developmental challenges. Madison, CT: International Universities Press.

Greenspan, S. I., \& Wieder, S. (1997). Developmental patterns and outcomes in infants and children with disorders in relating and communicating: A chart review of 200 cases of children with autistic spectrum diagnoses. Journal of Developmental and Learning Disorders, 1(1), 87-141.

Gresham, F. M., Beebe-Frankenberger, M. E., \& MacMillan, D. L. (1999). A selective review of treatments for children with autism: Description and methodological considerations. School Psychology Review, 28(4), 559-575.

Guralnick, M. J. (Ed.). (1997).The effectiveness of early intervention. Baltimore: Brookes.

Guskey, T. R. (2000). Evaluating professional development. Thousand Oaks, CA: Corwin. 
Harrison, J., \& Hare, D.J. (2004). Brief report: Assessment of sensory abnormalities in people with autistic spectrum disorders. Journal of Autism and Developmental Disorders, 34(6), 727-730.

Heflin, L. J., \& Alberto, P. A. (2001). Establishing a behavioral context for learning for students with autism. Focus on Autism and Other Developmental Disabilities, 16(2), 93-101.

Heflin, L. J., \& Simpson, R. L. (1998). Interventions for children and youth with autism: Prudent choices in a world of exaggerated claims and empty promises. Part I: Intervention and treatment option review. Focus on Autism and Other Developmental Disabilities, 13(4), 194-211.

Henry, S., \& Myles, B. S. (2007). The comprehensive autism planning system (CAPS) for individuals with Asperger syndrome, autism and related disabilities: Integrating best practice throughout the student's day. Shawnee Mission, Kansas: Autism Asperger.

Holmes, D. (1998). Autism through the lifespan: The Eden model. Bethesda, MD: Woodbine House.

Hoover, W. A. (1996). The practice implications of constructivism. SEDL Letter, 9(3), 112.

Horner, R. H., Carr, E. G., Strain, P. S., Todd, A. W., \& Reed, H. K. (2000). Problem behavior interventions for young children with autism: A research synthesis. Paper presented at the Second Workshop of the Committee on Educational Interventions for Children with Autism, National Research Council, Department of Special Education, University of Oregon.

Hosseini, D. (2012). The art of autism shifting perceptions. San Rafael, CA: Bolton.

Howlin, P., Savage, S., Moss, P., Tempier, A., \& Rutter, M. (2014). Cognitive and language skills in adults with autism: A 40-year follow-up. Journal of Child Psychology and Psychiatry, 55(1), 49-58.

Howlin, P., \& Yates, P. (1989). Treating autistic children at home: A London based programme. In C. Gillberg (ed) Diagnosis and Treatment of Autism. New York: Plenum.

Hurth, J., Shaw, E., Izeman, S. G., Whaley, K., \& Rogers, S. J. (1999). Areas of agreement about effective practices among programs serving young children with autism spectrum disorders. Infants and Young Children, 12(2), 17-26.

Hyman, S. L. (2013). New DSM-5 includes changes to autism criteria. American Academy of Pediatrics. Retrieved from http://www.aappublications.org/content/ early/2013/06/04/aapnews.20130604-1 
Ikeda, M., J. (2002). Best practices for supporting students with autism. In Thomas, A., \& Grimes, J. (Eds), Best practices in school psychology ( $4^{\text {th }}$ ed.). Washington, DC: NASP.

Individual with Disabilities Education Act, Amendments of 1997, 20 USC.sec. 1499 et.seq. (statute); 34 CFR 300 (regulations published in 1999). http://www2.ed.gov/legislation/FedRegister/finrule/1999-1/031299a.pdf

Iovannone, R., Dunlap, G., Huber, H., \& Kincaid, D. (2003). Effective educational practices for students with autism spectrum disorder. Focus on Autism and Other Developmental Disabilities, 18(3), 150-165.

Jacobson, J., \& Mulick, J. (2000). System and cost research issues in treatments for people with autistic disorders. Journal of Autism \& Developmental Disorders, 30(6), 585-593.

Jacobson, J. W., Mulick, J. A., \& Green, G. (1998). Cost-benefit estimates for early intensive behavioral intervention for young children with autism: General model and single state case. Behavioral Interventions, 13(4), 201-226.

Jarbrink, K., \& Knapp, M. (2001). The economic impact of autism in Britain. Autism, 5(1), 7-22.

Johnson, C. P., Myers, S. M., \& the Council on Children with Disabilities. (2007). Identification and evaluation of children with autism spectrum disorders. Pediatrics, 120(5), 1183-1215.

Joyce, B. R., \& Showers, B. (2002). Student achievement through staff development (3rd ed.).Association for Supervision and Curriculum Development.

Kanner, L. (1943). Autistic disturbances of affective contact. The Nervous Child, 2, 217250.

Kerlinger, F. N., \& Lee, H. B. (2000). Foundations of behavioral research (4th ed.). Fort Worth, TX: Harcourt College.

Killion, J. (2002). Assessing impact: Evaluating staff development. Oxford, OH: National Staff Development Council.

Kim, C. (2015). Nerdy, shy, and socially inappropriate. London, UK: Jessica Kinsley Publishers.

Klinger, L., \& Dawson, G. (1996). Autistic disorder. In E. Mash and R. Barkley (Eds). Child Psychopathology (pp. 311-339). New York: Guilford Press.

Knowles, M. S. (1970). The modern practice of adult education: Andragogy versus pedagogy. New York, NY: Association Press. 
Knowles, M. S. (1980). The modern practice of adult education: Andragogy versus pedagogy (Ed.). Englewood Cliffs: Prentice Hall Regents.

Knowles, M. S. (1984). Andragogy in action: Applying modern principles of adult education. San Francisco: Jossey Bass.

Koegel, L. K., Singh, A. K., \& Koegel, R. L. (2010). Improving motivation for academics in children with autism. Journal of Autism and Developmental Disorders, 40(9), 1057-1066.

Krantz, P., \& McClannahan, L. E. (1993). Teaching children with autism to initiate with peers: Effects of script fading procedure. Journal of Applied Behavior Analysis, 26(1), 121-132.

Kusch, M., \& Peterman, F. (1995). Pervasive developmental disorders. In D. Ciccetti, \& D. Cohen (Eds.), Developmental psychology (pp. 177-218). New York: Wiley.

Lindgren, S., \& Doobay, A. (2011). Evidence-Based Interventions for Autism Spectrum Disorders. Iowa Department of Human Services by the Center for Disabilities and Development of the University of Iowa's Children's Hospital.

Lord, C. (1994). The complexity of social behavior in autism. In S. Baron-Cohen, H. Tager-Flusberg, \& D. Cohen. Understanding Others' Minds: Perspectives in Autism. New York: Oxford University Press.

Lord, C., Wagner, A., Rogers, S., Szatmari, P., Aman, M., Charman, T., ... \& Harris, S. (2005). Challenges in evaluating psychosocial interventions for autistic spectrum disorders. Journal of Autism and Developmental Disorders, 35(6), 695-708.

Lovaas, I. O. (1981). Teaching developmentally disabled children: The me book. Baltimore, MD: University Park Press.

Mackin, A. (2013, January 3). How my autistic son got lost in the public school system. The Atlantic. Retrieved from http://www.theatlantic.com/national/archive/ 2013/01/how-my-autistic-son-got-lost-in-the-public-school-system/266782/

McCroskey, J. C., \& McCroskey, L. L. (1988). Self-report as an approach to measuring communication competence. Communication Research Reports, 5(2). 108-113.

Mesibov, G. B., \& Shea, V. (2010). Evidence-based practices and Autsim. Autism 2011, $15(1), 114-133$.

Morse, J. M. (1991). Approaches to qualitative-quantitative methodological triangulation. Nursing research, 40(2), 120-123.

Mundy, P., Sigman, M., \& Kasari, C. (1990). A longitudinal study of joint attention and language development in autistic children. Journal of Autism and Developmental Disorders, 20(1), 115-128. 
National Alliance for Autism Research. (2005). What is autism? Retrieved October 4, 2005 from http://www.naar.org/aboutaut/whatis_hist.htm

National Autism Center. (2009). National Standards Report. Retrieved from http://www.nationalautismcenter.org/affiliates/reports.php

The National Professional Development Center (2007). Autism Spectrum Disorders, Evidence Base Practices. Retrieved from http://autismpdc.fpg.unc.edu/ content/ national-standards-project.

National Research Council. (2001). Educating children with autism: Committee on Educational Interventions for Children with Autism. Washington, DC: National Academy Press.

New Jersey Department of Education. (2004). Autism program quality indicators. Trenton: Author.

New York State APQI. (2001). Autism program quality indicators. Albany: Author.

Novella, S. (2008). Autism and vaccines: Responding to Poling and Kirby. Retrieved April 16, 2008, from http://www.sciencebasedmedicine.org/?p=95

Odom, S. L., Collet-Klingenberg, L., Rogers, S. J., \& Hatton, D. D. (2010). Evidencebased practices in interventions for children and youth with autism spectrum disorders. Preventing School Failure: Alternative Education for Children and Youth, 54(4), 275-282.

Odom, S. L., \& McLean, M. E. (1996). Early intervention/early childhood special education: Recommended practices. Austin, TX: Pro-Ed.

Odom, S. L. \& Strain, P. S. (1984). Peer-mediated approaches to promoting children's social interaction: A review. American Journal of Orthopsychiatry, 54(4), 545553.

Olley, G. J. (1999). Curriculum for students with autism. School Psychology Review, 28(4), 595-607.

Peterson, N. L., \& Haralick, J. G. (1977). Integration of handicapped and nonhandicapped preschoolers: An analysis of play behaviors and social interaction. Education and Training of the Mentally Retarded, 12(3), 235-245.

Plumb, A. M., \& Wetherby, A. M. (2013). Vocalization development in toddlers with autism spectrum disorder. Journal of Speech, Language and Hearing Research, $56(2), 721$.

Pollack, R. (1997). The creation of Dr. B: A biography of Bruno Bettelheim. New York: Simon \& Schuster. 
Powers, M. D. (1992). Early intervention for children with autism. In D. E. Berkell (Ed.), Autism: Identification, education and treatment, (pp. 225-252).

Pratt, C. L., Vicker, B. A., \& Davis, K. (2001). Early intervention for young children with autism spectrum disorders: Recommendations for designing effective programs. Indiana Resource Center for Autism, Indiana Institute on Disability and Community, Indiana University.

Prizant, B. M. (1996). Language, social and communication development in autism. Journal of Autism and Development Disorders, 26(2), 173-178.

Prizant, B., \& Rubin, E. (1999). Contemporary issues in interventions for autism spectrum disorders: A commentary. Journal of the Association of Persons with Severe Handicaps, 24(3), 199-208.

Prizant, B. M., Schuler, A. L., Wetherby, A. M., \& Rydell, P. (1997). Enhancing language and communication: Language approaches. In D. Cohen \& F. Volkmar (Eds.), Handbook of autism and pervasive developmental disorders ( $2^{\text {nd }} \mathrm{Ed}$.). New York: Wiley.

Quill, K. A. (2000). Do-watch-listen-say: Social communication intervention for children with autism. Baltimore: Paul H. Brookes.

Rieber, R. W., \& Carton, A. S. (eds) (1993). The collected works of L.S. Vygotsky: Volume 2 - The fundamentals of defectology (abnormal psychology of learning disabilities). New York: Plenum.

Ritvo, E.R., \& Freeman, B. J. (1977). National Society for Autistic Children definition of the syndrome of autism. Journal of American Academy of Child Psychology, 2(4), 146-148.

Rogers, S. J. (1999). Intervention for young children with autism: From research to practice. Infants and Young Children, 12(2), 1-16.

Rutter, M. (1999). The Emanuel Miller memorial lecture 1998. Autism: Two-way interplay between research and clinical work. Journal of Child Psychology and Psychiatry 40(2), 169-188.

Rutter, M. (2005). Incidence of autism spectrum disorders: Changes over time and their meaning. Acta Paediatr, 94(1), 2-15.

Safran, S. P. (2001). Asperger syndrome: The emerging challenge to special education. Exceptional Children, 67(2), 151-160.

Schopler, E., \& Reichler, R. J. (1971). Parents as co therapists in the treatment of psychotic children. Journal of Autism and Childhood Schizophrenia, 1(1), 87102. 
Schreibman, L., \& Ingersoll, B. (2005). Behavioral interventions to promote learning in individuals with autism. In Volkmar, F. R., Paul, R., Klin, a. \& Cohen, D. (Eds.), Handbook of autism and pervasive developmental disorders: Volume 2: Assessment, interventions, and policy ( $3^{\text {rd }}$ ed.) (pp. 882-896), Hoboken, NJ: John Wiley \& Sons.

Schroeder, S. R., Bickel, W. K., \& Richmond, G. (1986). Primary and secondary prevention of self-injurious behaviors: A life-long problem. Advances in Learning and Behavioral Disabilities, 5, 63-85.

Seltzer, M. M., Krauss, M. W., Shattuck, P. T., Orsmond, G., Swe, A., \& Lord, C. (2003). The symptoms of autism spectrum disorders in adolescence and adulthood. Journal of Autism and Developmental Disorders, 33(6), 565-581.

Sigman, M. (1994). What are the core deficits in autism? In Broman S., \& Grafman J. Atypical Cognitive Deficits in Developmental Disorders: Implications for Brain Function. Hillsdale, NJ: Erlbaum.

Simpson, D. E., Hanley J. J., \& Quinn, G. (Filmakers). (2002). Refrigerator Mothers [Motion Picture]. United States: Public Broadcasting Service. http://www.pbs.org/ pov/refrigeratormothers/fridge/

Simpson, R. L. (2001). ABA and students with autism spectrum disorders: Issues and considerations for effective practice. Focus on Autism and Other Developmental Disabilities, 16(2), 68-71.

Simpson, R. L., \& Myles, B. S. (1998). Understanding and responding to the needs of students with autism. In R.L. Simpson \& B. S. Myles (Eds.), Educating children and youth with autism: Strategies for effective practice (pp. 1-23). Austin, TX: Pro-Ed.

Simpson, R. L., \& Zionts, P. (2000). Autism: Information and resources for professionals and parents. Austin, TX: Pro-Ed.

Smith, T. (2001). Discrete trial training in the treatment of autism. Focus on Autism and Other Developmental Disabilities, 16(2), 86-92.

Smith, T. (2013). What is evidence-based behavior analysis? Behavior Analyst, 36(1), 7.

Smith, T., Scahill, L., Dawson, G., Guthrie, D., Lord, C., Odom, S., ... \& Wagner, A. (2007). Designing research studies on psychosocial interventions in autism. Journal of autism and developmental disorders, 37(2), 354-366.

Smithson, J. L., \& Porter, A. C. (1994). Measuring classroom practice: Lessons learned from efforts to describe the enacted curriculum. The Reform Up Close Study (CPRE Research Series No. 31). Madison: University of Wisconsin-Madison, Consortium for Policy Research in Education. 
Smylie, M. A., \& Wenzel, S. A. (2003). The Chicago Annenberg challenge: Successes, failures, and lessons for the future.. Chicago, IL: Consortium on Chicago School Research, University of Chicago.

Stratis, E. A., \& Lecavalier, L. (2013). Restricted and repetitive behaviors and psychiatric symptoms in youth with autism spectrum disorders. Research in Autism Spectrum Disorders, 7(6), 757-766.

Staits, W., \& Wilke, R. (2007). How constructivist are we? Representations of transmission and participatory models of instruction. Journal of College Science Teaching, 36(7), 58-61.

Stone, W., Ousley, O., Yoder, P., Hogan, K., \& Hepburn, S. (1997). Nonverbal communication in 2- and 3-year old children with autism. Journal of Autism and Developmental Disorders 27(6), 677-696.

Strain, P. S., \& Cordisco, L. K. (1994). LEAP Preschool. In S. Harris \& J. Handleman (Eds.), Preschool education programs for children with autism (pp. 225-252).

Student Achievement and School Accountability Conference (October 2002). EvidenceBased Education. From www.ed.gov/nclb/methods/whatworks/eb/ edliteslide001.html \}

Tager-Flusberg, H. (1996). Brief report: Current theory and research on language and communication in autism. Journal of Autism and Developmental Disorders, 26(2), 169-178.

Taylor, B. (2006). Vaccines and the changing epidemiology of autism. Child Care Health Development, 32(5), 511-519.

Travis, L., \& Sigman, M. (1998). Social deficits and interpersonal relationships in autism. Mental Retardation and Developmental Disabilities Research Reviews 4(2), 6572 .

Turnbull, H. R., \& Turnbull, A. P. (2000). Free appropriate public education: The law and children with disabilities. Denver, CO: Love.

U. S. Government Accountability Office. (January 2005). Report to the chairman and ranking minority member, Subcommittee on Human Rights and Wellness, Committee on Government Reform, House of Representatives, Special Education: Children with Autism (GOA-05-220 Special Education). Washington, DC: Author.

Volkmar, F. R., Lord, C., Bailey, A., Schultz, R. T., \& Klin, A. (2004). Autism and pervasive developmental disorders. Journal of Child Psychology and Psychiatry, 45(1), 135-170. 
Volmer, L. (1997). Best practices in working with students with autism. In Thomas, A. \& Grimes, J. (Eds.), Best practices in school psychology (pp.1031-1038). Washington, DC: The National Association of School Psychologists.

Watson, L., Lord, C., Schaffer B., \& Schopler, E. (1989). Teaching spontaneous communication to autistic and developmentally handicapped children. New York, NY: Irvington.

Westling, D. L., \& Fox, L. (2000). Teaching students with severe disabilities ( $2^{\text {nd }}$ ed.). Englewood Cliffs, NJ: Prentice Hall.

Wetherby, A. M. \& Prutting, C. A. (1984). Profiles of communicative and cognitivesocial abilities in autistic children. Journal of Speech and Hearing Research, 27(3), 364-377.

Wheatley, M. J. (1999). Leadership and the new science: Discovering order in a chaotic world. San Francisco: Berrett-Koehler.

Whitehurst, G. (March, 2003). The Institute of Education Sciences: New wine, new bottles. Presentation at the annual conference of the American Educational Research Association, Chicago, IL. Available at http://www.ed.gov/print/ rschstat/research/pubs/ies.html

Willey, L. H. (2015). Pretending to be normal. London, UK: Jessica Kingsley.

Wing, L. (1988). The continuum of autistic disorders. In E. Schopler \& G.M. Mesihov Eds.), Diagnosis and Assessment In Autism (pp.91-110). New York: Plenum.

Wing, L. (1997). The history of ideas on autism legends, myths and reality. Autism: The International Journal of Research and Practice 1(1), 13-23.

Wing, L. (2001). The autistic spectrum. Berkeley, CA: Ulysses Press.

Wing, L., \& Potter, D. (2002). The epidemiology of autistic spectrum disorders: Is the prevalence rising? Mental Retardation and Developmental Disabilities Research Reviews, 8(3), 151-161.

Winter, M., \& Lawrence, C. (2011). Asperger syndrome: What teachers need to know, (2nd ed.). London, UK: Jessica Kingsley Publishers.

Winter-Messiers, M.A. (2007). From tarantulas to toilet brushes: Understanding the special interest areas of children and adolescents with Asperger Syndrome. Remedial and Special Eduaction, 28(3), 140-152.

Wolery, M., \& Garfinkle, A. R. (2000). Measures in Intervention Research with Young Children Who Have Autism. Paper presented at the Second Meeting of the Committee on Educational Interventions for Children with Autism, National Research Council. 
Wong, C., Odom, S. L., Hume, K., Cox, A. W., Fettig, A., . . Schultz, T. R. (2013). Evidence-based practices for children, youth, and young adults with Autism Spectrum Disorder. Chapel Hill: The University of North Carolina, Frank Porter Graham Child Development Institute, Autism Evidence-Based Practice Review Group.

Woods, J. J., \& Wetherby, M. (2003). Early identification of and intervention for infants and toddlers who are at risk for autism spectrum disorder. Language, Speech, \& Hearing Services in Schools, 34(3), 180-193.

Yell, M. L. \& Drasgow, E. (2005). No Child Left Behind: A guide for professionals. Upper Saddle River, NJ: Merrill/Prentice Hall. 
VITA 


\section{LINDA K. GRIMM}

HOME

445 Laurel Grove Road

Middletown, Connecticut 06457

(860) 346-4392
WORK

50 N. Plains Highway

Wallingford, CT 06492

(203) 774-0008

\section{EDUCATION}

Southern Connecticut State University, New Haven, CT

Intermediate Administrator Certification, 1991

Master of Science, Special Education, 1989

Special Education Certification, Pre-Kindergarten through Grade 12, 1989

Central Connecticut State University, New Britain, CT

Bachelor of Science, Elementary Education, 1980

Andrews University, Berrien Springs, MI

Ph.D.; Leadership, projected graduation 2016

\section{ADDITIONAL LEARNING}

National Personnel Training Program for Children and Adults with Autism (Anne Donnelan, Ph.D. and Gary Lavigna, Ph. D.)

Applied Behavior Assessment Training from the Institute of Applied Behavior Analysis (Gary LaVigna, Ph.D.)

Personal Futures Planning Training (Joseph Patterson, Ph.D.)

Toward a Technology of Nonaversive Behavioral Support Training (DMR sponsored in cooperation with the Oregon Research \& Training Center)

\section{EXPERIENCE}

Benhaven, Inc., North Haven, CT 06473

Managing Consultant, Benhaven Learning Network (2001 to present)

Created an educational consultation group with a focus on supporting individuals with Autism Spectrum Disorder. Manage and participate in a team of consultants who provide assessment, technical support, structured staff learning, and leadership to public school personnel and teams (including families) in the areas of:

- Understanding the disability and programmatic needs of students with Autism and Asperger Syndrome

- Inclusion of students on the Autism Spectrum

- Person-centered futures planning and team building 
- Positive behavioral support

- Teaching strategies

- Functional analysis and positive behavioral support

Have presented at national, regional and local conferences/workshops. Currently involved on the ICAN federal project charged with developing on-line modules for educating parents and professionals about strategies for educating individuals with autism.

Educational Director, Benhaven School (1989 to 2001)

Provide leadership and oversee implementation of administrative and programmatic services of Benhaven School. Member of the senior leadership team for the organization, responsible for activities related to Benhaven's Vision and Mission.

Educational Program Coordinator, Benhaven School (1985 to 1989) Provided supervision to classroom teachers in the development and implementation of individualized educational programs. Mentored teachers In providing appropriate training and supervision for paraprofessionals. Served as a team leader and provided in-vivo training for teachers to assume this leadership role on student centered teams. Liaison to families, provided guidance and support in implementing strategies in the home. Facilitated a family learning and support group. Ensured coordination with residential programs.

Teacher, Benhaven School (1981 to 1985)

Implemented responsibilities of a classroom teacher in program development, for students with autism and other developmental disabilities, including assessment, program design, implementation and evaluation. Developed effective relationships with families to ensure continuity for their child. Provided training and supervision for paraprofessionals. Collaborated with residential teachers to provide a coordinated program. Developed and implemented a school-wide competency based signing curriculum for all staff

St. Mary of Chestohowa, Middletown, CT 06457

Teacher, St. Mary School (1980 to 1981)

Taught seventh grade. Responsibilities included classroom management and organization; instructed in the subject area s of Mathematics, Science, Reading and Language Arts. Participated in departmental Math and Science instruction for grades five through eight. 